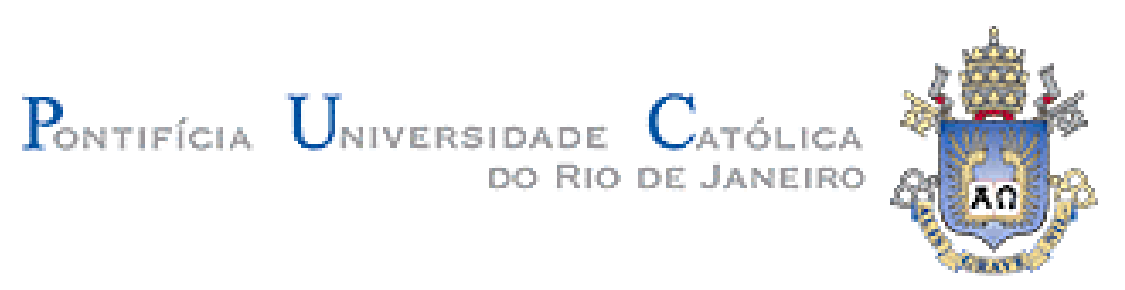

Claudia Corrêa Torquato de Souza

\title{
Viabilidade técnica e econômica da adoção da Diretiva RoHS por Organização Militar da Marinha do Brasil
}

\author{
Dissertação de Mestrado
}

Dissertação apresentada ao Programa de Pós-graduação em Engenharia Urbana e Ambiental da PUC-Rio como requisito parcial para obtenção do título de Mestre em Engenharia Urbana e Ambiental (Opção Profissional).

Orientador: Prof. Celso Romanel

Rio de Janeiro

Dezembro de 2015 


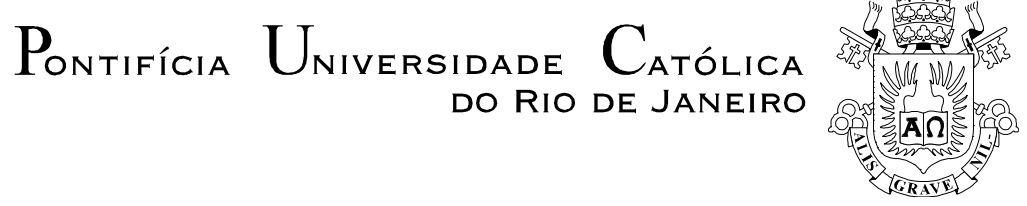

\section{CLAUDIA CORRÊA TORQUATO DE SOUZA}

\section{Viabilidade técnica e econômica da adoção da Diretiva RoHS por Organização Militar da Marinha do Brasil}

Dissertação apresentada como requisito parcial para obtenção do título de Mestre em Engenharia Urbana e Ambiental (opção profissional) pelo Programa de Pós-Graduação em Engenharia Urbana e Ambiental da PUC-Rio. Aprovada pela Comissão Examinadora abaixo assinada.

Prof. Celso Romanel Presidente / Orientador Departamento de Engenharia Civil - PUC-Rio

Profa. Ana Ghislane Henriques Pereira van Elk UERJ

Prof. Ricardo Abranches Félix Cardoso Júnior UFF

Profa. Ana Cristina Malheiros Gonçalves Carvalho

PUC-Rio

Prof. Márcio da Silveira Carvalho Coordenador Setorial de Pós-Graduação do Centro Técnico Científico - PUC-Rio

Rio de Janeiro, 11 de dezembro de 2015. 
Todos os direitos reservados. É proibida a reprodução total ou parcial do trabalho sem autorização da universidade, da autora e do orientador.

\section{Claudia Corrêa Torquato de Souza}

Graduou-se em Engenharia Elétrica, ênfase em eletrônica, pelo Centro Federal de Educação Tecnológica Celso Suckow da Fonseca (CEFET/RJ). Possui certificado de Aperfeiçoamento em Engenharia Elétrica pela Pontifícia Universidade Católica (PUC-Rio). Foi responsável pela Divisão de Sensores da Diretoria de Sistemas de Armas da Marinha (DSAM). Encarregada da Seção de Navegação da DSAM. Principais áreas de interesse: eletrônica, sustentabilidade ambiental e equipamentos militares.

Ficha Catalográfica

Souza, Claudia Corrêa Torquato de

Viabilidade técnica e econômica da adoção da Diretiva RoHS por Organização Militar da Marinha do Brasil / Claudia Corrêa Torquato de Souza; orientador: Celso Romanel. - 2015.

150 f. : il. color. ; $30 \mathrm{~cm}$

Dissertação (Mestrado) - Pontifícia Universidade Católica do Rio de Janeiro, Departamento de Engenharia Civil, Programa de Pós-Graduação em Engenharia Urbana e Ambiental, 2015.

Inclui bibliografia

1. Engenharia civil - Teses. 2. Engenharia urbana Teses. 3.RoHS. 4. Sustentabilidade. 5. Eletroeletrônicos. 6. Especificação. 7. Militar. I. Romanel, Celso. II. Pontifícia Universidade Católica do Rio de Janeiro. Departamento de Engenharia Civil. Programa de Pós-Graduação em Engenharia Urbana e Ambiental. III. Título. 
Para minha filha, Camila, e meu marido, Carlos.

Por meus pais, Anna Maria e Haroldo.

(in memoriam) 


\section{Agradecimentos}

Inicialmente, gostaria de agradecer ao atual e ao ex Diretor da Diretoria de Sistemas de Armas da Marinha, o Exmo. Vice-Almirante Mathias e ao Exmo. ViceAlmirante Alípio Jorge, respectivamente, por terem me autorizado a ter acesso às dependências, pessoal e material da DSAM que permitiu que eu pudesse desenvolver o tema da dissertação.

Aos meus colegas de trabalho, em particular aos colegas da Divisão de Sensores, e aos amigos Cláudia Reis, Maria Inês e Cláudio Vasconcellos pelo apoio durante todo o curso.

Á engenheira Vanda Mondego pela troca de experiência profissional que facilitou o desenvolvimento de minha pesquisa.

Ao professor Celso Romanel pelas orientações e apoio, por acreditar em minha pesquisa e por me fazer superar minhas limitações.

Ao professor Jean Marcel Novo por nortear minha pesquisa em sua metodologia.

À Paula Enoy Nobrega Teixeira pelas demonstrações de amizade e fraternidade que permitiram que eu concluísse o mestrado de forma tranquila.

Aos professores do Mestrado Profissional em Engenharia Urbana e Ambiental que compartilharam seus conhecimentos e experiências agregando valores à minha formação acadêmica.

Aos colegas do curso de mestrado, em particular à Priscilla Radd, Mônica Patrícia, Ricardo Atta e Ricardo Saldanha pela amizade e motivação. 
Aos meus pais (in memorium), Anna Maria e Haroldo, pelo incentivo ao estudo como forma de transpor barreiras. Ao meu pai por ter despertado em mim o desejo pelo saber. Por ter me alimentado de cultura e me instigado o conhecimento.

À minha mãe por sua dedicação, amor incondicional, e por te me transmitido o sentido do caráter e da honra.

À minha irmã Márcia pelo apoio emocional e por ter cuidado de nossa mãe enquanto eu fazia o curso de mestrado.

Ao meu marido pelo companheirismo de uma vida, por sua amizade e apoio.

À minha filha, meu grande amor, por seu incentivo e pela paciência e compreensão em entender minhas ausências.

A Deus, por ter me abençoado nesta trajetória, e ter permitido que eu concluísse mais esta etapa de minha vida. 


\section{Resumo}

Souza, Claudia Corrêa Torquato de; Romanel, Celso (orientador) Viabilidade técnica e econômica da adoção da Diretiva $R o H S$ por Organização Militar da Marinha do Brasil. Rio de Janeiro, 2015. 150p. Dissertação de Mestrado - Departamento de Engenharia Civil, Pontifícia Universidade Católica do Rio de Janeiro.

Visando reduzir a quantidade de substâncias nocivas descartadas no meio ambiente, a União Europeia (UE) elaborou a Diretiva Restriction of The Use of Certain Harzardous Substances in Electric Electronic Equipment (RoHS) para mitigar os danos ambientais resultantes do descarte de resíduos sólidos eletrônicos no meio ambiente. A Diretiva RoHS restringe a quantidade de certas substâncias consideradas tóxicas nos materiais que compõem os equipamentos eletroeletrônicos (EEE) produzidos, e a serem adquiridos, pelos Estados-membros da UE. As empresas fabricantes de equipamentos eletroeletrônicos se esforçam para alinhar seus produtos à Diretiva $R o H S$, garantindo suas permanências no mercado fornecedor de EEE para a UE. O Ministério do Planejamento Orçamento e Gestão (MPOG) emitiu em 19 de janeiro de 2010 a Instrução Normativa $\mathrm{N}^{\circ} 01$ que dispõe sobre critérios de sustentabilidade ambiental na aquisição de bens pela Administração Pública Federal Direta. Pelo seu artigo 5º inciso IV recomenda atendimento à Diretiva $R o H S$. Este tudo faz uma análise sobre a viabilidade técnica e econômica da inclusão de critérios de sustentabilidade ambiental a serem considerados na aquisição de equipamentos eletroeletrônicos de emprego dual (emprego civil e militar) das áreas de navegação, acústica e de detecção radar por Organização Militar da Marinha do Brasil (MB), tendo a Diretiva RoHS e o Modelo Militar de Decisão (EMA-332) como referência. Academicamente, a Diretiva RoHS foi desvinculada da diretiva europeia de descarte de resíduos eletroeletrônicos. O trabalho sofreu limitações devido à falta de dados estatístico ambientais sobre equipamentos utilizados na esfera da Defesa. Foi verificado que a MB já utiliza equipamentos submetidos à Diretiva $R o H S$ com boa resposta técnica e econômica. Considerada viável, foi concebido modelo de fluxograma de decisão para 
verificação da necessidade de inclusão dos fundamentos da Diretiva $R o H S$ nas especificações para aquisição de EEE e seus sobressalentes.

\section{Palavras-chave}

RoHS; sustentabilidade; eletroeletrônicos; especificação; militar. 


\section{Extended Abstract}

Souza, Claudia Corrêa Torquato de; Romanel, Celso (advisor). Technical and economic availability of adopting the Directive RoHS for Military Organization of the Navy of Brazil. Rio de Janeiro, 2015. 150p. MSc. Dissertation - Departamento de Engenharia Civil, Pontifícia Universidade Católica do Rio de Janeiro.

Because of the large volume of Waste Electrical and Electronic Equipment (WEEE) produced worldwide, and its low rate of reuse and recycling, it was observed that the control and the effective reduction of harmful impacts to the environment produced by a particular product should be performed at the begining of lifecycle, controlling your production process The idea propagated by centuries of the earth's natural resources were inexhaustible no longer holds because these are finite. The growth of cities, added to the great technological advances and population growth in the twentieth and twenty-first, caused negative environmental impacts of great intensity.

This context made the European Union (EU) to develop a specific standard, the Restriction of Certain Hazardous Substances (RoHS) Directive for restricting the use of certain hazardous substances in electrical and electronic equipment (EEE) in order in this way ensure a reduction in the poisoning potential due to human handling EEE, as well as reducing of the amount of toxic waste released into the environment. maximum concentration of toxic substances by weight is determined for homogeneous materials, i.e., materials that can not be mechanically divided into various others. Maximum concentration recommended for cadmium is $0.01 \%$ while for lead, mercury, hexavalent chrome, polybrominated (PBB) and polybrominated diphenyl echers (PBDE) is $0.1 \%$.

This year, 2015, was enacted Directive 2015/863 / EU that updates the RoHS2 Directive, establishing restriction chemicals to DEPHP, BBP, DBP and DIBP. In this sense, due to its recent enactment and the deadline for the EEA meet Directive 2015/863 / EU, this study did not include the analysis of impacts of the inclusion of DEPHP, BBP, DBP and DIBP substances in RoHS2 Directive, being the study restricted to the substances lead, mercury, cadmium, hexavalent chromium, polibromato biphenyl (PBB) and diphenyl ether polibromato (PBDE) with 
maximum concentration of toxic substances by weight is determined for homogeneous materials, i.e., materials that can not be mechanically divided into various others. Maximum concentration recommended for cadmium is $0.01 \%$ while for lead, mercury, hexavalent chrome, polybrominated (PBB) and polybrominated diphenyl echers (PBDE) is $0.1 \%$.

Aware of its environmental responsibility, Brazil has been engaged in seeking solutions to reduce also the environmental impacts resulting from the improper disposal of hazardous waste on the environment, by investing primarily in education and prevention. For this reason, it has been legislated in favor of environmental protection, regulating instruments of disposal and control of chemical substances in products.

However, it does not have specific regulations with environmental sustainability criteria for the production of EEE. In this context, it is possible to mention the environmental contamination, technological stagnation and environmental compliance as some potential adversities caused by the lack of control over the presence of harmful substances in electrical and electronic equipment.

In June 2015, the Communications and Information Technology Directorate of Brazilian Navy issued the DCTIMARINST standard No. 30-14 that guides about sustainability criteria, including the RoHS Directive on the acquisition of Information Technology devices.

In this scenario, public and private companies, including the Brazilian Navy, must conform to the environmental legislation and thereby encourage a sustainable economy and development. The Military Organization in focus is responsible for the acquisition and maintenance of electronic equipment in the fields of acoustics, radar and navigation to be integrated to the naval combat systems of the Brazilian Navy ships and airplanes. In 2010, the Ministry of Planning and Management from Brazil by the Normative Instruction No. 01 determined the use of environmental sustainability criteria in the evaluation and classification of tenders for procurement of goods by the direct federal public administration. In its section V, the RoHS Directive is proposed as an alternative to environmental sustainability criteria. To comply with the recommendation, it became necessary to carry out studies to verify 
the feasibility of the adoption of those criteria in the specifications for the acquisition of naval electronics equipment.

The objective of this research was to analyze the technical and economic feasibility of adopting the RoHS Directive by the Military Organization for acquisition of EEE. That is, check if the RoHS Directive ensures the necessary technical reliability to the EEE within acceptable price range. The coverage areas of research was limited to commercial equipment of dual use (civil and military) in navigation, radar and acoustic detection. The RoHS Directive does not cover military weapons because, as can be easily seen, the nature and purpose of these objects are opposite to the concepts of sustainability.

Conscious of their duties as consumer of maximum relevance to the national economic system, the Brazilian government has legislated in order to establish sustainability criteria for acquisitions of goods and services made by the public sector

The legal mechanism used by the Federal Public Administration for the acquisition of goods and service are the bidding, which purpose to select the best product in free competition with the lowest price. Including sustainability criteria, these bidding are called Sustainable Biddings or Green Biddings. Among all the current legislation, the publication of Normative Instruction 01/2010 is considered the legal apparatus of the inclusion of environmental criteria in federal government purchases. Chapter III, of the Normative Instruction on goods and services, is of great interest in this work. In its section IV, recommends compliance with RoHS Directive in electrical and electronic equipment and underlines in its section II, the need of certification from the National Institute of Metrology, Standardization and Industrial Quality supporting the EEE compliance with environmental standards.

Adding to the text of Law No. 12,349 of 2010 keeps the balance between the various principles laid down in art. 3 of Law 8,666 / 93, which regulates procurement and contracts public administration, including the purpose of the bidding, with the promotion of sustainable national development. The analysis of the technical and economic feasibility of adopting the RoHS Directive as a criterion for sustainability in the acquisition of EEE was conducted with problem-solving method called the Military Staff Survey established by the General Staff of the Armed document EMA-332 (EMA, 2015). 
The methodology introduces the Military Model Decision allowing the lifting of possible solutions to a given problem, directing analyst at "selection and implementation of effective solutions to the problems that must solve" (EMA, 2015).

The solutions for the problem was subjected to the following evaluation tests: suitability, feasibility and acceptability. Suitability tests (relevancy, integrity and opportunity) and feasibility contain excluding aspects, with the approval in each conditional test to be subjected to the next examination. The acceptance test is qualifier, allowing forecast solutions ranking. (EMA, 2015).

The conditioning factors identified to the adoption of the RoHS Directive by the Military Organization were current legislation, equipment in use in the Brazilian Navy and existence of RoHS electronics equipment manufacturers.

In addition to these factors related to the RoHS Directive, equipment must meet minimum technical requirements, similar to the currently in use by the Brazilian Navy.

After completing the analysis of the conditioning factors, two solutions were contemplated to verify the technical and economic appropriateness of adopting EEE that comply with the RoHS sustainability criteria.

The first, to develop in Brazil EEE according to the criteria of the RoHS Directive. Although relevant, it was not timely for the too long development of EEE to the technical feasibility check. So, this proposal was considered INADEQUATE.

The second one, acquire of RoHS EEE in the international market was considered technically opportune inasmuch as it can have immediate use, since there is company that currently provides EEE, and spare parts, in compliance with the RoHS Directive, some in use by the MB.

There are not Brazilian RoHS EEE suppliers of the areas under consideration.

Thus, the solution to acquire RoHS EEE in the international market was admitted as PROPERLY.

Considered adequate, the next step was to test the solution as their feasibility by analyzing factors such as availability of human, material, technological and financial resources and availability of time in the process of acquisition of naval equipment. 
It was found that the Electronic Maintenance Center of the Brazilian Navy has technical qualified staff in sufficient numbers for the solution development. There were no other identified needs of material and technological resources, installation and maintenance of equipment, in addition to materials already commonly used.

There were also not identified additional financial costs acquisition process to meet RoHS EEE because the same public bidding process for unsustainable EEE acquisition would be used for the purchase of electronic equipment that meet the RoHS Directive. Time availability analysis was unnecessary because the EEE acquisitions can be immediate.

How it were not detected restrictions on implementation of the second solution it was considered PRACTICABLE.

Regarding the costs there are no conclusive data on the increase attributed to the adaptation of EEE to the RoHS Directive. The Institute for Technological Research of São Paulo City, the maximum increase costs observed in product technological adaptations would be around $20 \%$ to $30 \%$. It is noteworthy that variations in equipment prices also occur due to technological innovations.

In this study the comparison between previous and after RoHS Directive prices was carried out between equipment with similar technical characteristics. All equipment compared was from Furuno Company. The previous costs were obtained from studies and technical reports elaborate by the Military Organization staff responsible for examining the feasibility of replacement of obsolete electronic equipment. EEE values with sustainability criteria were obtained from the Furuno company WEB site.

The costs of the RoHS equipment were analyzed, compared to equipment manufactured before the policy, with maximum acceptable increase of $30 \%$, consistent with the forecast for development of equipment to comply with RoHS sustainability criteria.

Finally, according to the EMA-332 document, the acceptance should be checked verifying the rate between cost and technical benefits of the proposed solution, justifying its implementation. Checking the results of the tests of suitability and of feasibility, the solution was considered ACCEPTABLE. 
Finally, it was observed that the Navy already has RoHS equipment installed in their naval assets. This fact confirms the possibility of the Brazilian Navy line up to environmental standards to dual EEE without thereby incurring extra costs or requiring additional human and material resources.

It is noteworthy that these findings, although consistent can not be generalized because of the lack of sustainability of data available in the Defense area as well as information concerning the electronic equipment put on the market before the RoHS Directive be established. In addition, some information considered confidential were not considered in this study to be of interest and application restricted to the military area.

Even with these limitations, the research was available to demonstrate highlight the possibility of adding up criteria of environmental sustainability to EEE of the Brazilian Navy.

\section{Keywords}

RoHS; sustainability; electronics; specification; military. 


\section{Sumário}

1. Introducão 24

1.1. Definição do problema 25

1.2. Importância do tema 26

1.3. Razão da escolha do tema 29

1.4. Objetivos 29

1.5. Estrutura do trabalho 30

2. Os eletroeletrônicos e seus resíduos: adversidades e controle 32

2.1. A indústria de eletroeletrônicos no Brasil e no mundo 32

2.2. Geração de REEE 34

2.3. Composição toxicológica dos REEE - impacto do descarte 38 indevido de REEE na saúde humana e no meio ambiente 2.3.1. Vida útil de EEE determinado pela obsolescência 44 programada

2.3.2. Início do COTs nos Sistemas de Defesa 46

2.4. Legislação ambiental 49

2.4.1. Legislação aplicável ao controle da toxidade de EEE e de 50 seus resíduos

2.4.2. Legislação ambiental do Setor Militar Naval 52

2.5. Política governamental para contratações públicas 54 sustentáveis

2.5.1. Contratações sustentáveis na Administração Pública 54 Federal

2.5.2. Contratações sustentáveis na Administração Pública do 61 Estado do Rio de Janeiro

2.5.3. Contratações sustentáveis na Administração Pública da 63 Cidade do Rio de Janeiro

2.5.4. Contratações sustentáveis no Ministério da Defesa e na 64 Organização Militar da Marinha do Brasil 
3.1.RoHS Europeia (EU): definição e escopo da Diretiva 68

3.1.1. Exceções da Diretiva RoHS2 72

3.1.2 Certificações de EEE

3.1.3. Primeira atualização da Diretiva RoHS2 76

3.2. Adoção da Diretiva RoHS fora da União Europeia 77

3.2.1. RoHS China $\quad 77$

3.2.2. RoHS Coréia $\quad 79$

3.2.3. RoHS Califórnia (EUA) 80

3.2.4. RoHS Japão 81

4. Metodologia para a análise da viabilidade técnica e econômica 86

4.1.Modelo Militar de Decisão EMA-332 86

4.2 Fatores da Matriz SWOT 88

4.2.1. Ambiente externo 88

4.2.2. Ambiente interno $\quad 89$

4.3 Definição da Matriz SWOT e sua análise 90

4.3.1. Análise dos fatores externos 92

4.3.2. Análise dos fatores internos 95

4.4. Fatores Condicionantes (FC) 99

4.4.1. Análise dos fatores condicionantes 100

5. Avaliação de propostas para adoção da Diretiva RoHS 110

5.1 Desenvolvimento de EEE com os critérios da Diretiva RoHS 110 no Brasil

5.2 Adquirir EEE com os critérios da Diretiva RoHS no mercado 112 internacional.

6. Conclusões e sugestões de trabalhos futuros 127

6.1 Conclusões 127

6.2 Sugestões de trabalhos futuros 131

7. Referências bibliográficas 132

$\begin{array}{ll}\text { Anexos } & 148\end{array}$ 


\section{Lista de Tabelas}

Tabela 1 - Quantidade percentual de EEE nas residências do Brasil. 33

Tabela 2 - Quantidade de Telefones Celulares no Brasil. 34

Tabela.3 - Quantidade de Computadores Pessoais e Tablets no Brasil. 34

Tabela 4 - Panorama da geração de REEE no mundo. 36

Tabela 5 - Porcentagem de resíduo eletrônico identificado no lixo 36 domiciliar do Município do Rio de Janeiro.

Tabela 6 - Quantidade de REEE, em kg, gerados no período de 2008 - 2011 no Centro de Manutenção de Sistemas da MB.

Tabela 7 - Composição média das substâncias identificadas em uma placa de circuito impresso.

Tabela 8 - Relação das 20 substâncias em relação à sua frequência, toxidade e potencial de exposição humana.

Tabela 9 - Porcentagem da população mundial com níveis de chumbo no sangue considerados danosos à saúde humana.

Tabela 10 - Quantidade estimada da redução de substâncias.

tóxicas em lâmpadas fluorescentes descartadas pelo CMS em decorrência do estipulado pela RoHS, caso adotada.

Tabela 11 - Relação de normas ambientais da MB.

Tabela 12 - Relação de Leis que normatizam a inclusão de

critérios de sustentabilidade ambiental em licitações da Administração Pública Federais.

Tabela 13 - Relação de Substâncias Tóxicas restritas na Diretiva

RoHS e seus efeitos nocivos à saúde e ao meio ambiente.

Tabela 14 - Parâmetros a serem considerados na avaliação de 72 exceções da Diretiva RoHS 2.

Tabela 15 - Resumo das exceções da Diretiva RoHS2.

Tabela 16 - Resumo de datas limites para adequação à Diretiva 73 RoHS2

Tabela 17 - Relação de equipamentos utilizados na detecção de substâncias químicas. 
Tabela 18 - Valores limites de aceitabilidade de substâncias químicas

em EEE em atendimento à RoHS estipulados pelo IPT-SP.

Tabela 19 - Resumo comparativo das Diretivas RoHS. 84

Tabela 20 - Matriz SWOT. 91

Tabela 21 - Relação de materiais sustentáveis mais licitados 96 por órgãos públicos, em porcentagem.

Tabela 22 - Relação de materiais sustentáveis mais licitados por 96 públicos, em reais.

Tabela 23 - Características Técnicas de um ECDIS.

Tabela 24 - Características Técnicas de um GPS.

Tabela 25 - Características Técnicas de um Radar de navegação. 102

Tabela 26 - Características Técnicas de uma Giro-Satélite. 102

Tabela 27 - Características Técnicas de uma Repetidora Digital. 102

Tabela 28 - Composição de soldas sem chumbo. 106

Tabela 29 - Relação de ligas de soldas sem chumbo produzidas pela 107 empresa Indium Corporation.

Tabela 30 - Equipamentos Furuno que atendem à Diretiva RoHS.

Tabela 31 - Exemplo de EEE RoHS fabricados pela empresa MarineData Systems.

Tabela 32 - Relação de equipamentos Furuno que atendem a critérios de sustentabilidade por meios/OM da MB.

Tabela 33 - Relação de preços de equipamentos de até 2003.

Tabela 34 - Relação de preço de equipamentos fabricados pela 123 empresa Furuno em 2015.

Tabela 35 - Características técnicas de radares de navegação avaliados antes de 2003.

Tabela 36 - Características técnicas de radares de navegação à venda em 2015.

Tabela 37 - Percentual de variação no preço de radares.

Tabela 38 - Percentual de variação no preço de ecobatímetros.

Tabela 39 - Percentual de variação no preço de GPS.

Tabela 40 - Resumo do percentual de variação no preço dos equipamentos analisados. 


\section{Lista de Figuras}

Figura 1 - Importância do controle de substâncias tóxicas em $\quad 27$ EEE para a Soberania Nacional.

Figura 2 - Representação Gráfica da área protegida pela MB. 28

Figura 3 - Programa de reaparelhamento da Marinha do Brasil. $\quad 28$

Figura 4 - Gráfico demonstrativo de equipamentos alienados pela $\quad 38$

Organização Militar da MB entre os anos de 2005 - 2015.

Figura 5 - Expectativa da vida útil real versus expectativa de vida

ideal de equipamentos eletroeletrônicos.

Figura 6 - CPU MAD2 V28 do telefone celular NOKIA 6110.

Figura 7 - Exemplo de aquisição da CPU MAD2 V28.

Figura 8 - Apresentação de formação de migração eletrônica. 105

Figura 9 - Apresentação das dimensões de um filamento 105

decorrente de migração eletrônica frente a um fio de cabelo.

Figura 10 - Patentes americanas de soldas livres de chumbo 109 registradas nos Estados Unidos, Japão e Europa.

Figura 11 - Artigos científicos sobre solda livre de chumbo

publicado nos Estados Unidos, Europa e Japão (1990 - 2004).

Figura 12 - Display do Radar FR8065.

Figura 13 - Display do GPS GP33.

Figura 14 - Display da giro satélite SC-5.0.

Figura 15 - Configuração básica de interligação das unidades da 119 giro satélite SC-50.

Figura 16 - Sensor PG-500. 119i

Figura 17 - Configuração básica de integração do sensor PG-500. 119

Figura 18 - Aquisição de EEE sustentáveis.

Figura 19 - Aquisição de componentes e sobressalentes para EEE 130 sustentáveis. 


\section{Lista de Siglas}

\begin{tabular}{|c|c|}
\hline ABINEE & $\begin{array}{l}\text { Associação Brasileira da Indústria Elétrica e } \\
\text { Eletrônica }\end{array}$ \\
\hline ABNT & Associação Brasileira de Normas Técnicas \\
\hline AEA & Adequabilidade, Exequibilidade, Aceitabilidade \\
\hline $\mathrm{Ag}$ & Prata \\
\hline AGU & Advocacia Geral da União \\
\hline ATSDR & Agency for Toxic Substances and Disease Registry \\
\hline BSA & Bismuto-Estanho-Prata \\
\hline CA & Estado da Califórnia \\
\hline $\mathrm{Cd}$ & Cádmio \\
\hline CE & Comunidade Europeia \\
\hline CEA & Consumer Electronics Assossiation \\
\hline CEU & Council of the European Union \\
\hline COMLURB & Companhia Municipal de Limpeza Urbana \\
\hline CONAMA & Conselho Nacional do Meio Ambiente \\
\hline COTS & Commercial off-the-shell \\
\hline $\mathrm{Cr}$ & Cromo \\
\hline Daly & Disability adjusted life years \\
\hline DF & Distrito Federal \\
\hline DSAM & $\begin{array}{l}\text { Diretoria de Sistemas de Armas da Marinha do } \\
\text { Brasil }\end{array}$ \\
\hline EEB & European Environmental Bureau \\
\hline EEE & Equipamento Eletroeletrônico \\
\hline EFUP & Efriendly Use Period \\
\hline EMA & Estado Maior da Armada \\
\hline
\end{tabular}




\begin{tabular}{|c|c|}
\hline EPA & Environmental Protection Agency \\
\hline ESG & Escola Superior de Guerra \\
\hline EU & European Union \\
\hline EUA & Estados Unidos da América \\
\hline FEAM & Fundação Estadual do Meio Ambiente \\
\hline FOFA & Forças, Oportunidades, Fraquezas e Ameaças \\
\hline FGV & Fundação Getúlio Vargas \\
\hline $\mathrm{Hg}$ & Mercúrio \\
\hline IBGE & Instituto Brasileiro de Geografia e Estatística \\
\hline IDEC & Instituto Brasileiro de Defesa do Consumidor \\
\hline IEC & International Electrotechnical Commission \\
\hline INMETRO & $\begin{array}{l}\text { Instituto Nacional de Metrologia, Qualidade e } \\
\text { Tecnologia }\end{array}$ \\
\hline JIG & Joint Industry Guide \\
\hline MB & Marinha do Brasil \\
\hline KLRI & Korean Legislation Research Institute \\
\hline LVAD & Lista de Verificação e Destinação \\
\hline MilStandard & Military Specificarion \\
\hline MOTs & Modified Off-The-Shelf \\
\hline MPOG & Ministério do Planejamento, Orçamento e Gestão \\
\hline NBR & Norma Brasileira \\
\hline Octa-BDE & Octabromodiphenyl oxide \\
\hline OMS & Organização Mundial de Saúde \\
\hline ONU & Organização das Nações Unidas \\
\hline $\mathrm{Pb}$ & Chumbo \\
\hline PBB & Polibromato Bifenil \\
\hline
\end{tabular}




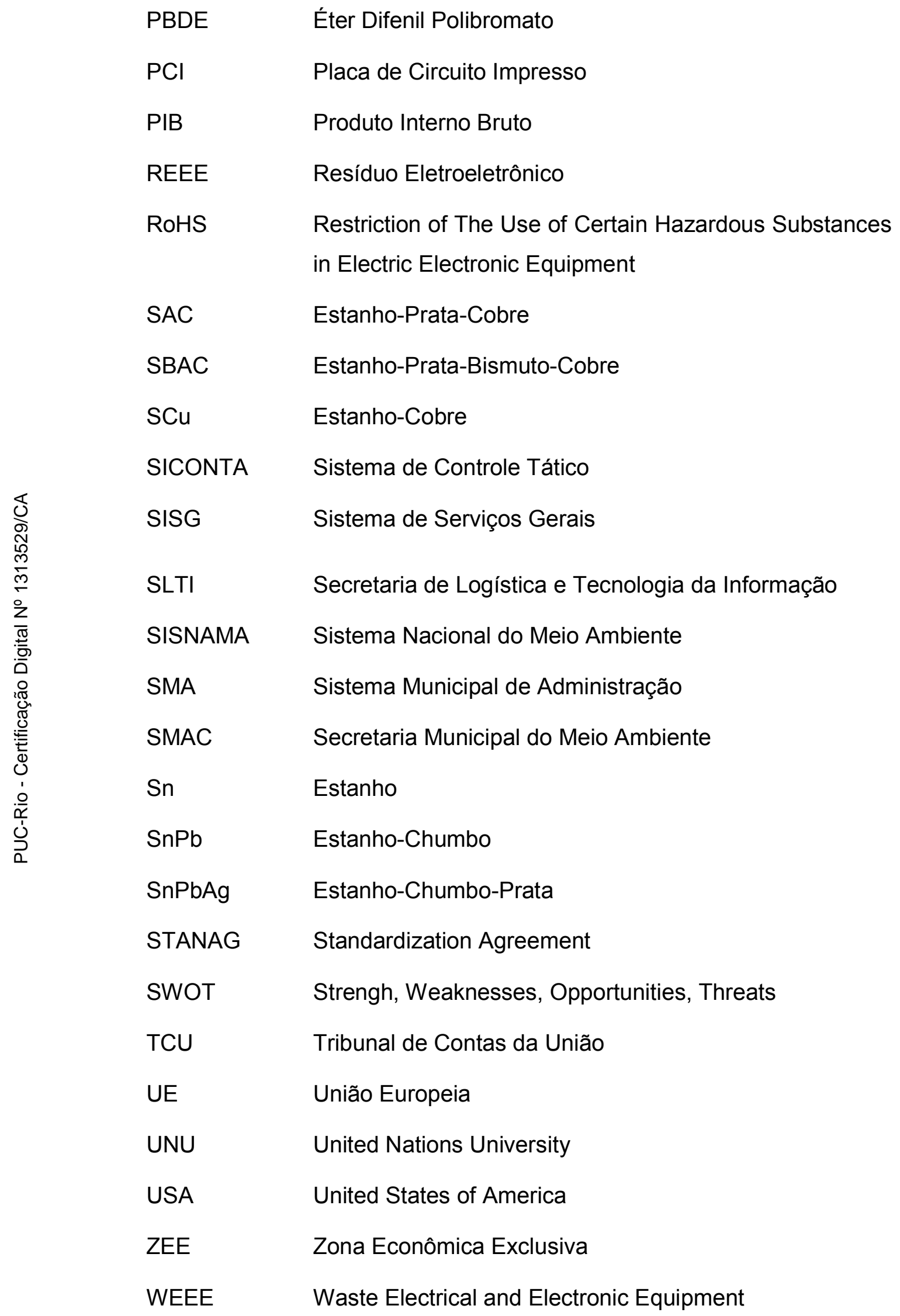


Todo mundo é capaz de dominar uma dor, exceto quem a sente. William Shakespeare 


\section{1.}

\section{Introdução}

Em virtude do grande volume de resíduo eletroeletrônico (REEE) produzido no mundo, e ao baixo índice de seu reuso e reciclagem, foi observado que o controle e a redução eficaz de impactos nocivos ao meio ambiente produzidos por um determinado produto deveriam ser realizados no início de seu ciclo de vida, controlando-se seu processo de fabricação visando-se seu descarte final (Montrose, 2011).

Atualmente, outro fator determinante do aumento do volume de Resíduos Sólidos eletrônicos é a diminuição da vida útil dos equipamentos eletroeletrônicos (Araújo, 2013).

Este contexto fez com que a União Europeia (UE) elaborasse norma específica, a Diretiva Restriction of Certain Hazardous Substances (RoHS), para restrição do uso de certas substâncias nocivas em equipamentos eletroeletrônicos visando, desta maneira, garantir a redução do potencial de intoxicação humana devido ao manuseio de equipamentos eletroeletrônicos (EEE), bem como a redução de substâncias tóxicas lançadas no meio ambiente devido ao descarte de REEE.

O Brasil, consciente de sua responsabilidade socioambiental, tem se empenhado na busca de soluções para diminuir os impactos ambientais decorrentes da disposição inadequada de resíduos nocivos no meio ambiente investindo, principalmente, em educação e prevenção. Para isso, tem legislado em favor da proteção ambiental, regulamentando instrumentos de descarte e o controle de substâncias químicas em produtos. Entretanto, o Brasil não possui legislação ambiental específica que regulamente a quantidade máxima de substâncias tóxicas para equipamentos eletroeletrônicos. 


\section{1}

\section{Definição do Problema}

Várias substâncias tóxicas fazem parte da composição dos equipamentos eletroeletrônicos (EEE) que podem ocasionar danos ao meio ambiente e à saúde humana. Vários Órgãos Públicos e Institutos de Pesquisa têm alertado para o crescente aumento de REEE no mundo, e consequente impacto negativo ocasionado por seu descarte indevido. Diferentemente da Comunidade Europeia, o Brasil, não possui regulamentação específica com critérios de sustentabilidade ambiental para a fabricação de EEE. Atualmente a Organização Militar da Marinha do Brasil em pauta não inclui critérios ambientais em suas especificações para aquisição de EEE.

Neste sentido, é possível visualizar as adversidades referentes à inexistência de normas no Brasil que determinem a quantidade de substâncias nocivas em EEE: - Contaminação humana e ambiental: os REEE são formados por substâncias químicas. Várias destas substâncias são comprovadamente nocivas à saúde e ao meio ambiente. Os metais pesados como o chumbo, o mercúrio e o cádmio, presentes nos componentes eletrônicos e nas placas de circuitos impressos (PCI), são altamente tóxicos, e caso não sejam descartados corretamente acabam por contaminar o solo, os lençóis de águas subterrâneas e o ar. A contaminação também ocorre devido ao manuseio indevido do REEE;

- $\quad$ Estagnação tecnológica: a inexistência de normas que regulamentem a inclusão de critérios de sustentabilidade na fabricação de EEE não estimula a busca por tecnologias que possibilitem o avanço tecnológico alinhado ao conceito de desenvolvimento sustentável. Fator limitador de exportação; e

- Submissão ambiental: é grande a possibilidade de o Brasil tornar-se lixeira (dumping ground) de componentes e equipamentos que não podem ser mais produzidos, e ou vendidos em países que adotam a Diretiva RoHS. (Ansanelli, 2008).

Mesmo não possuindo legislação específica para controle de substâncias nocivas em EEE, o MPOG determinou em sua Instrução Normativa 01 que os Órgãos Públicos Federais atendessem à Diretiva RoHS. Neste sentido, faznecessário verificar a viabilidade desta determinação. 
Problema em análise: a adoção da Diretiva $R o H S$ na aquisição de EEE por Organização Militar da Marinha do Brasil responsável por aquisição de equipamentos eletroeletrônicos de emprego dual (emprego civil e militar) das áreas de navegação (hodômetro e GPS), acústica (ecobatímetros) e de deteç̧ão radar (radar de navegação), em face ao contido na Instrução Normativa 01/2010 do MPOG, assegura a confiabilidade técnica e operativa dos EEE dentro de faixa de preços aceitáveis?

\section{2}

\section{Importância do Tema}

A ideia acalentada por séculos de que os recursos naturais da terra eram inesgotáveis não mais se sustenta. Os recursos naturais são finitos. O crescimento desordenado das cidades, somado ao grande avanço tecnológico e ao aumento populacional nos séculos XX e XXI, ocasionaram impactos ambientais de grande intensidade.

Os Estados necessitam de estratégias urgentes para evitar degradação e consumo desenfreado de seus recursos naturais, insumos necessários ao desenvolvimento de uma nação. Seja pela prevenção ou por ações punitivas.

A conscientização ambiental é necessária para se alcançar o equilíbrio entre o desenvolvimento econômico e o desenvolvimento socioambiental, obtendo-se desta maneira um desenvolvimento sustentável.

Conforme o Ministério do Meio Ambiente preconiza em sua página na web, para existir um Brasil sustentável é necessário que os Órgãos Públicos realizem mudanças em sua forma de atuação junto aos demais setores da sociedade. Os Órgãos Públicos devem servir de exemplo.

"O Planejamento se constitui numa ferramenta de intervenção na realidade de forma a se buscar, com ele, a obtenção de uma situação desejada num periodo de tempo determinado. Diferentemente do que se tem no setor privado, o setor público não tem, e não pode ter, como objetivo primordial o retorno financeiro, mas, sim o de proporcionar beneficios sociais através do desenvolvimento sustentável, em cujo conceito hoje são consideradas outras dimensões, como a social, a política, a cultural e a do meio ambiente, sendo que, em todo o caso, este conceito é associado a um processo de melhoria e transformações".

Fonte: Gestão Estratégica, página na WEB do MMA (2015). 
“[...] Internamente, o desafio é a construção de uma política de integração entre o setor produtivo e o meio ambiente, na busca pela antecipação das incertezas, transformações e dos problemas, promovendo a adequação do país às novas exigências de competitividade no comércio internacional."

Fonte: Economia Verde, página na WEB do MMA (2015).

Neste cenário, os Órgãos Governamentais, inclusive a MB, deve adequar-se às legislações ambientais existentes incentivando uma economia sustentável, afinal, o controle de substâncias tóxicas e o controle de consumo de EEE impacta diretamente na preservação do meio ambiente de nosso país, resumidamente, na Soberania Nacional. (Figura 1)

A MB é responsável pela proteção de nossa fronteira marítima, sendo que a Zona Econômica Exclusiva (ZEE) com a Plataforma Continental (PC) representam, juntas, mais de $52 \%$ do território Nacional, sendo esta grande área conhecida por Amazônia Azul. Além da proteção da Amazônica Azul, a MB é a responsável pela proteção dos rios da Amazônia Verde. (Figura 2)

\section{Importância do Controle de Substâncias Tóxicas em EEE para a Soberania Nacional}

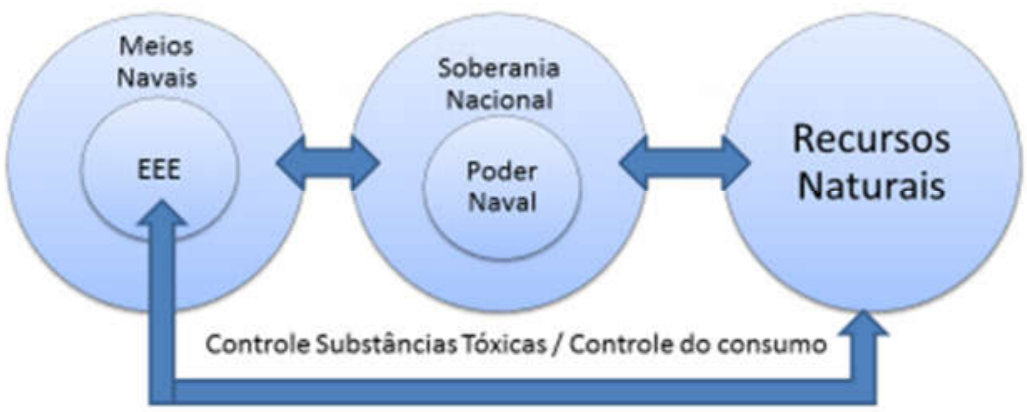

Figura 1 - Importância do controle de substâncias tóxicas em EEE para a Soberania Nacional.

Fonte: Autor 


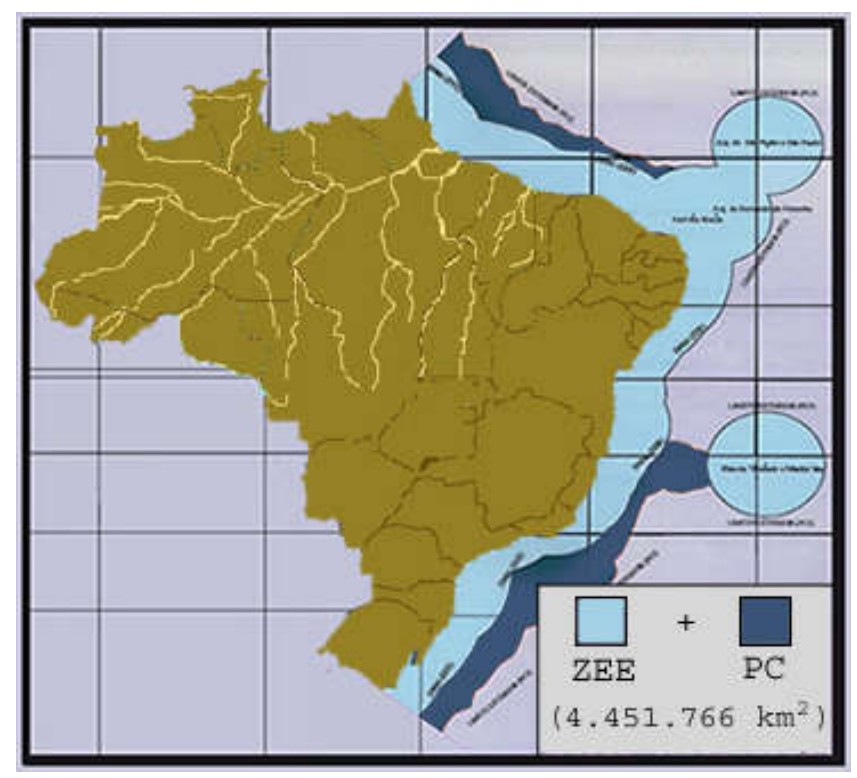

Figura 2 - Representação Gráfica da área protegida pela MB. Fonte: DEFESA BR, 2015.

Para poder proteger esta imensa área detalhada na figura 2 a MB verificou a necessidade de reaparelhamento de sua esquadra, sendo com aquisições de oportunidade, como foi o caso da aquisição dos Navios Patrulha Classe "Amazonas" ou construindo novos navios como os Navios Patrulha Classe "Macaé". A retomada do reaparelhamento da Armada Naval pode ser a oportunidade de inserção de critérios ambientais na aquisição de EEE para os novos meios aeronavais. A figura 3 apresenta o Programa de Reaparelhamento da Marinha.

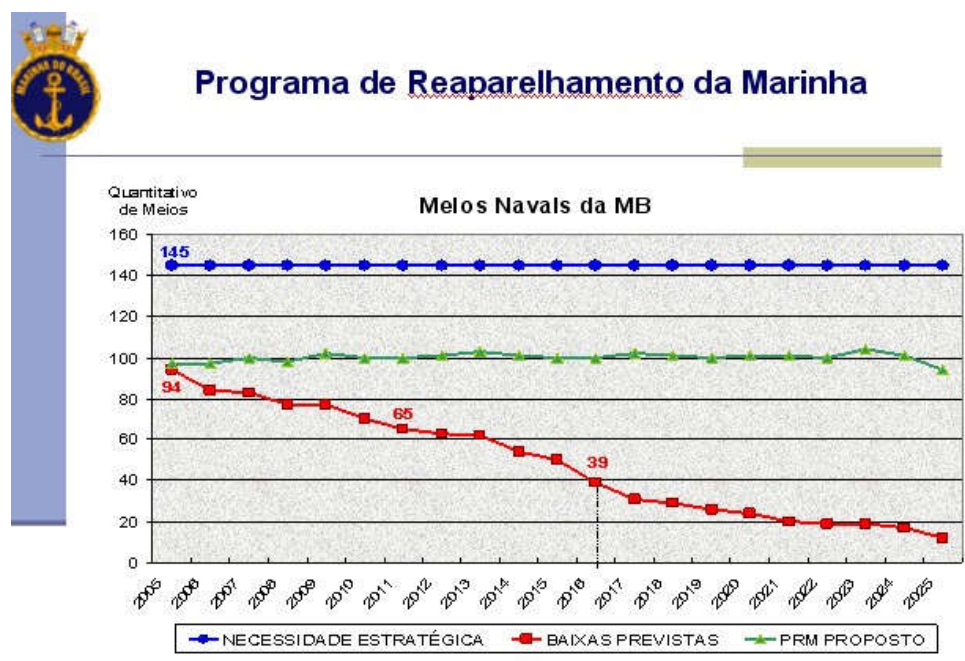

Figura 3 - Programa de reaparelhamento da Marinha do Brasil Fonte: página na web da DEFESA BR, 2015. 


\section{3}

\section{Razão da Escolha do tema}

Em 2010, o MPOG através da Instrução Normativa No 01 determina a inserção de critérios objetivos de sustentabilidade ambiental para avaliação e classificação de propostas na aquisição de bens pela Administração Pública Federal Direta. Em seu inciso V propõe, como alternativa de critério de sustentabilidade ambiental, a Diretiva RoHS.

Em atendimento à Instrução Normativa, torna-se necessário a realização de estudo para verificar a viabilidade de inserção dos critérios de sustentabilidade ambiental determinados na Diretiva $R o H S$ nas especificações de aquisição de equipamentos eletroeletrônicos de emprego dual nas áreas de acústica, detecção radar e navegação por Organização Militar da Marinha do Brasil visando mitigar os problemas identificados no item 1.1.

\section{4 \\ Objetivos}

O objetivo geral deste trabalho foi o de verificar, mediante a ótica dos critérios de adequabilidade, exequibilidade e aceitabilidade impostos pelo modelo militar de decisão EMA-332 (EMA, 2015) a possibilidade de desenvolvimento de EEE no Brasil e a possibilidade de aquisição de EEE no mercado internacional que atendessem aos critérios ambientais da Diretiva $R o H S$ para atestar a viabilidade de adoção de EEE sustentáveis por Organização Militar da MB. Neste trabalho a verificação da viabilidade técnica e econômica se refere a equipamentos eletroeletrônicos RoHS, de emprego militar e civil, nas áreas de navegação (hodômetro e GPS), acústica (ecobatímetro) e detecção radar (radar de navegação) utilizados por Órgão Militar da Marinha do Brasil.

Foram identificados os seguintes objetivos específicos:

- Levantamento dos percentuais de alienação dos equipamentos das áreas em análise da Organização Militar da Marinha do Brasil (2005 a 2015);

- Verificação da aplicabilidade da Diretiva RoHS no país e na Organização Militar da MB; 
- Apresentação das Diretivas RoHS Europeia, China, Coréia, Califórnia e Japão, discutindo seus fatores positivos e negativos, dúvidas técnicas, certificação e exceções;

- Levantamento de empresas internacionais fornecedoras de EEE das áreas de navegação, acústica e detecção radar que atendam aos critérios de sustentabilidade determinados pela Diretiva RoHS; e

- Elaboração de fluxogramas de decisão para aquisição ou desenvolvimento de EEE e para aquisição de itens sobressalentes.

\section{5}

\section{Estrutura do Trabalho}

Visando alcançar os objetivos deste estudo, este trabalho está dividido nos seguintes capítulos:

O capítulo 2 apresenta o resumo das substâncias tóxicas identificadas em EEE e seus impactos na saúde humana e no meio ambiente. Apresentará pesquisa documental que consistiu em verificar, através dos Laudos de Vistoria, Avaliação e Destinação (LVAD) os equipamentos da jurisdição da Organização Militar da MB que foram alienados de 2004 a 2015 obtendo-se, percentualmente, a quantidade de REEE das áreas em análise gerados pela Organização Militar. São apresentadas as legislações ambientais vigentes no Brasil e a legislação ambiental adotada pela Marinha do Brasil. Examina, ainda, a política governamental quanto a inclusão de critérios de sustentabilidade nas contratações públicas. Apresenta, também, a vida útil de EEE determinada pela obsolescência programada e o uso de elementos COTs em sistemas de defesa.

O capítulo 3 inclui o detalhamento da Diretiva $R o H S$, sua aplicação, exceções e atualização. Será apresentada a adoção da Diretiva RoHS por países não pertencentes a Comunidade Europeia. Este capítulo apresentará, também, dados

apresentados em vários trabalhos acadêmicos quanto aos impactos resultantes da aplicação da Diretiva RoHS.

No capítulo 4 é apresentada a metodologia de análise de viabilidade técnica e econômica da adoção dos critérios de restrição de substâncias tóxicas propostos pela Diretiva RoHS, neste caso, o Modelo Militar de Decisão (EMA, 2015). O método analítico SWOT (Strengh, Weaknesses, Opportunities, Threats) foi utilizado para análise dos fatores internos e externos, bem como para identificar 
fatores condicionantes, que pudessem afetar a adoção da Diretiva RoHS. Foram analisados estudos e pareceres elaborados pela Organização Militar que apresentam análises da viabilidade de substituição de EEE obsoletos dos meios da MB cujos dados de custo constantes dos mesmos foram utilizados na avaliação da variação dos preços de EEE de antes, e após a Diretiva RoHS entrar em vigor. Além disso, o conhecimento do pesquisador em relação aos equipamentos das áreas em análise $\mathrm{e}$ da Organização Militar fez parte da abordagem metodológica empregada.

O Capítulo 5 avalia, mediante a ótica dos critérios de adequabilidade, exequibilidade e aceitabilidade impostos pelo modelo militar de decisão EMA-332 as soluções identificadas no capítulo 4 para adoção da Diretiva $R o H S$.

O capítulo 6 apresenta as conclusões do estudo, incluindo modelos de fluxogramas de decisão para aquisição de EEE e seus sobressalentes, bem como sugestões de trabalhos futuros.

Os anexos incluem cópias de declaração de conformidade à Diretiva RoHS emitidos pela empresa Furuno, além de documento com declaração de material emitido pela mesma empresa. 


\section{2.}

\section{Os eletroeletrônicos e seus resíduos: adversidades e controle}

A indústria eletroeletrônicos foi a indústria que mais revolucionou o mundo. Não temos mais como imaginar a vida moderna sem os EEE que tanto nos ajudam no dia-a-dia. Os equipamentos eletroeletrônicos estão inseridos em vários setores do mundo atual como na área médica, na educação, nas artes, no entretenimento, nas áreas de defesa e militar, em brinquedos, bem como nas áreas de informática e telefonia, sendo que estas duas últimas são responsáveis por tornar o mundo menor, facilitando a aproximação entre as pessoas e as nações, sendo responsáveis pela tão discutida globalização.

Entretanto, os equipamentos eletroeletrônicos são compostos de substâncias perigosas com alto grau de periculosidade e toxidade, podendo ocasionar risco à saúde e ao meio ambiente. O crescente aumento do consumo de EEE no mundo, inclusive no Brasil, faz crescer, proporcionalmente, a preocupação com as técnicas de produção dos EEE e com o descarte de seus resíduos. O impacto ambiental da produção de EEE é observado já no tipo e na quantidade de insumos necessários à fabricação dos equipamentos. Para a produção de um computador pessoal são necessários $240 \mathrm{~kg}$ de combustível fóssil, $22 \mathrm{~kg}$ de compostos químicos sintéticos e 1.500 litros de água (cinza). Ao todo, aproximadamente $1.700 \mathrm{~kg}$ de material bruto. (EEB-CE, 2014).

\section{1.}

\section{A indústria de eletroeletrônicos no Brasil e no mundo}

O uso de equipamentos eletroeletrônicos em todas as áreas da sociedade é crescente. A quantidade de EEE colocados no mercado anualmente está em expansão, tanto em países industrializados, quanto nos em desenvolvimento. Numa sociedade onde o ter define o que se é, o consumo, muitas vezes, está atrelado à posição social ao 
qual o indivíduo pretende pertencer. Talvez, este novo parâmetro da sociedade possa explicar o aumento considerável de EEE no mundo.

Nos últimos anos, o Brasil foi marcado pelo consumo expressivo de serviços e bens, principalmente de EEE, por parte da população que ascendeu financeiramente devido aos programas de inclusão social do Governo, e ao crescimento econômico do país

Conforme o índice de crescimento do rendimento mensal disponibilizado pelo Instituto Brasileiro de Geografia e Estatística (IBGE, 2014), o rendimento do trabalhador brasileiro teve aumento de 21,2\% no período de 2001 a 2013. Este aumento expressivo do rendimento dos brasileiros foi decisivo para que a população brasileira pudesse consumir mais.

A tabela 1 apresenta o percentual de equipamentos eletroeletrônicos nas residências do Brasil em 2009 e 2013, de acordo com os dados da Pesquisa Nacional por Amostra de Domicílios, sendo possível verificar o aumento de equipamentos eletroeletrônicos nos lares dos brasileiros. Pela mesma tabela podemos observar, ainda, que existe mercado consumidor potencialmente próspero tanto na área de informática quanto na de eletrodomésticos.

Tabela 1 - Quantidade percentual de EEE nas residências do Brasil
\begin{tabular}{|c|r|r|}
\hline Equipamentos eletroeletrônico & \multicolumn{2}{|c|}{ Porcentagem } \\
\cline { 2 - 3 } & 2009 & 20013 \\
\hline Geladeira & 96,1 & 97,3 \\
\hline Freezer & 14,3 & 16,9 \\
\hline Máquina de lavar roupa & 49,3 & 58,3 \\
\hline Televisão & 97,2 & 97,2 \\
\hline Computador Pessoal & 39,3 & 49,5 \\
\hline
\end{tabular}

Fonte: IBGE - Pesquisa Nacional por Amostra de Domicílios, 2014

Segundo a Associação Brasileira da Indústria Elétrica e Eletrônica (ABINEE, 2015) houve queda no faturamento do setor eletroeletrônico no $1^{\circ}$ semestre de 2014 em comparação com o mesmo semestre de 2013, principalmente, devido à retração econômica do país no último ano. Entretanto, baseada em pesquisas realizadas pela empresa IDC de consultoria em tendências tecnológicas, a ABINEE (2015) informa que o setor de telecomunicações continua crescendo, tendo apresentado aumento no mesmo período $\left(1^{\circ} \mathrm{sem} / 2013-1^{\circ} \mathrm{sem} / 2014\right)$, de $21 \%$ na venda de tablets, sendo 
que durante o ano de 2014 o aumento total foi de $13 \%$ com o total de 9,5 milhões de aparelhos comercializados. Já a venda de smartphones cresceu 55\% passando de 35,19 milhões em 2013 para 54,55 milhões em 2014. No total, foram vendidos aproximadamente 70,3 milhões de celulares em 2014, cerca de 7\% de aumento em relação ao ano de 2013.

As tabelas 2 e 3 resumem os volumes de venda dos equipamentos eletrônicos do setor de telefonia.

Tabela 2 - Quantidade de Telefones Celulares no Brasil

\begin{tabular}{|c|c|c|c|}
\hline \multirow[t]{2}{*}{ Mercado de Telefones Celulares } & Tradicionais & Smartphones & Celulares Total \\
\hline & \multicolumn{3}{|c|}{ (Em mil unidades) } \\
\hline 2012 & 42.215 & 16.010 & 58.226 \\
\hline 2013 & 30.378 & 35.195 & 65.573 \\
\hline 2014 & 15.752 & 54.551 & 70.303 \\
\hline $2015^{*}$ & 4.928 & 63.611 & 68.539 \\
\hline
\end{tabular}

Fonte: ABINEE, 2015.

* projeção

Tabela.3 - Quantidade de Computadores Pessoais e Tablets no Brasil

\begin{tabular}{|c|r|r|r|r|}
\hline \multirow{2}{*}{$\begin{array}{c}\text { Mercado de computadores } \\
\text { pessoais e Tablets }\end{array}$} & Desktops & Notebooks & Tablets & $\begin{array}{c}\text { Computadores Pessoais } \\
\text { + Tablets }\end{array}$ \\
\cline { 2 - 5 } & \multicolumn{5}{|c|}{ (Em mil unidades) } \\
\hline 2012 & 6.582 & 8.932 & 3.267 & 18.781 \\
\hline 2013 & 5.748 & 8.196 & 8.386 & 22.331 \\
\hline 2014 & 3.974 & 6.361 & 9.463 & 19.798 \\
\hline $2015^{*}$ & 3.870 & 6.202 & 9.327 & 19.399 \\
\hline
\end{tabular}

Fonte: ABINEE, 2015.

* projeção

Pelo exposto nas tabelas 1 a 3, observa-se que o consumo de eletroeletrônicos no Brasil é crescente, principalmente na área de telefonia, com grande potencial para geração de REEE

\section{2}

\section{Geração de REEE}

As estatísticas mundiais indicam o crescimento de resíduo eletrônico. Na era da obsolescência programada e do consumo desenfreado é natural que os REEE 
apresentassem aumento significativo, principalmente quando a reciclagem e o reuso são tão pouco incentivados pelo poder público.

Em 2014, conforme dados da Universaty Nations University (UNU) a geração mundial de resíduo eletrônico foi de 41,8 milhões de toneladas $(5,9 \mathrm{~kg} / \mathrm{Hab}$.) sendo 6,3 milhões de penas de monitores.

No mesmo ano as Américas foram responsáveis pela produção de 11,7 milhões de toneladas de REEE. O Brasil foi o $2^{\circ}$ país na produção de resíduo eletrônico com 1,4 milhões, ficando atrás apenas dos Estados Unidos que geraram 7 milhões de toneladas. O terceiro no ranking foi o México com 1 milhão de tonelada. Entretanto, em relação a geração per capta, os Estados Unidos continuam em $1^{\circ}$ lugar no ranking com 22,1 kg/Hab., porém em $2^{\circ}$ lugar é o Canada com 20,4 $\mathrm{kg} / \mathrm{Hab}$. e em $3^{\circ}$ lugar as Bahamas com 19,1 kg/Hab (UNU, 2014). A tabela 4 cita exemplos de geração de resíduo eletrônico no mundo.

Existem vários estudos brasileiros que apontam o aumento da geração de resíduos eletroeletrônicos no Brasil. Rodrigues (2007, p.140) calcula que a quantidade de resíduo eletrônico acumulado de 2002 até 2016 chegará à 7.400 .928 toneladas. Em estudo da FEAM (2009) o Brasil aparece como sendo responsável pela geração de 680 mil toneladas de REEE no ano de 2009. O mesmo estudo prevê, ainda, que de 2001 a 2030 o acúmulo de REEE no Brasil chegará a 22 milhões de toneladas, sendo a média anual por habitante de 3,4 kg/Hab. para o mesmo período.

Embora a geração de REEE esteja no foco de várias instituições públicas e privadas, no Brasil ainda existem poucos dados estatísticos oficiais sobre o assunto. A preocupação com a coleta de dados é recente. Como exemplo pode ser citado o caso do Município do Rio de janeiro que em seu banco de dados da gravimetria do lixo domiciliar da cidade com dados desde 1995 possui dados de resíduo eletrônico em lixo domiciliar apenas partir de 2008. Pela tabela 5 pode-se observar que de 2008 a 2013 o percentual de resíduo eletrônico em lixo doméstico dobrou no Município do Rio de Janeiro. 
Tabela 4 - Panorama da geração de REEE no mundo

\begin{tabular}{|c|c|}
\hline Região & REEE gerados 2014 \\
\hline Mundo & $\begin{array}{c}\text { 41,8 milhões de toneladas } \\
\qquad 5,9 \mathrm{~kg} / \mathrm{Hab}\end{array}$ \\
\hline Europa & $\begin{array}{c}\text { 11,6 milhões de toneladas } \\
18,7 \mathrm{~kg} / \mathrm{Hab} .\end{array}$ \\
\hline Estados Unidos & $\begin{array}{l}7 \text { milhões de toneladas } \\
22,1 \mathrm{~kg} / \mathrm{Hab} .\end{array}$ \\
\hline Brasil & 1,4 milhões de toneladas \\
\hline
\end{tabular}
na página na WEB da Step initiative.

Tabela 5 - Porcentagem de lixo eletrônico identificado no lixo domiciliar do Município do Rio de Janeiro

\begin{tabular}{|c|c|c|c|c|c|c|}
\hline Ano & 2008 & 2009 & 2010 & 2011 & 2012 & 2013 \\
\hline$\%$ & 0,13 & 0,13 & 0,20 & 0,23 & 0,20 & 0,29 \\
\hline
\end{tabular}

Fonte: COMLURB, 2014.

Um dos fatores determinantes do aumento de resíduo eletrônico é a obsolescência programada imposta pelo mercado produtor a ser analisado no item 2.3.1.

$\mathrm{Na}$ área da Defesa são poucos os dados sobre resíduo eletrônico coletado. Mondego (2012) em seu estudo informa a quantidade de REEE gerado no período de 2008 a 2011 no Centro de Manutenção Sistemas organização responsável pelo reparo de equipamentos eletroeletrônicos da MB. O peso acumulado de REEE deste período está representado na tabela 6 .

A Organização Militar da MB responsável pela aquisição dos EEE das áreas em estudo, é responsável, também, pela indicação de EEE à alienação, sendo os mesmos alienados através do documento Lista de Verificação e Destinação (LVAD). Além das áreas em estudo, a Organização Militar abrange outras áreas, como sistemas de combate e armamentos. A figura 4 apresenta, percentualmente, dentro da área de sensores, dos 396 REEE, as áreas com maior incidência de EEE alienados entre os anos de 2005 e 2015. 
Tabela 6 - Quantidade de REEE, em kg, gerados no período de 2008 - 2011 no Centro de Manutenção de Sistemas da MB.

\begin{tabular}{|c|c|c|c|c|c|}
\hline \multirow[t]{2}{*}{ REEE } & \multicolumn{5}{|c|}{ Quantidades geradas em kg } \\
\hline & 2008 & 2009 & 2010 & 2011 & $\begin{array}{l}\text { Acumulado } \\
2008 \text { - } 2011\end{array}$ \\
\hline $\begin{array}{l}\text { Lâmpada } \\
\text { fluorescente }\end{array}$ & 671,54 & 329,29 & 206,78 & 394,10 & 1601,69 \\
\hline $\begin{array}{l}\text { Bateria } \\
\text { chumbo-ácido }\end{array}$ & 194,80 & 204,08 & 260,60 & 357,00 & 1016,48 \\
\hline Pilha & 48,77 & 39,69 & 31,39 & 13,10 & 132,95 \\
\hline Bateria NiMH & 33,47 & 27,90 & 11,62 & 23,87 & 96,86 \\
\hline Bateria lítio & 31,88 & 0,48 & 6,709 & 0,14 & 39,21 \\
\hline $\begin{array}{ll}\text { Rejeitos } & \text { de } \\
\text { solda } & \end{array}$ & 16,78 & 11,01 & 7,51 & 3,17 & 38,46 \\
\hline $\begin{array}{l}\text { Lâmpada vapor } \\
\text { de mercúrio }\end{array}$ & 5,6 & 5,00 & 8,00 & 7,76 & 23,36 \\
\hline Transistor & 9,80 & 5,83 & 2,94 & 1,96 & 20,52 \\
\hline $\begin{array}{l}\text { Circuito } \\
\text { integrado }\end{array}$ & 5,16 & 3,43 & 2,31 & 1,07 & 11,97 \\
\hline Capacitor & 4,31 & 3,55 & 1,68 & 0,41 & 9,96 \\
\hline $\begin{array}{l}\text { Lâmpada } \\
\text { incandescente }\end{array}$ & 2,57 & 2,52 & 0,20 & 0,46 & 5,75 \\
\hline Bateria NiCd & 1,27 & 2,58 & 0,03 & 0,34 & 4,23 \\
\hline Diodo & 0,81 & 0,39 & 2,91 & 0,04 & 4,15 \\
\hline Fusível & 2,08 & 0,52 & 0,45 & 0,27 & 3,32 \\
\hline Resistor & 1,13 & 1,11 & 0,48 & 0,25 & 2,98 \\
\hline Relé & 0,19 & 0,20 & 0,08 & 0,00 & 0,47 \\
\hline Tiristor & 0,17 & 0,10 & 0,02 & 0,01 & 0,29 \\
\hline Varistor & 0,03 & 0,04 & 0,02 & 0,00 & 0,09 \\
\hline Total & $1.030,35$ & 637,71 & 543,73 & 803,95 & $3.015,73$ \\
\hline
\end{tabular}

Fonte: Mondego (2012, p. 85) 


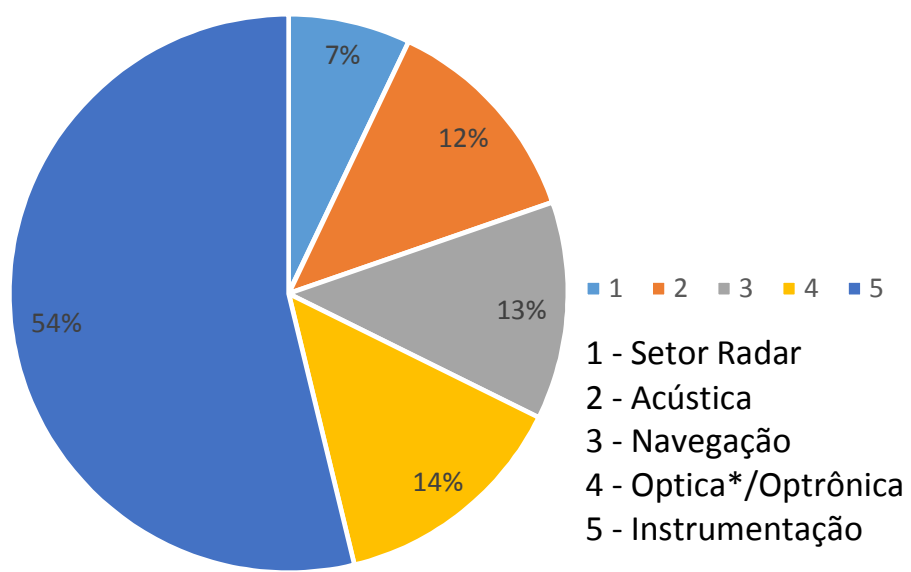

Figura 4: Gráfico demonstrativo de equipamentos alienados pela Organização Militar da MB entre os anos de 2005 - 2015.

* Não coberta pela Diretiva RoHS.

Fonte: Autor

\section{3. \\ Composição toxicológica dos REEE - impacto do descarte indevido de REEE na saúde humana e no meio ambiente}

O consumo dos equipamentos eletroeletrônicos acompanha a evolução tecnológica, que dependendo da tecnologia utilizada, tornando-se obsoletos rapidamente, em média conforme artigo da "Wellcorps International, LLC", "Think before you shuffle" (Montrose, 2011), os equipamentos eletrônicos tornam-se obsoletos no prazo de 12 meses. É verificado, na realidade, que o prazo de obsolescência está vinculado à área de atuação dos EEE como será demonstrado no item 2.3.1 deste estudo, reservado à obsolescência programada. A acelerada obsolescência de EEE tem gerado quantidade expressiva de lixo eletrônico a ser descartado.

O resíduo eletrônico é crescente, também, no Brasil. Os Resíduos de Equipamentos Elétricos e Eletrônicos (REEE) consistem, atualmente, no tipo de resíduo sólido urbano que mais aumenta no mundo. Se não forem processados corretamente acabam por contaminar o solo, os lençóis freáticos e o ar. Apenas uma pequena parcela do resíduo eletrônico é reciclada ou reutilizada. 
Conforme Relatório do Programa das Nações Unidas para o Meio Ambiente (PNUMA) - "Recycling - from E-Waste to Resources" (Schluep et al., 2009), o Brasil é, entre os países emergentes, aquele que mais produz resíduo eletrônico. Estima-se que o resíduo lixo eletrônico cresça nos próximos anos nos países em desenvolvimento, inclusive no Brasil, devido ao ingresso de uma nova classe média no mercado consumidor.

Os REEE (geladeiras, equipamentos médicos, computadores, tablets, celulares e afins) são formados por polímeros e metais pesados. Os metais pesados, como o chumbo, o mercúrio e o cádmio presentes nos componentes eletrônicos e nas placas de circuitos impressos de computadores, por exemplo, são altamente tóxicos podendo ocasionar encefalopatia, lesões cerebrais e problemas pulmonares.

As técnicas ambientais mais utilizadas no processamento do resíduo eletrônico são: o reuso, a reciclagem, a incineração e a disposição final em aterros sanitários. Em alguns países da Ásia, incluindo a Índia e a China, os metais existentes em alguns REEE estão sendo obtidos através de procedimentos rudimentares realizados em pequenos estabelecimentos. A solda é recuperada de placas de circuitos impressos (PCI) utilizando-se fogueira. Os componentes eletrônicos obtidos são reutilizados ou descaracterizados para obtenção de outros metais. Outra técnica utilizada é a queima do REEE, também, para a recuperação de metal. Na China as PCI originárias de PCs são picadas, e trituradas, para aproveitamento dos metais existentes nas PCIs. O pó de metal gerado por estes processos acarreta contaminação ambiental e prejuízo à saúde. O processo de aquecimento e queima de REEE resulta na emissão de metais para o ar sendo mais um fator de prejuízo à saúde humana e ao meio ambiente. O revestimento plástico dos EEE de computadores, celulares e os existentes em PCIs, por exemplo, podem conter retardastes de chama, os polibromatos. A queima destas substâncias à 400 $800^{\circ} \mathrm{C}$ resulta em outros produtos químicos chamados de polybrominated dibenzo dioxins and furens (PBDD/Fs) que propiciam impacto negativo ao sistema imunológico, sistema reprodutivo e ao desenvolvimento do feto.

As placas de circuito impresso, conforme já mencionado, são compostas de vários metais e plásticos. Abaixo, a Tabela 7 apresenta a composição média das substâncias identificadas em uma placa de circuito impresso. 
Tabela 7 - Composição média das substâncias identificadas em uma placa de circuito impresso.

\begin{tabular}{|c|c|c|c|}
\hline \multicolumn{2}{|c|}{ Material } & Metais & Valores Médios \\
\hline \multirow{8}{*}{ Metais } & \multirow{8}{*}{$28 \%$} & $\mathrm{Cu}$ & 14 \\
\hline & & $\mathrm{Fe}$ & 6 \\
\hline & & $\mathrm{Ni}$ & 2 \\
\hline & & $\mathrm{Zn}$ & 2 \\
\hline & & $\mathrm{Sn}$ & 2 \\
\hline & & $\mathrm{Ag}$ & 0,3 \\
\hline & & $\mathrm{Au}$ & 0,04 \\
\hline & & $\mathrm{Pd}$ & 0,02 \\
\hline \multicolumn{3}{|c|}{ Plásticos } & $19 \%$ \\
\hline \multicolumn{3}{|c|}{ Bromo } & $4 \%$ \\
\hline \multicolumn{3}{|c|}{ Material cerâmico, vidro e óxidos } & $49 \%$ \\
\hline
\end{tabular}

Fonte: Veit (2005) apud Gerbase (2011).

Da relação de substâncias, de um total de 275, analisadas pela Agency for Toxic Substances and Disease Registry (ATSDR, 2015), com base em uma combinação de sua frequência, toxicidade e potencial de exposição humana, 4 substâncias das 6 contidas na Diretiva RoHS estão entre as 20 primeiras substâncias do ranking, estando o chumbo posicionado em $2^{\circ}$, o mercúrio em $3^{\circ}$, o cádmio em $7^{\circ}$ e o cromo hexavalente em $17^{\circ}$. A tabela 8 discrimina o ranking das 20 primeiras substâncias em relação à sua frequência, toxidade e potencial de exposição humana.

A Organização Mundial de Saúde (OMS) fornece indicadores que permitem avaliarmos o nível de contaminação à qual a população mundial está exposta em relação à determinadas substâncias nocivas. Como exemplo, podemos mencionar os dados disponibilizados pela OMS (2004) que informa que os níveis de chumbo no sangue considerados danosos à saúde humana são os de $5 \mu \mathrm{g} / \mathrm{dl}$ e de $10 \mu \mathrm{g} / \mathrm{dl}$, ou menores, valores referência para, respectivamente, danos neurais e danos aos sistemas reprodutivo, cardiovascular e imunológico. A estimativa mundial (OMS, 2004) é que $49 \%$ das crianças e $42 \%$ dos adultos tenham nível sanguíneo acima de $5 \mu \mathrm{g} / \mathrm{dl}$ e $16 \%$ das crianças e $13 \%$ dos adultos tenham acima de $10 \mu \mathrm{g} / \mathrm{dl}$. A tabela 9 resume os dados disponibilizados pela OMS sobre os níveis de chumbo no sangue na população mundial. 
Tabela 8 -Relação das 20 substâncias em relação à sua frequência, toxidade e potencial de exposição humana.

\begin{tabular}{|c|c|c|}
\hline Posição & Substância & Efeitos Adversos \\
\hline $1^{\circ}$ & Arsênio & Aborto espontâneo, parto prematuro \\
\hline $2^{\circ}$ & Chumbo & $\begin{array}{l}\text { Deficiência neurocomportamental, } \\
\text { aborto espontâneo, parto prematuro }\end{array}$ \\
\hline $3^{\circ}$ & Mercúrio & $\begin{array}{l}\text { Aborto espontâneo, parto prematuro, } \\
\text { retardo mental, surdez. }\end{array}$ \\
\hline $4^{\circ}$ & Cloreto de Vinila & $\begin{array}{l}\text { Danos ao sistema nervoso e câncer no } \\
\text { fígado. }\end{array}$ \\
\hline $5^{\circ}$ & Bifenila Policlorados & $\begin{array}{l}\text { Crescimento deficiente, recém- } \\
\text { nascido de baixo peso, diminuição do } \\
\text { perímetro cefálico, parto prematuro e } \\
\text { distúrbio neurocomportamental. }\end{array}$ \\
\hline $6^{\circ}$ & Benzeno & $\begin{array}{l}\text { Aborto espontâneo, alteração do ciclo } \\
\text { menstrual, recém-nascido de baixo } \\
\text { peso. }\end{array}$ \\
\hline $7^{\circ}$ & Cádmio & Recém-nascido de baixo peso. \\
\hline $8^{\circ}$ & Benzopireno & Carcinogênico e mutagênico. \\
\hline $9^{\circ}$ & Hidrocarbonetos aromáticos & Diminuição da fertilidade. \\
\hline $10^{\circ}$ & Benzo fluoretano & Carcinogênico. \\
\hline $11^{\circ}$ & Clorofórmio & Nefrotoxidade e carcinogênico. \\
\hline $12^{\circ}$ & Aroclor 1260 & $\begin{array}{l}\text { Anemia, alteração da função da } \\
\text { tireóide e carcinogênico. }\end{array}$ \\
\hline $13^{\circ}$ & Diclorodifeniltricloetano & Carcinogênico. \\
\hline $14^{\circ}$ & Aroclor 1254 & $\begin{array}{l}\text { Anemia, alteração da função da } \\
\text { tireóide e carcinogênico. }\end{array}$ \\
\hline $15^{\circ}$ & Dibenzoantracena & Carcinogênico \\
\hline $16^{\circ}$ & Tricloroetileno & Doenças cardíacas congênitas. \\
\hline $17^{\circ}$ & Cromo Hexavalente & $\begin{array}{l}\text { Carcinogênico, problemas } \\
\text { respiratórios e lesões no fígado e nos } \\
\text { rins. }\end{array}$ \\
\hline
\end{tabular}




\begin{tabular}{|c|c|l|}
\hline $18^{\circ}$ & Dieldrin & Aborto espontâneo, parto prematuro \\
\hline Posição & Substância & \multicolumn{1}{|c|}{ Efeitos Adversos } \\
\hline $19^{\circ}$ & Fósforo Branco & $\begin{array}{l}\text { Queimadura química. Ocasiona } \\
\text { falência múltipla dos órgãos em caso } \\
\text { de absorção através da área queimada. }\end{array}$ \\
\hline $20^{\circ}$ & Hexaclorobutadieno & $\begin{array}{l}\text { Carcinogênico, danos ao sistema } \\
\text { nervoso e degeneração do fígado. }\end{array}$ \\
\hline
\end{tabular}

Fontes: Elaborada a partir de dados disponibilizados pela ATSDR (2013).

Tabela 9 - Porcentagem da população mundial com níveis de chumbo no sangue considerados danosos à saúde humana.

\begin{tabular}{|c|r|r|r|r|}
\hline \multirow{2}{*}{ Região } & \multicolumn{2}{|c|}{$\geq 5 \mu \mathrm{g} / \mathrm{dl}$} & \multicolumn{2}{c|}{$\geq 10 \mu \mathrm{g} / \mathrm{dl}$} \\
\cline { 2 - 5 } & Criança (\%) & Adulto (\%) & Criança (\%) & Adulto (\%) \\
\hline Américas & 35,7 & 37,9 & 9,0 & 10,1 \\
\hline Ásia & 73,9 & 75 & 23,9 & 26,3 \\
\hline Europa & 16,7 & 19,9 & 1,9 & 2,6 \\
\hline
\end{tabular}

Fonte: OMS, 2004

O documento sobre a saúde do trabalhador exposto ao chumbo (Ministério da Saúde, 2006) alerta que já foi observada elevação da pressão arterial sanguínea com níveis de chumbo no sangue em torno de $14 \mu \mathrm{g} / \mathrm{dl}$, e alterações na creatinina com níveis de chumbo de $10,4 \mu \mathrm{g} / \mathrm{dl}$. Mulheres com níveis de chumbo de $20 \mu \mathrm{g} / \mathrm{dl}$ são desaconselhadas de engravidar.

O Relatório Final N 30-CE-0095296/00-09 (Bogaert et al., 2008) discrimina na tabela 4.40 as quantidades percentuais estimadas das substâncias delimitadas pela Diretiva RoHS em produtos pré-selecionados, inclusive de lâmpadas fluorescentes em cenário onde são utilizadas as maiores concentrações das substâncias RoHs antes desta e concentração máxima após RoHS para os itens com isenção; e $0,1 \%$ em concentração de peso para $\mathrm{Pb}, \mathrm{Hg}$, Deca-BDE; $0,01 \%$ em peso de concentração de $\mathrm{Cd}$ e de $0 \%$ em peso de concentração para $\mathrm{Cr}$ (VI) e Octa-BDE após RoHS para os itens sem isenção. A tabela 4.37 discrimina o peso atribuído as lâmpadas fluorescentes, $0,12 \mathrm{~kg}$, e a tabela 4.35 discrimina as quantidades máximas das substâncias RoHS em lâmpadas fluorescentes, antes e após a Diretiva RoHS respectivamente. Mediante os valores discriminados na tabela 6 e nas tabelas do 
relatório de Bogaert et al. (2008) foi estimada a quantidade de substâncias tóxicas existentes no REEE de lâmpadas fluorescente descartadas pelo Centro de Manutenção de Sistemas (CMS) da MB, antes e após a Diretiva RoHS, caso adotada, quantidades estas discriminadas na tabela 10 .

Pela tabela 6 podemos constatar, também, o acumulado de resíduo de solda descartada pelo Centro de manutenção da MB entre 2008 a 2011 que foi de 38,46 $\mathrm{kg}$. Levando-se em consideração que nas soldas tradicionais a porcentagem é de 63Sn / 37PB, pode-se estimar que a quantidade de chumbo existente no rejeito de solda do Centro foi de $14,23 \mathrm{~kg}$.

Para remediar os problemas apresentados pela crescente produção de EEE e pelo descarte indevido de REEE, o Brasil deve, através de uma gestão ambiental adequada, incentivar o consumo sustentável e promover a consciência ambiental. O consumo e as demandas sociais devem estar atrelados ao desenvolvimento tecnológico, mas sobretudo com as exigências ambientais de salvaguarda humana e ambiental. Como exemplo, podemos verificar pela tabela 10 que a implementação da Diretiva RoHS é capaz de reduzir a quantidade de substâncias tóxicas em REEE.

Tabela 10 - Quantidade estimada da redução de substâncias tóxicas em lâmpadas fluorescentes descartadas pelo CMS em decorrência do estipulado pela RoHS, caso adotada.

\begin{tabular}{|c|c|c|c|c|c|c|c|}
\hline \multirow{6}{*}{ 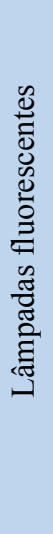 } & \multirow{6}{*}{$\begin{array}{c}1.601,69 \\
(\mathrm{~kg})\end{array}$} & \multicolumn{6}{|c|}{ Quantidades estimadas antes da Diretiva $R o H S(\mathrm{~kg})$} \\
\hline & & $\mathrm{Pb}$ & $\mathrm{Cd}$ & $\mathrm{Hg}$ & $\mathrm{Cr}(\mathrm{VI})$ & $\begin{array}{l}\text { Deca- } \\
\text { BDE }\end{array}$ & $\begin{array}{l}\text { Octa- } \\
\text { BDE }\end{array}$ \\
\hline & & 66,73 & 6,67 & 0,06 & 0,26 & 40 & - \\
\hline & & \multicolumn{6}{|c|}{ Quantidades estimadas depois da Diretiva $R o H S(\mathrm{~kg})$} \\
\hline & & $\mathrm{Pb}$ & $\mathrm{Cd}$ & $\mathrm{Hg}$ & $\mathrm{Cr}(\mathrm{VI})$ & $\begin{array}{l}\text { Deca- } \\
\text { BDE }\end{array}$ & $\begin{array}{l}\text { Octa- } \\
\text { BDE }\end{array}$ \\
\hline & & 26,69 & 0,667 & 0,10 & 0 & 40 & - \\
\hline & $\begin{array}{l}\text { ntagem } \\
\text { Redução }\end{array}$ & 57 & 90 & 67 & 100 & 0 & - \\
\hline
\end{tabular}

Fonte: obtido a partir de Mondego,2012 \& Bogaert et al., 2008 


\subsection{1 \\ Vida útil de EEE determinada pela obsolescência programada}

Obsolescência programada baseia-se na redução da vida útil dos EEE visando o aumento da produção e do lucro, incentivando o consumo, promovendo a indústria dos "descartáveis". A obsolescência programada desencadeia a vida útil precoce do produto, gerando necessidades que até então eram inexistentes. A utilização dos componentes Commercial off-the-shelf (COT), produzidos em grande quantidade, e de emprego geral no desenvolvimento de EEE, proporcionou a crescente taxa de inovação no desenvolvimento de equipamentos eletroeletrônicos, principalmente nas áreas de telefonia e eletro portáteis. Por COTs entende-se qualquer produto, "hardware" ou "software" de pronto uso, dito de prateleira, que não exige desenvolvimento dedicado para uso.

Embora os itens COTs tenham favorecido o desenvolvimento da indústria eletroeletrônica, barateando custos e reduzindo tempo de desenvolvimento de produtos, possuem vida útil menores que os produtos desenvolvidos antes da adoção desta tecnologia, sendo a obsolescência programa utilizada pelas empresas para fazer girar o capital das indústrias relacionadas a produção de EEE. Entretanto, favorecem quantidades maiores de itens a serem descartados sendo produzido mais resíduo eletrônico a ser tratado. Foladori (2001) e Mészaros $(1989,2011)$ apud Rodrigues (2012, p.53) preconiza que "[ ] a obsolescência precoce é fator indutor do consumo insustentável de recursos e da conseguinte geração de resíduos [ ]”.

Para Rodrigues (2012, p.51-52), existem 4 motivos para a obsolescência de EEE:

1. Funcional - comprometimento físico e elétrico: equipamento avariado (King et al, 2006 apud Rodrigues, 2012);

2. Psicológica - relacionada às necessidades pessoais, reais, ou não, na aquisição de novos produtos;

3. Técnica - novas tecnologias, obsolescência de itens;

4. Moda - "perdem seu atrativo frente a novos produtos com características diferentes e complementares"; e

5. Circunstancial - mudanças de paradigmas pessoais (Heisnanken, (1996 apud Cooper, 2004) apud Rodrigues, 2012). 
Atualmente, o marketing é o principal mecanismo responsável por gerar necessidades e desejos nos consumidores mediante a promoção da obsolescência psicológica e de moda, incentivando o consumo e impulsionando setores da economia.

Neste contexto, o Brasil inserido na globalização de EEE, importador e consumidor cada vez mais de equipamentos eletroeletrônicos com vida útil reduzida, que possuem obsolescência programada, sofre com as consequências desta dita inserção eletrônica. É crescente o consumo de telefones celulares, tablets e notebooks no Brasil.

Em pesquisa realizada pelo Instituto Brasileiro de Defesa do Consumidor (IDEC, 2013), para verificação da expectativa em relação à durabilidade de EEE pelos consumidores, ficou constatado que a expectativa de vida útil dos EEE pelos consumidores gira em torno de 2 a 3 anos a mais do que a vida útil real atual dos equipamentos eletrodomésticos.

A figura 5 resume a vida útil real versus a ideal idealizada pelos consumidores para os equipamentos eletroeletrônicos.

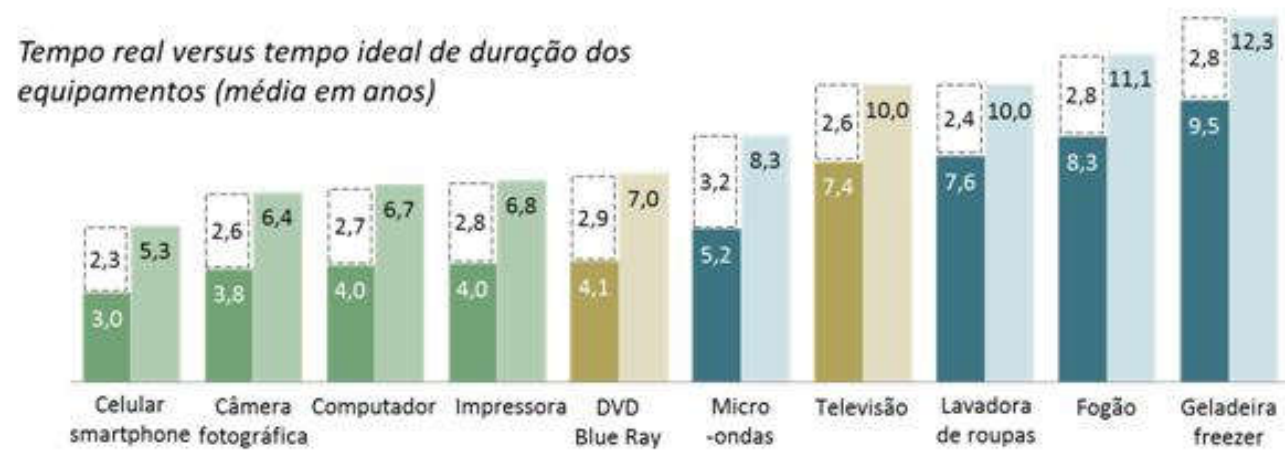

Figura 5 - Expectativa da vida útil real versus expectativa de vida ideal de equipamentos eletroeletrônicos.

Fonte: IDEC, 2013

Pode-se observar pela figura 5 que a vida útil dos equipamentos é proporcional às dimensões e ao peso dos equipamentos eletrônicos. Quanto menor e mais leve for os EEE, teoricamente mais frágeis, menor a vida útil do equipamento

Como exemplo de obsolescência programada podemos citar o caso do IPAD 3, fabricado pela empresa Apple, relatado pela professora e pesquisadora Lucia Helena Xavier durante o $4^{\circ}$ Fórum Internacional de Resíduos Sólidos (FIRS) (Jornal do Comércio, 2013). O IPAD3 tornou-se obsoleto em 7 meses com o lançamento do IPAD4. Em ação coletiva, o Brasil moveu dois processos contra a 
empresa Apple, já que não havia diferencial funcional e tecnológico que justificasse

o lançamento da nova versão do IPAD. Segundo informa o artigo do jornal do Comercio, [...] o processo teve como motivação a prática desleal contra os consumidores".

No Brasil, o ciclo de vida dos produtos é normatizado tecnicamente pelas normas ABNT NBR ISSO 14040:2009 (ABNT, 2009) e 14044:2009 (ABNT, 2009) de Gestão ambiental, sendo a norma 14040:2009 responsável pela definição de princípios e estrutura, e a norma 14044:2009 responsável pela definição de requisitos, e estabelecimento de orientações gerais.

\subsection{2}

\section{O início do COTS nos Sistemas de Defesa}

Na década de 90, foi incentivado dentro das Forças Armadas Americanas o uso de componentes COTS. O Departamento de Defesa dos Estados Unidos da América na figura do Secretário de Defesa dos USA, em artigo oficial do Departamento de Defesa intitulado Commercial item acquisiton considerations and lessons learned (USA,2000), delibera sobre vários assuntos pertinentes sobre o uso de Cots em Sistemas de Defesa e, principalmente, orienta como os técnicos das organizações podem garantir o apoio aos itens durante sua vida útil.

Este mesmo artigo salienta que os riscos associados com o desenvolvimento do sistema tradicional não desaparecem simplesmente porque o sistema faz uso de artigos comerciais. Este último ponto é fundamental: não importa o quanto um sistema é fornecido por itens comerciais, em geral, ainda deve ser projetado, desenvolvido e integrado e testado.

Tradicionalmente, os sistemas voltados para aplicação militar eram especificados conforme padrões técnicos rígidos, em sua maioria atendendo normas militares conhecidas como MilStandard (Military Specification) nos EUA e Standardization Agreement (STANAG) principalmente, relacionados a parâmetros ambientais, de choque, de vibração e de interferência eletromagnética, Muitas vezes sistemas dedicados que atendiam às necessidades específicas de sistemas militares, como robustez e confiabilidade. 
Atualmente, como tendência mundial, os sistemas militares empregam cada vez mais itens COTS visando a redução de custos e do tempo de desenvolvimento de projeto. Entretanto, o uso de itens COTS apresentam desvantagens, a saber:

- Obsolescência em prazos cada vez mais curtos: desenvolvimento, produção e manutenção descontinuados.

Como consequência ocorre:

a) Dependência de fornecimento de itens adquiridos no exterior;

b) Disponibilidade dos meios de Defesa dependentes de itens de reposição controlados pelos países desenvolvedores;

c) Equipamentos alienados devido à difículdade de obter-se peças de reposição; e

d) Perda de conhecimento técnico pelos mantenedores dos Sistemas de Defesa: tempo e recurso insuficientes para capacitar técnicos para cada versão COTs.

Segundo Afonso (2000), a inserção do conceito COTS na MB foi iniciada através do processo de desenvolvimento do Sistema de Combate SICONTA MKI do Navio Aeródromo Ligeiro (NAeL) "Minas Gerais", que já deu baixa. Os computadores do SICONTA MKI eram integralmente constituídos de itens COTS cuja integração foi efetuada pelo Instituto de Pesquisas da Marinha (IPqM). Contudo, os consoles do MKI utilizavam itens dedicados, desenvolvidos especialmente para o SICONTA MKI. O Sistema de Combate SICONTA MKII, instalado nas Fragatas "Niterói” Modernizadas (FNM) foi o primeiro projeto da MB totalmente desenvolvido baseado em itens COTS.

Também conforme Afonso (2000), devido a vida útil reduzida devida à obsolescência precoce dos itens COTs, o projeto FNM teve itens COTs substituídos ainda durante o processo de desenvolvimento, sendo o responsável pela integração dos itens no projeto informado pelo fabricante da descontinuidade dos componentes.

$\mathrm{Na}$ realidade, o projeto iniciou-se obsoleto.

As empresas de um modo geral não garantem apoio logístico para fornecimento de COTs por longos períodos. A vida útil média dos componentes COTs fica em torno de 2 a 5 anos, enquanto que para componentes dedicados a sistemas militares, por sua vez, são desenvolvidos para uma vida útil de, no mínimo, 15 anos. 
Algumas citações relevantes de Petterson (2000, p.1-2) apud Carneiro (2010, p.1), resumem a utilização de itens COTs no desenvolvimento de produtos:

- "Once it's in production is obsolete"; e

- "Commercial components are not a solution to the obsolescence problem, they are part of the problem".

A obsolescência precoce de itens COTs na MB carreta problemas de logística dos sistemas, que se não forem bem equacionados irão reduzir a disponibilidade operativa do meio aeronaval, bem como reduz a confiabilidade dos sistemas à bordo de nossas aeronaves e navios.

Mediante os problemas de logística identificados, estes podem ser tradados de duas maneiras (adaptado de Carneiro, 2010, p.6-7):

1. Reativa - "caracterizado pela não ação até se sentir o impacto na manutenção de Sistemas de Defesa por falta de componentes. As ações possiveis restringem-se à procura dos componentes originais ou de substitutos, à canibalização de componentes de outros Sistemas de Defesa, ou à substituição de todo o sistema”. e

2. Proativa - "caracterizado por um conjunto de ações preventivas e proativas que ao longo de toda a vida útil do Sistema de Defesa assegurem a disponibilidade do sistema".

Como ação proativa principal deve-se incentivar a aquisição de itens de reposição suficiente para manter os sistemas e equipamentos durante sua vida útil.

Além da prevenção de ações proativas indicadas por Carneiro (2010), Afonso (2000, p.4), em seu estudo sobre o uso de COTs na MB informa possíveis soluções para resolver os problemas de logística em se manter COTs.

1. "Congelar o projeto ao final do desenvolvimento, adquirindo itens de reposição para toda a vida útil do sistema”;

2. "Substituir os itens originais na medida que novos itens tornam disponíveis no mercado"; e

3. "Programar atualizações periódicas em todo o sistema".

Afonso (2000) sugere, ainda, dentre outras, as seguintes medidas de auxílio à manutenção dos sistemas de defesa da MB que utilizem componentes COTs:

1. Firmar contrato de manutenção por tempo determinado com as empresas fornecedoras de componentes COTs; $e$ 
2. Modificar o processo de envio de material para reparo no exterior, visando a redução de tempo médio de reparo do item e seu reenvio ao país.

Componentes COTs não são, como alguns imaginam, intercambiáveis em função, fixação e formato. Embora possam ser mecanicamente compatíveis e terem funções iguais ou semelhantes, necessitam, na maioria das vezes, de atualizações de software operacionais e de desenvolvimento de software de integração para poderem ser integrados a equipamentos e sistemas. Por isto, a cada atualização de componentes COTs há a necessidade de atualizações de requisitos, testes de aceitação e integração, bem como a homologação de equipamentos e sistemas gerando custos adicionais que devem ser contabilizados no custo total dos produtos.

Conforme Rosa (2002) apud Vieira (2007), Sistemas Digitais Operativos podem empregar, também, além dos itens Mil-STD e COTs, itens Comerciais Modificados (Modified Off-The-Shelf - MOT), ou seja, itens COTs com adaptações para emprego militar. Embora seu custo de aquisição e de desenvolvimento sejam baixo, apresentam alto custo de apoio logístico à longo prazo e dificuldades no desenvolvimento dos projetos, conforme os itens COTs.

Como consequência da adoção da filosofia COTs na MB, atualmente ocorre maior dependência aos fabricantes de EEE, quase em sua totalidade, empresas estrangeiras, acarretando perda de confiabilidade e atraso na prontidão dos sistemas de defesa, além do aumento de resíduo eletrônico.

\section{4}

\section{Legislação Ambiental}

Este capítulo apresentará as principais Leis Ambientais Federais Brasileiras aplicáveis ao controle da toxidade de EEE e ao controle e seus resíduos. Apresentará, também, informações sobre contratações públicas sustentáveis e sobre legislação afeta à gestão ambiental na MB. 


\subsection{1}

\section{Legislação aplicável ao controle da toxidade de EEE e de seus resíduos}

Diversos marcos regulatórios foram elaborados pelo Brasil com o intuito de mitigar os danos decorrentes da produção de EEE e do descarte de seus resíduos.

Pelo Decreto 4.581 (Brasil, 2003) o Brasil internaliza o determinado pela Conferência das Partes Kurchinga realizada na Malásia em 1998, que relaciona os resíduos classificados como perigosos.

Já a norma NBR 10.004:2004 (ABNT, 2004), estabelece critérios para a classificação dos resíduos sólidos, sendo estes classificados em perigosos e não perigosos. A classificação dos resíduos é estabelecida mediante a identificação de sua origem, da descrição de matéria prima, de seus insumos e do processo pelos quais foi gerado. Deve ser utilizada como referência no gerenciamento de resíduos sólidos.

O Decreto $\mathrm{N}^{\circ} 5940$ (Brasil, 2006) "Institui a separação dos resíduos recicláveis descartados pelos Órgãos e Entidades da Administração Pública Federal Direta e Indireta, na fonte geradora, e a sua destinação às associações e cooperativas dos catadores de materiais recicláveis" Aplica-se aos REEE, também. Este decreto enfatiza a reciclagem, sem se preocupar com o tipo de material a ser reciclado.

Como avanço na Legislação, a Resolução do Conselho Nacional do Meio Ambiente, CONAMA 401/08(MMA, 2008) estabelece os limites máximos das substâncias chumbo, cádmio e mercúrio para pilhas e baterias, itens amplamente utilizados junto a EEE. Norma alterada pela Resolução nº 424, de 2010.

A Instrução Normativa № 01 (MPOG, 2010) "Dispõe sobre os critérios de sustentabilidade ambiental na aquisição de bens, contratação de serviços ou obras pela Administração Pública Federal Direta, Autarquia e Fundação, e dá outras providências. " Em seu capítulo I, Art. $3^{\circ}$ determina: “inserção de critérios objetivos de sustentabilidade ambiental para avaliação e classificação das propostas." Seu inciso V recomenda certificação pelo Instituto Nacional de Metrologia, Qualidade e Tecnologia (INMETRO) e atendimento à Diretiva RoHS.

Também em 2010 foi promulgada a Lei $\mathrm{n}^{\mathrm{o}}$ 12.305, a Política Nacional de Resíduos Sólidos (PNRS). Como a Diretiva Européia 2002/96/EC Waste Electrical 
and Electronic Equipment (WEEE) é utilizada como agente orientador e incentivador da reutilização, reciclagem e descarte do resíduo eletrônico

A Política Nacional de Resíduos Sólidos (Brasil, 2010) em seu Art. $7^{\circ}$ incisos III, IV e V determina a adoção de medidas para emprego de tecnologias limpas, redução do volume e da periculosidade dos resíduos perigosos.

Seu Art. $30^{\circ}$, inciso IV, "incentiva a utilização de insumos de menor agressividade ao meio ambiente e de maior sustentabilidade”.

Semelhante à WEEE a PNRS em seu artigo 33 estabelece a Logística Reversa:

"São obrigados a estruturar e implementar sistemas de logística reversa, mediante retorno dos produtos após o uso pelo consumidor, de forma independente do serviço público de limpeza urbana e de manejo dos resíduos sólidos, os fabricantes, importadores, distribuidores e comerciantes de":

\section{I - Agrotóxicos,}

II - Pilhas e baterias;

III - Pneus;

IV - Óleos lubrificantes, seus resíduos e embalagens;

$\boldsymbol{V}$ - Lâmpadas fluorescentes, de vapor de sódio e mercúrio e de luz mista;

VI - Produtos eletroeletrônicos e seus componentes.

Em seu capítulo II art. 6 inciso VII a Política Nacional de Resíduos Sólidos insere o conceito de responsabilidade compartilhada, onde todos são responsáveis pelo descarte do lixo gerado, responsabilidade compartilhada por todo o ciclo de vida dos EEE, ou seja, do fabricante ao comerciante, passando pelo importador e pelo distribuidor. O mesmo conceito é abordado pela WEEE em seu artigo 5.

A coleta coletiva é abordada, tanto pela PNRS quanto pela WEEE, respectivamente, no capítulo III art. 8 inciso III e no artigo 7. Ainda em seu Art. 49 a PNRS proíbe a importação de resíduos sólidos perigosos.

Complementando a PNRS, é verificada urgência na realização de acordo setorial para equipamentos eletroeletrônicos, que normatize requisitos que restrinjam a quantidade de substâncias nocivas em EEE, assim como a RoHS 
Européia. Desta maneira, o ciclo de vida de EEE estaria coberta pela legislação ambiental brasileira.

Em 2012, a ABNT internaliza a norma técnica IEC 62474 (IEC, 2012) que normatiza os requisitos para a declaração das substâncias que compõem os itens que fazem parte dos EEE. A indústria de EEE necessita de tais dados para que possa se comprometer com requisitos de conformidade ambiental, principalmente junto às normas específicas de controle de substâncias tóxicas em EEE, como a Diretiva RoHS, ou outras normas regulatórias.

\subsection{2}

\section{Legislação Ambiental do Setor Militar Naval}

A gestão ambiental na MB iniciou-se em 2002 quando a Diretoria de Portos e Costas (DPC), através da Portaria $N^{\circ} 218$ foi designada como Órgão responsável pelo Sistema de Gestão Ambiental da MB.

A Legislação do Setor Naval baseia-se nas Normas Técnicas Ambientais (NORTAM) elaboradas pela DPC. As NORTAMs, quanto aos resíduos sólidos, restringem-se a regulamentar a separação e a destinação de resíduos recicláveis. A tabela 11 relaciona as normas ambientais da MB.

Tabela 11 - Relação de normas ambientais da MB

\begin{tabular}{|l|}
\hline \multicolumn{1}{|c|}{ Normas Ambientais da MB } \\
\hline NORTAM-01-Coleta e Transporte de Amostras de Derramamento de Óleo \\
\hline NORTAM-02-Sistema de Gestão Ambiental nas OM de Terra \\
\hline NORTAM-03-Plano de Emergência Individual (PEI) para as OM de Terra \\
\hline NORTAM-04-Auditoria Ambiental nas OM de Terra \\
\hline NORTAM-05-Plano de Emergência de Navios para Poluição por Óleo \\
\hline NORTAM-06-Separação de Resíduos Recicláveis Descartados pelas OM \\
\hline NORTAM-07-Controle do Uso do Amianto na MB \\
\hline NORTAM-08-Participação da Autor. Marítima na Gestão da Zona Costeira \\
\hline NORTAM-09-Elaboração de Laudo Técnico Ambiental \\
\hline Fonte: Dados disponibilizados na página na WEB da Diretoria de Portos e Costas, 2014.
\end{tabular}


A NORTAM-06 normatiza quanto à separação de resíduos recicláveis a serem descartados pela MB. Neste sentido foi criada a Comissão de Coleta Seletiva Solidária visando cumprir o determinado no Decreto 5940 (Brasil, 2006).

Embora os meios navais e aeronavais da $\mathrm{MB}$ possuam diversos equipamentos eletroeletrônicos, até o momento, não existe Norma Técnica no âmbito naval que venha a atender ao determinado no inciso $\mathrm{V}$ da Instrução Normativa $\mathrm{N}^{\circ} 01$ do Ministério do Planejamento (MPOG, 2010).

Atualmente, o Centro responsável pelo reparo e manutenção de equipamentos eletroeletrônicos não possui sistema de segregação de resíduo eletrônico eficaz, sendo os resíduos eletrônicos gerados, independente do grau de toxidade, depositados em caçambas disponibilizadas pelo órgão Coletor de resíduos, estes subordinados à Prefeitura da Ilha das Cobras, onde se localiza o Órgão responsável pela manutenção de equipamentos eletrônicos da MB. O Órgão Coletor, entretanto, vem avançando em cumprir o determinado no Decreto 5940/2006, conveniando-se à empresas e cooperativas de catadores de materiais recicláveis (Mondego, 2012).

A necessidade de inserção de requisitos e critérios de sustentabilidade na aquisição de equipamentos eletroeletrônicos por Organização Militar da Marinha do Brasil é real. A Organização Militar da MB deveria estar alinhada com critérios de sustentabilidade ambiental. Entretanto, este não utiliza as recomendações da Diretiva RoHS em suas especificações para aquisição de equipamentos eletroeletrônicos

Em junho de 2015, a Diretoria de Comunicações e Tecnologia da Informação da Marinha emitiu a norma DCTIMARINST $\mathrm{N}^{\circ} 30-14$ que orienta sobre a inclusão de critérios de sustentabilidade na aquisição de equipamentos de Tecnologia e Informação na $\mathrm{MB}$, além de orientar quanto ao descarte dos mesmos. 


\section{5}

\section{Política Governamental para contratações públicas sustentáveis}

\subsection{1.}

\section{Contratações sustentáveis na Administração Pública Federal}

Num mundo cada vez mais preocupado com a necessidade de se preservar o meio ambiente, o Brasil apresenta-se no cenário mundial como um país consciente de seu papel na manutenção de ideais e propostas de um mundo mais sustentável.

Para isto, é signatário de vários Tratados Internacionais, inclusive sediando a Conferência das Nações Unidas para o Desenvolvimento Sustentável Rio-92 e a Rio+20, que estabeleceram planos de ação para o desenvolvimento sustentável das Nações.

Em documento oficial encaminhado à Organização das Nações Unidas (ONU) como parte da agenda para a Rio+20, o Brasil ratifica o papel do Estado no desenvolvimento sustentável:

"[...] é fundamental que o Estado retome seu papel de indutor e regulador do desenvolvimento, favorecendo a adoção de práticas econômicas e processos produtivos inovadores, calcados no uso racional e na proteção dos recursos naturais e na incorporação de pessoas excluídas à economia, por meio do acesso ao emprego, ao trabalho decente e à renda. Por meio de instrumentos econômicos e politicas públicas, o Estado deve remover barreiras e criar incentivos positivos, que facilitem a adesão do setor produtivo a padrões mais sustentáveis sob as óticas econômicas, ambiental e social [...]"

Fonte: (MMA, 2015)

Em nível mundial, as compras públicas são responsáveis por aproximadamente $15 \%$ da composição do Produto Interno Bruto (PIB) dos países (Chelala, 2012). No Brasil, estima-se de $10 \%$ a $16 \%$ do PIB as compras governamentais. (Betiol, 2012).

Neste contexto, o Estado é fundamental em seu papel incentivador para a restruturação de uma economia com novos paradigmas.

Sabedor de seu importante papel como consumidor de extrema relevância para o Sistema Econômico Nacional, e mediante o aparato institucional do Setor Público Federal, o Governo Brasileiro tem legislado em favor de estabelecer critérios de sustentabilidade em aquisições realizadas pelo setor público, seja de bens, de serviços ou de obras 
O mecanismo legal utilizado pela Administração Pública Federal para aquisição de bens e serviço são as licitações, que visam selecionar o melhor produto, em livre concorrência, pelo menor preço. Incluindo critérios de sustentabilidade, as licitações são denominadas Licitações Sustentáveis ou Licitações Verdes.

Conforme o Guia de compras públicas sustentáveis licitação sustentável é:

"[...] uma solução para integrar considerações ambientais e sociais em todos os estágios do processo da compra e contratação dos agentes públicos (de governo) com objetivo de reduzir impactos à saúde humana, ao meio ambiente e aos direitos humanos."

Fonte: (Clement et al, pag. 21)

O mesmo guia salienta que as licitações sustentáveis não são uma solução cara, já que a busca por novas técnicas que permitam atender aos critérios de sustentabilidade alavanca a competição na indústria, promovendo soluções mais baratas.

O Governo Federal para normatizar a inclusão de critérios de sustentabilidade em licitações da Administração Pública elaborou leis e normas que estão hierarquicamente sintetizadas na tabela 12 .

Tabela 12 - Relação de Leis que normatizam a inclusão de critérios de sustentabilidade ambiental em licitações da Administração Pública.

\begin{tabular}{|c|c|}
\hline Legislação & Descrição \\
\hline $\begin{array}{l}\text { Lei } N^{\circ} 8.666,21 \text { de junho } \\
\text { de } 1993 \text {. }\end{array}$ & $\begin{array}{l}\text { "Regulamenta o art. 37, inciso XXI, da Constituição Federal, } \\
\text { institui normas para licitações e contratos da Administração } \\
\text { Pública e dá outras providências. Enfatiza que as obras, serviços, } \\
\text { compras e alienações serão contratadas através de Licitações } \\
\text { Públicas que assegurem a todos os concorrentes igualdade na } \\
\text { concorrência." }\end{array}$ \\
\hline $\begin{array}{l}\text { Lei } \mathrm{N}^{\circ} 10.257 \text { de } 10 \text { de } \\
\text { julho de } 2001\end{array}$ & $\begin{array}{l}\text { "Regulamenta os Arts. } 182 \text { e } 183 \text { da Constituição Federal de } 1988 \\
\text { e estabelece diretrizes gerais da política urbana, dentre as quais a } \\
\text { adoção de padrões de proteção e consumo de bens e serviços de } \\
\text { expansão urbana compativeis com os limites da sustentabilidade } \\
\text { ambiental, social e econômica do Município e do Território sob } \\
\text { sua área de influência (Art. 2, VIII)." } \\
\text { "Lei conhecida como Estatuto da Cidade: regula o uso da } \\
\text { propriedade urbana, tendo como parâmetros a serem obtidos o } \\
\text { bem-estar do cidadão e equilíbrio ambiental." }\end{array}$ \\
\hline
\end{tabular}




\begin{tabular}{|c|c|}
\hline Lei $\mathrm{N}^{\circ} 12.349$, de 2010 & $\begin{array}{l}\text { "Altera o art. } 3^{\circ} \text { da Lei } N^{\circ} 8.666 / 93 \text {. Inclui como finalidade da } \\
\text { licitação a promoção do desenvolvimento nacional sustentável. } \\
\text { Esse normativo definiu como não comprometedores e não } \\
\text { restritivos da competividade das licitaçães vários dispositivos } \\
\text { incluídos no Art. } 3^{\circ} \text { da Lei } N^{\circ} 8.666 / 93\left(\$ \xi 5^{\circ} \text { ao } 12^{\circ}\right) \text {, muitos } \\
\text { voltados à proteção à indústria e produção locais, dentre os quais, } \\
\text { o } \$ 5^{\circ} \text {, que autoriza o estabelecimento de margem de preferência } \\
\text { para produtos manufaturados e serviços nacionais que atendem às } \\
\text { normas técnicas brasileiras." }\end{array}$ \\
\hline Lei $\mathrm{N}^{\circ} 12.462$, de 2011 & $\begin{array}{l}\text { "Instituiu Regime Diferenciado de Contratações Públicas - (RDC) } \\
\text { para os Jogos Olimpicos e Paraolímpicos de 2016, Copa das } \\
\text { Confederações da Federação Internacional de Futebol Associação } \\
\text { Fifa } 2013 \text { e Copa do Mundo de futebol de 2014." }\end{array}$ \\
\hline $\begin{array}{l}\text { Decreto } \mathrm{N}^{\circ} 2.783 \text { de } 17 \\
\text { de setembro de } 1998\end{array}$ & $\begin{array}{l}\text { "Dispõe sobre a proibição de aquisição de produtos ou } \\
\text { equipamentos que contenham ou façam uso de substâncias que } \\
\text { destroem a camada de ozônio, pelos órgãos e entidades da } \\
\text { Administraçấo Pública direta, autarquia efundacional." }\end{array}$ \\
\hline $\begin{array}{llll}\text { Decreto } & \mathrm{N}^{\circ} & 5.940, & \mathrm{de} \\
2006 & & & \end{array}$ & $\begin{array}{l}\text { "Instituiu a separação dos residuos recicláveis descartados pelos } \\
\text { órgãos e entidades da administração pública federal direta e } \\
\text { indireta, na fonte geradora, e a sua destinação às associações e } \\
\text { cooperativas dos catadores de materiais recicláveis, e dá outras } \\
\text { providências.Art. } \text { Io }^{o} \text { Art.2oPara fins do disposto neste Decreto, } \\
\text { considera-se: } \\
\text { - Coleta seletiva solidária: coleta dos residuos recicláveis } \\
\text { descartados, separados na fonte geradora, para destinação às } \\
\text { associações e cooperativas de catadores de materiais recicláveis; } \\
\text { e } \\
\text { - Residuos recicláveis descartados: materiais passiveis de retorno } \\
\text { ao seu ciclo produtivo, rejeitados pelos órgãos e entidades da } \\
\text { administração pública federal direita e indireta. } \\
\text { Art. } 3 \text { o estarão habilitadas a coletar os residuos recicláveis } \\
\text { descartados pelos órgãos e entidades da administração pública } \\
\text { federal direita e indireta as associações e cooperativas de } \\
\text { catadores de materiais recicláveis que atenderem aos seguintes } \\
\text { requisitos: } \\
\text { - Estejam formal e exclusivamente constituidas por catadores de } \\
\text { materiais recicláveis que tenham a catação como única fonte de } \\
\text { renda; } \\
\text { - Não possuam fins lucrativos; } \\
\text { dos residuos recicláveis descartados; e }\end{array}$ \\
\hline
\end{tabular}




\begin{tabular}{|c|c|}
\hline & $\begin{array}{l}\text { IV - Apresentem o sistema de rateio entre os associados e } \\
\text { cooperados. } \\
\text { Parágrafo único. A comprovação dos incisos I e II será feita } \\
\text { mediante a apresentação do estatuto ou contrato social e dos } \\
\text { incisos III e IV, por meio de declaração das respectivas } \\
\text { associações e cooperativas." }\end{array}$ \\
\hline $\begin{array}{l}\text { Decreto } \mathrm{N}^{\circ} 7.746 \text { de } 05 \\
\text { de junho de } 2012\end{array}$ & $\begin{array}{l}\text { "Regulamenta o artigo } 3^{\circ} \text { da Lei 8.666/93, agregando como } \\
\text { objetivo da Lei de Licitações e Contratos, o desenvolvimento } \\
\text { nacional sustentável. Institui a Comissão Interministerial de } \\
\text { Sustentabilidade na Administração Pública." }\end{array}$ \\
\hline 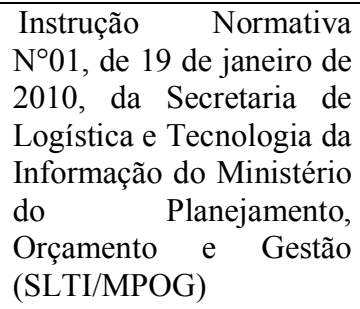 & $\begin{array}{l}\text { "Prevê expressamente que as especificações técnicas para } \\
\text { aquisições de bens e contratações de obras e serviços deverão } \\
\text { conter critérios ambientais, sem frustrar o caráter competitivo do } \\
\text { certame. } \\
\text { Determina em seu Capitulo III (Dos Bens e Serviços) a inclusão } \\
\text { dos critérios de sustentabilidade ambientais estipulados pela } \\
\text { Diretiva RoHS. }\end{array}$ \\
\hline $\begin{array}{l}\text { Portaria } \mathrm{N}^{\circ} 2 \text {, de 2010, da } \\
\text { Secretaria de Logística e } \\
\text { Tecnologia da } \\
\text { Informação do MPOG }\end{array}$ & $\begin{array}{l}\text { "Dispõe sobre as especificações padrão de bens de Tecnologia da } \\
\text { Informação no âmbito da Administração Pública Federal direta, } \\
\text { autárquica e fundamental. Estabelece condicionantes RoHS (TI } \\
\text { Verde) nas especificações técnicas em seus anexos III e VII." }\end{array}$ \\
\hline $\begin{array}{l}\text { CONAMA } \mathrm{N}^{\circ} 12 \mathrm{de} \\
2011\end{array}$ & $\begin{array}{l}\text { "Recomenda a adoção de práticas sustentáveis no âmbito da } \\
\text { administração pública." }\end{array}$ \\
\hline
\end{tabular}

A Constituição Federal de 1988 (Brasil, 1988) já incluía em seu texto conceitos de sustentabilidade a serem cumpridas, inclusive em contratações públicas, se pensarmos, principalmente, que preconizava o direito de todos a um meio ambiente equilibrado.

Em seu Art. 170 dos princípios gerais da atividade econômica, inciso VI determina:

"[..] defesa do meio ambiente, inclusive mediante tratamento diferenciado conforme o impacto ambiental dos produtos e serviços e de seus processos de elaboração e prestação."

(Redação dada pela Emenda Constitucional n ${ }^{\circ}$ 42, de 19.12.2003).

Já em seu Art. 225 (Normas de proteção ao meio ambiente e princípio do desenvolvimento sustentável) institui que:

"Todos têm direito ao meio ambiente ecologicamente equilibrado, bem de uso comum do povo e essencial à sadia qualidade de vida, impondo-se ao Poder Público 
e à coletividade o dever de defendê-lo e preservá-lo para as presentes e futuras gerações."

(Brasil, 1988)

E estabelece várias restrições visando a prevenção do meio ambiente, a saber:

I - Preservar e restaurar os processos ecológicos essenciais e prover o manejo ecológico das espécies e ecossistema;

II - Preservar a diversidade e a integridade do patrimônio genético do País e fiscalizar as entidades dedicadas à pesquisa e manipulação de material genético;

III - definir, em todas as unidades da Federação, espaços territoriais e seus componentes a serem especialmente protegidos, sendo a alteração e a supressão permitidas somente através de lei, vedada qualquer utilização que comprometa a integridade dos atributos que justifiquem sua proteção:

IV - Exigir, na forma da lei, para instalação de obra ou atividade potencialmente causadora de significativa degradação do meio ambiente, estudo prévio de impacto ambiental, a que se dará publicidade;

$V$ - Controlar a produção, a comercialização e o emprego de técnicas, métodos e substâncias que comportem risco para a vida, a qualidade de vida e o meio ambiente;

VI - Promover a educação ambiental em todos os níveis de ensino e a conscientização pública para a preservação do meio ambiente;

VII - Proteger a fauna e a flora, vedadas, na forma da lei, as práticas que coloquem em risco sua função ecológica, provoquem a extinção de espécies ou submetam os animais a crueldade.

$\S 2^{\circ}$ - Aquele que explorar recursos minerais fica obrigado a recuperar o meio ambiente degradado, de acordo com solução técnica exigida pelo órgão público competente, na forma da lei.

$\S 3^{\circ}$ - As condutas e atividades consideradas lesivas ao meio ambiente sujeitarão os infratores, pessoas físicas ou jurídicas, a sanções penais e administrativas, independentemente da obrigação de reparar os danos causados.

$\S 4^{\circ}$ - A Floresta Amazônica brasileira, a Mata Atlântica, a Serra do Mar, o Pantanal Mato-Grossense e a Zona Costeira são patrimônio nacional, e sua utilização far-se-á, na forma da lei, dentro de condições que assegurem 
a preservação do meio ambiente, inclusive quanto ao uso dos recursos naturais.

$\S 5^{\circ}$ - São indisponíveis as terras devolutas ou arrecadadas pelos Estados, por ações discriminatórias, necessárias à proteção dos ecossistemas naturais.

$\S 6^{\circ}$ - As usinas que operem com reator nuclear deverão ter sua localização definida em lei federal, sem o que não poderão ser instaladas.

Dentre todas as legislações vigentes, a publicação da Instrução Normativa 01 (MPOG, 2010) é considerada como marco legal da inclusão de critérios ambientais nas Contratações Públicas Federais. O Capítulo III, Dos Bens e Serviços, é de vital interesse neste trabalho. Em seu inciso IV, recomenda o atendimento à Diretiva RoHS, que restringe o uso das substâncias tóxicas mercúrio, chumbo, cromo hexavalente, cádmio, bifenil-polibromados e éteres difenil-polibromados em equipamentos eletroeletrônicos. Salienta ainda em seu inciso II da necessidade dos bens adquiridos possuírem certificação junto ao Instituto Nacional de Metrologia, Normalização e Qualidade Industrial comprobatórios do atendimento às normas ambientais.

No mesmo capítulo, a Instrução Normativa em seu inciso I incentiva a reciclagem instituindo que os bens adquiridos sejam constituídos, no todo ou em parte, por material reciclado, atóxico e biodegradável.

A alteração realizada na Lei 8.666/93, através do Decreto 7746 (Brasil, 2012), regulamentando o Art. $3^{\circ}$ da Lei 8.666, estabelece critérios, práticas e diretrizes de sustentabilidade nas licitações realizadas pela Administração Pública Federal, também reforçou o processo de legitimação das Contratações Verdes.

Agregando valores instituiu a Comissão Interministerial de Compras Públicas, origem das compras compartilhadas entre os Ministérios, tornando-se fator facilitador na aquisição de bens sustentáveis por diversos órgãos, promovendo a redução no valor do produto devido à grande quantidade adquirida. As compras compartilhadas viabilizam a aquisição de bens dentro de padrões socioambientais sustentáveis.

Entretanto, apesar de todo aparato normativo ambiental e de instrumentos legais para contratações públicas sustentáveis, a política ambiental adotada pelo Governo Federal não se reflete na totalidade da Administração Pública. Observa-se 
que as questões ambientais são tratadas predominantemente pelos Órgãos vinculados aos assuntos ambientais, sendo que os gestores dos demais órgãos do Governo deixam de considerar critérios de sustentabilidade nas licitações públicas. Segundo Chelala (2012), não existe política Governamental centralizada para aquisições sustentáveis.

De acordo com o guia para "Compras Sustentáveis" de Betiol et al (2012), em pesquisa realizada junto a 79 órgãos da Administração Federal, 73\% não realizam licitações com critérios de sustentabilidade. No entanto pelo mesmo documento, de 2010 a 2012 as compras sustentáveis aumentaram 200\%.

Quanto à legitimidade das licitações sustentáveis, segundo Gripp (2010) em artigo publicado na página na web da Advocacia Geral da União (AGU), a AGU finalizou parecer sobre licitações sustentáveis na Administração Pública. O mesmo artigo participa que o Consultor-Geral da AGU na época, durante o Congresso Internacional de Contratações Públicas Sustentáveis, realizado em Brasília (DF) afirmou na palestra que:

“É preciso disseminar essa política em todas as instâncias públicas do país, em face ao seu elevado poder de proteção e preservação ambiental. Não é necessária alteração legislativa no nível constitucional ou legal, pois as normas ambientais já existentes, cotejadas com o artigo 30, inciso IV da Lei 8.666/93, que trata da observação de leis específicas, permitem ao intérprete a construção da tese da licitação sustentável."

Fonte: Gripp, 2010.

Afirma, ainda, que (existe):

"A necessidade de os gestores responsáveis pelas compras governamentais e os especialistas em matéria ambiental formularem uma base técnica, com a especificação de obras, serviços e compras para estimular a máxima concorrência, menores custos e efetiva proteção ambiental. Ambientais "

Fonte: Gripp, 2010.

Alertou, também, para:

"A necessidade de capacitação permanente dos responsáveis pelos setores ambientais de compra e controle, além de advogados públicos, para atualiza-los com as principais inovações nos produtos e processos de proteção e preservação ambiental."

Fonte: Gripp, 2010.

O Tribunal de Contas da União (TCU), através da Secretaria de Controle Externo e Ambiental esclarece que para a realização de licitações sustentáveis é necessário que (Adaptado de Dantas, 2013, p.22, 24 e 25): 
1. $O$ objeto da licitação deve ser definido adequadamente com a inclusão do correto aspecto ambiental, quando da definição das características do bem a ser adquirido;

2. "Equilibrio entre os diversos princípios previstos no art. 3 da Lei 8.666/93”; $e$

3. O critério de seleção permanecerá o mesmo, ou seja, o menor preço, desde que os bens e serviços oferecidos satisfaçam o interesse da Administração Pública, cujo objeto e justificativas constem previamente do edital de licitação.

O TCU, em geral, não aceita certificações como critério eliminatório, sugere avaliar se (Dantas, 2013, p. 28):

"[..] a existência de certificação ambiental por parte das empresas produtoras é situação predominante no mercado".

Atendido o parâmetro acima descrito, conforme Dantas (2013, P. 25) “[ ]não haverá óbice quanto à legalidade das licitações verdes”.

\subsection{2 \\ Contratações sustentáveis na Administração Pública do Estado do Rio de Janeiro}

O Poder Executivo do Estado do Rio de Janeiro promulgou o Decreto $\mathrm{N}^{\circ}$ 43.629 (Estado do Rio de Janeiro, 2012) que dispõe sobre os critérios de sustentabilidade ambiental na aquisição de bens, serviços e obras pela Administração Estadual Direta e Indireta do Estado do Rio de janeiro.

O Decreto $\mathrm{N}^{\circ} 43.629$ considera em seu escopo o artigo 170, Inciso VI da Constituição Federal que "estabelece que compete ao Poder Público a defesa e preservação do meio ambiente". Considera, também, o art. $3^{\circ}$ da Lei 8.666 que estabelece a inclusão de critérios de sustentabilidade nas Contratações Públicas, e ainda, o estabelecido na Lei Estadual № 5.690 (Estado do Rio de Janeiro, 2010) e da Lei Federal $N^{\circ}$ 12.187/09, art. $6^{\circ}$ (Brasil, 2009), que instituem, respectivamente, a Política Estadual sobre mudança global do clima e desenvolvimento sustentável, e a Política Nacional sobre mudança do clima.

Os critérios de julgamento das Contratações serão pelo menor preço, desde que atendidos os parâmetros técnicos mínimos contidos no edital de licitação. 
Nas Disposições gerais, em seu art. 1, o Decreto determina:

"Fixação de critérios de sustentabilidade ambiental nas especificações para aquisição de bens, contratação de serviço e obras por parte dos Órgãos e entidades da Administração Pública Estadual Direta e Indireta”.

São considerados critérios de sustentabilidade ambiental (Art. 2):

I. Economia no consumo de água e energia;

II. Minimização da geração de resíduos e destinação final ambientalmente adequada dos que forem gerados;

III. Racionalização do uso de matérias-primas;

IV. Redução da emissão de poluentes;

V. $\quad$ Adoção de tecnologias menos agressivas ao meio ambiente;

VI. Implementação de medidas que reduzam as emissões de gases efeito estufa e aumentem os sumidores;

VII. Utilização de produtos de baixa toxidade;

VIII. Utilização de produtos com a origem ambiental sustentável comprovada, quando existir certificação para o produto.

O mesmo Decreto delibera pelo seu Art. $4^{\circ}$, da Seção I, Capítulo II que a comprovação dos critérios ambientais, quando exigidas, podem ser realizadas mediante apresentação de certificação emitida por Instituições Públicas ou Instituições credenciadas. Em parágrafo único do Capítulo II, seção III, o Decreto estabelece:

"A Administração Pública poderá solicitar a certificação da qualidade do produto ou do processo de fabricação sob o aspecto ambiental, por qualquer Instituição Oficial competente ou, por entidades credenciadas".

O Decreto $\mathrm{N}^{\circ} 43.629$ estabelece, entretanto, exigências de sustentabilidade ambiental de maneira vaga e dúbia. Em seu Art. 7, Inciso I, Capítulo II, Seção III, determina que bens devam ser reciclados e atóxicos, respeitando as Normas Técnicas Brasileiras, sem direcionamentos específicos, podendo ocasionar elaborações de especificações e procedimentos técnicos equivocados.

A Secretaria de Estado de Planejamento e Gestão é o Órgão Estadual do Rio de Janeiro responsável por propor as diretrizes, normas e procedimentos para a adoção de critérios de sustentabilidade ambiental na aquisição de bens, serviços e execução de obras, sendo responsável, também, pela harmonização dos critérios de sustentabilidade ambiental adotados pelos órgãos da Administração Pública 
Estadual. Entretanto, sua página oficial na web (www.rj.gov.br/web/seplag) não apresenta referências a serem adotadas para nortear as Licitações Sustentáveis do Estado do Rio de Janeiro.

\subsection{3}

Contratações Sustentáveis na Administração Pública da Cidade do Rio de Janeiro

A busca por adequação às exigências ambientais, conforme recomenda o CONAMA N ${ }^{\circ}$ 12/2011 (MMA, 2011), que sugere a adoção de práticas sustentáveis no âmbito da Administração Pública dos Órgãos participantes do Sistema Nacional de meio Ambiente (SISNAMA,) fez com que a Secretaria Municipal do meio Ambiente (SMAC) e a Secretaria Municipal de Administração (SMA) firmassem parceria para produzir o Catálogo Sustentável de Bens e Serviços Comuns, o Catálogo Verde, meio de orientação às Contratações Públicas da Cidade do Rio de janeiro.

O Catálogo Verde foi instituído pela Resolução Conjunta SMA/SMAC N ${ }^{\circ}$ 003 (Cidade do Rio de Janeiro, 2013). Semelhante às Contratações Públicas do Estado do Rio de Janeiro, as Contratações Públicas da Cidade do Rio de Janeiro consideram a Lei Federal $N^{\circ} 12.349 / 2010$, que altera a Lei Federal 8.666/93, que determina a inclusão de critérios de sustentabilidade ambiental nas especificações para a aquisição de bens e serviços através de editais de licitação. A Resolução considera, também, o disposto na Lei Municipal N ${ }^{\circ}$ 5.248/11 (Cidade do Rio de Janeiro, 2011) que estabelece a Política Municipal sobre Mudança do Clima e Desenvolvimento Sustentável, e na Lei Municipal № 4.352 (Cidade do Rio de Janeiro, 2009) que regulamenta as Contratações Públicas Municipais que envolvem produtos e subprodutos da madeira.

O Catálogo Verde inclui orientação a um grande número de produtos tais como: material de construção, material de escritório, material de limpeza, equipamentos eletrônicos, equipamentos de informática e veículos.

O Catálogo Verde pode ser acessado pelos portais:

www.ecocomprasrio.rio.rj.gov.br; www.ecocomprasrio.rio.rj.gov.br/sigma/cat_verde.asp. 


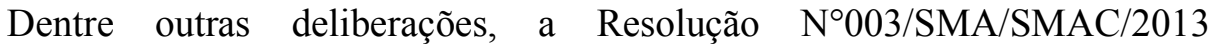
determina:

-[...]Que os bens e os insumos de serviços contratados sejam constituídos, sempre que possivel, no todo ou em parte, por material reciclável, reciclado, atóxico, biodegradável, conforme as normas da Associação Brasileira de Normas Técnicas (ABNT);

- Que sejam observados os requisitos ambientais para a obtenção de certificação do Instituto Nacional de Metrologia, normalização e Qualidade Industrial (INMETRO) como produtos sustentáveis ou de menor impacto ambiental em relação aos seus similares;

- Que os bens e os insumos de serviços contratados não contenham substâncias perigosas em concentração acima da recomendada na diretiva RoHS (Restriction of Certain Hazardous Substances), tais como: mercúrio $(\mathrm{Hg})$, chumbo $(\mathrm{Pb})$, cromo Hexavalente $(\mathrm{Cr} \mathrm{VI})$, cádmio $(\mathrm{Cd})$, bifenilpoliberomados (PBBs) e éteres difenil-polibromados (PBDEs); e

- A comprovação poderá ser feita mediante apresentação de certificação emitida por instituição pública oficial ou instituição credenciada, ou por qualquer outro meio de prova que ateste que o bem fornecido elou os insumos de serviços contratados cumpra com as exigências solicitadas.

\subsection{4 \\ Contratações Sustentáveis no Ministério da Defesa e na Organização Militar da Marinha do Brasil}

Como Órgão Federal, o Ministério da Defesa, bem como o Comando da Marinha e suas Diretorias Especializadas, subordinados a este Ministério, estão submetidos à Legislação Federal.

A Legislação contida na tabela 12 deve nortear as Compras e Licitações Sustentáveis, também, dos Órgãos Militares.

Segundo informativo do Ministério do Planejamento Orçamento e Gestão, Informações Gerenciais de Contratações Públicas Sustentáveis, (janeiro a março de 2014) através da Secretaria de Logística e Tecnologia da Informação, cita que o Ministério da Defesa foi o Órgão Federal que realizou aquisições sustentáveis com 
o maior valor monetário em 2014, montante final de $\mathrm{R} \$ 2.623 .535,05$, sendo responsável por 33,4\% das aquisições realizadas pelos os órgãos do Sistema de Serviços Gerais (SISG).

Mesmo após a implementação da Instrução Normativa $N^{\circ}$ 01/2010 do MPOG, a Organização Militar da Marinha do Brasil responsável pelos equipamentos eletrônicos analisados neste trabalho, não insere em suas especificações técnicas para aquisição de equipamentos sob sua jurisdição, os critérios de sustentabilidade ambiental descritos nos Art. $1^{\circ}$ e $5^{\circ}$ da Instrução Normativa $\mathrm{N}^{\circ} 01 / 2010$.

Conforme informação do Setor de Obtenção da Organização Naval, no caso de Compras e Licitações Sustentáveis a Organização é orientada pela Advocacia Geral da União a seguir o estipulado no Guia Prático de Licitações Sustentáveis da Consultoria Jurídica da União/SP (CJU/SP, 2013), documento que visa auxiliar os órgãos públicos no entendimento da legislação ambiental vigente. Entretanto, este documento não orienta quanto aos requisitos que farão parte das especificações técnicas inerentes de cada Órgão Público Federal.

Em relação aos EEE, o Guia Prático da CJU/SP orienta quanto ao desuso e aos seus resíduos. Não abrange o aspecto da prevenção estimulada através do Capítulo III, Art. $5^{\circ}$ da IN 01/2010 do MPOG.

De acordo com o Setor de Obtenção do Órgão Militar da Marinha do Brasil, nenhuma aquisição realizada pelo Órgão inclui em sua especificação critérios de sustentabilidade ambiental. 


\section{3}

\section{Diretiva RoHS}

Visando complementar a política ambiental vigente em vários países da Comunidade Européia em 2002 a CE elaborou a Diretiva RoHS que restringiu o uso de certas substâncias químicas nocivas em equipamentos eletroeletrônicos. A Diretiva Europeia 2002/95/EC - Restriction of Certain Hazardous Substances (RoHS) limitou o uso das substâncias chumbo, mercúrio, cádmio, cromo hexavalente, polibromato bifenil (PBB) e éter difenil polibromato (PBDE), sendo estes dois últimos utilizados como retardantes de chamas em plásticos.

A Diretiva RoHS determina que o limite destas substâncias perigosas em produtos eletroeletrônicos manufaturados na $\mathrm{CE}$, bem como de produtos importados de países pré-determinados, como dos Estados Unidos, seja em material homogêneo de $0,01 \%$ por peso de cádmio e de $0,1 \%$ para as demais substâncias.

A Diretiva $R o H S$ tem como principal objetivo a prevenção, ou seja, intervir na origem do produto para que possa ser garantida a proteção da saúde humana e a proteção do meio ambiente. Neste sentido, a Diretiva RoHS caminha junto à WEEE, atualizada em 2012 pela Diretiva 2012/19/EU, que abrange o tratamento e a reciclagem de equipamentos eletroeletrônicos. A WEEE é utilizada como agente orientador e incentivador da reutilização e reciclagem do resíduo eletrônico.

As duas Diretivas juntas abrangem a hierarquia do resíduo eletrônico prevenção na fabricação, Diretiva $R o H S$, e redução: reuso, reciclagem na disposição final, Diretiva WEEE. Desta maneira gerindo-se do início, até o fim, do ciclo de vida do produto.

Para fim ilustrativo, a tabela 13 relaciona as substâncias químicas limitadas nos EEE, pela Diretiva RoHS sua aplicabilidade e seus danos à saúde. 
Tabela 13 - Relação de Substâncias Tóxicas restritas na Diretiva RoHS e seus efeitos nocivos à saúde e ao meio ambiente.

\begin{tabular}{|c|c|c|c|c|}
\hline \multicolumn{5}{|c|}{ Substâncias com restrição } \\
\hline Substâncias & Utilização & $\begin{array}{l}\text { Concentração } \\
\text { Máxima (\%) }\end{array}$ & $\begin{array}{c}\text { Efeitos nocivos } \\
\text { ao meio } \\
\text { ambiente }\end{array}$ & $\begin{array}{c}\text { Efeitos nocivos à } \\
\text { saúde }\end{array}$ \\
\hline Cádmio & $\begin{array}{l}\text { Baterias, } \\
\text { Componentes } \\
\text { eletrônicos } \\
\text { semicondutores } \\
\text { Contatos elétricos, } \\
\text { relés, interruptores }\end{array}$ & 0,01 & $\begin{array}{l}\text { Contaminação } \\
\text { de lençóis } \\
\text { freáticos, solo e } \\
\text { ar. }\end{array}$ & $\begin{array}{c}\text { Carcinogênico } \\
\text { Desmineralização } \\
\text { óssea }\end{array}$ \\
\hline Chumbo & $\begin{array}{l}\text { Baterias } \\
\text { Soldas em placas } \\
\text { de circuitos } \\
\text { impressos } \\
\text { Revestimento de } \\
\text { terminais } \\
\text { componentes } \\
\text { eletrônicos } \\
\text { Tintas } \\
\text { pigmentos como } \\
\text { secantes } \\
\text { PVC } \\
\text { estabilizador }\end{array}$ & 0,1 & & $\begin{array}{l}\text { Cardiopatias, } \\
\text { gastrenterites, } \\
\text { danos ao sistema } \\
\text { nervoso central e } \\
\text { ao sistema } \\
\text { neurológico. }\end{array}$ \\
\hline Mercúrio & $\begin{array}{l}\text { Lâmpadas } \\
\text { Fluorescentes } \\
\text { Baterias } \\
\text { Relés e placas de } \\
\text { circuitos impressos }\end{array}$ & & & $\begin{array}{c}\text { Danos aos } \\
\text { sistemas nervoso, } \\
\text { digestivo e } \\
\text { imunológico. }\end{array}$ \\
\hline $\begin{array}{l}\text { Cromo } \\
\text { Hexavalente }\end{array}$ & $\begin{array}{l}\text { Tratamento } \\
\text { anticorrosivo de } \\
\text { circuitos integrados }\end{array}$ & & & $\begin{array}{l}\text { Danos aos } \\
\text { sistemas } \\
\text { respiratórios, } \\
\text { cardiovascular e } \\
\text { hepatológico, } \\
\text { genotóxico. }\end{array}$ \\
\hline $\begin{array}{l}\text { polibromato } \\
\text { bifenil (PBB) } \\
\text { e éter difenil } \\
\text { polibromato } \\
\text { (PBDE) }\end{array}$ & $\begin{array}{l}\text { Retardantes de } \\
\text { chamas em } \\
\text { plásticos, placas de } \\
\text { circuito impresso e } \\
\text { revestimento de } \\
\text { equipamentos } \\
\text { eletrônicos. }\end{array}$ & & & $\begin{array}{c}\text { Carcinogênicos, } \\
\text { hepatotoxicidade } \\
\text { e } \\
\text { embriotoxicidade }\end{array}$ \\
\hline
\end{tabular}

Fonte: Autor a partir de dados disponibilizado pelo Greenpeace. 


\section{1 .}

\section{RoHS Europeia (UE): definição e escopo da Diretiva}

A Diretiva RoHS tem por objetivo regulamentar a diminuição de substâncias tóxicas existentes em equipamentos eletroeletrônicos no intuito de reduzir os impactos negativos ao meio ambiente e à saúde humana.

Conforme verificado anteriormente a concentração máxima de substâncias tóxicas por peso é determinada para materiais homogêneos, ou seja, materiais que não podem ser mecanicamente divididos em diferentes materiais. $\mathrm{O}$ valor máximo das substâncias de $0,01 \%$ para cádmio e de $0,1 \%$ para chumbo, mercúrio, cromo hexavalente, polibromato bifenil (PBB) e éter difenil polibromato (PBDE).

A Diretiva RoHS não atua durante o processo de produção, apenas no produto final. Ou seja, os processos industriais não estão sujeitos ao escopo da Diretiva, e sim, aos produtos, ou equipamentos, colocados no mercado sob os artigos 2 e 3 da Diretiva.

Os equipamentos eletroeletrônicos atendidos pela Diretiva $R o H S$ devem atender ao especificado nos artigos 2, 3 e 4 da Diretiva. Aplica-se aos EEE e à todas as partes que os constitui.

Pelo artigo 3, inciso 3.1:

"Equipamentos eletroeletrônicos ou EEE significam equipamentos os quais são dependentes de correntes elétricas ou campo eletromagnético para operar adequadamente, e equipamentos para geração, transferência e medida de tais correntes e campo magnéticos, projetados para operarem com até $1000 \mathrm{~V}$ com corrente alternada e $1.500 \mathrm{~V}$ com corrente contínua."

Pelo inciso 3.2 temos:

"Para os propósitos do inciso 3.1, dependente significa, em relação aos EEE que necessitem de correntes elétricas ou campos magnéticos para cumprir, ao menos, uma função pretendida. "

A Diretiva abrange dez categorias de EEE:

1. Grandes eletrodomésticos;

2. Pequenos eletrodomésticos;

3. Equipamentos de Informática e de Telecomunicações;

4. Equipamentos de consumo;

5. Equipamentos de iluminação; 
6. Ferramentas elétricas e eletrônicas;

7. Brinquedos e equipamentos esportivos e de lazer;

8. Instrumentos médicos;

9. Instrumentos de monitorização e controle, incluindo instrumentos industriais de monitorização e controle;

10. Distribuidores automáticos; e

11. Outros EEE não cobertos por nenhuma das categorias acima listadas.

As figuras 6 e 7 apresentam exemplo de equipamento, e item de reposição, que atendem à Diretiva RoHS.

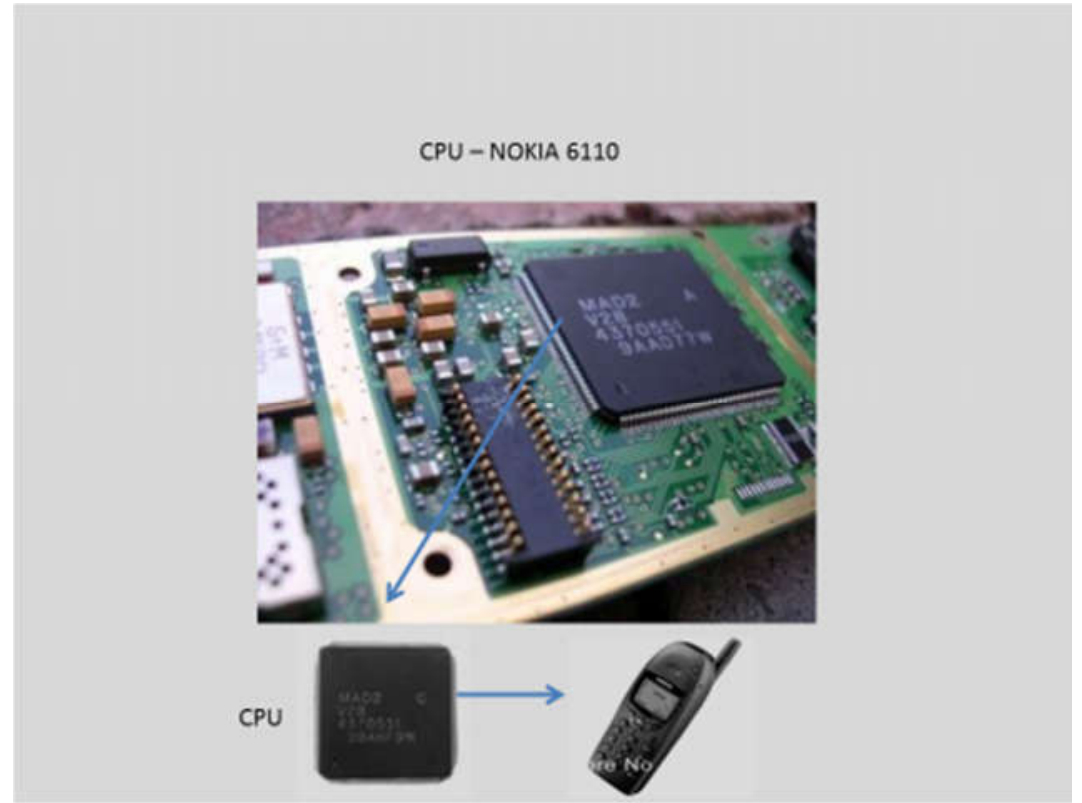

Figura 6: CPU MAD2 V28do telefone celular NOKIA 6110 Fonte: Autor, baseado em dados disponibilizados na WEB. 


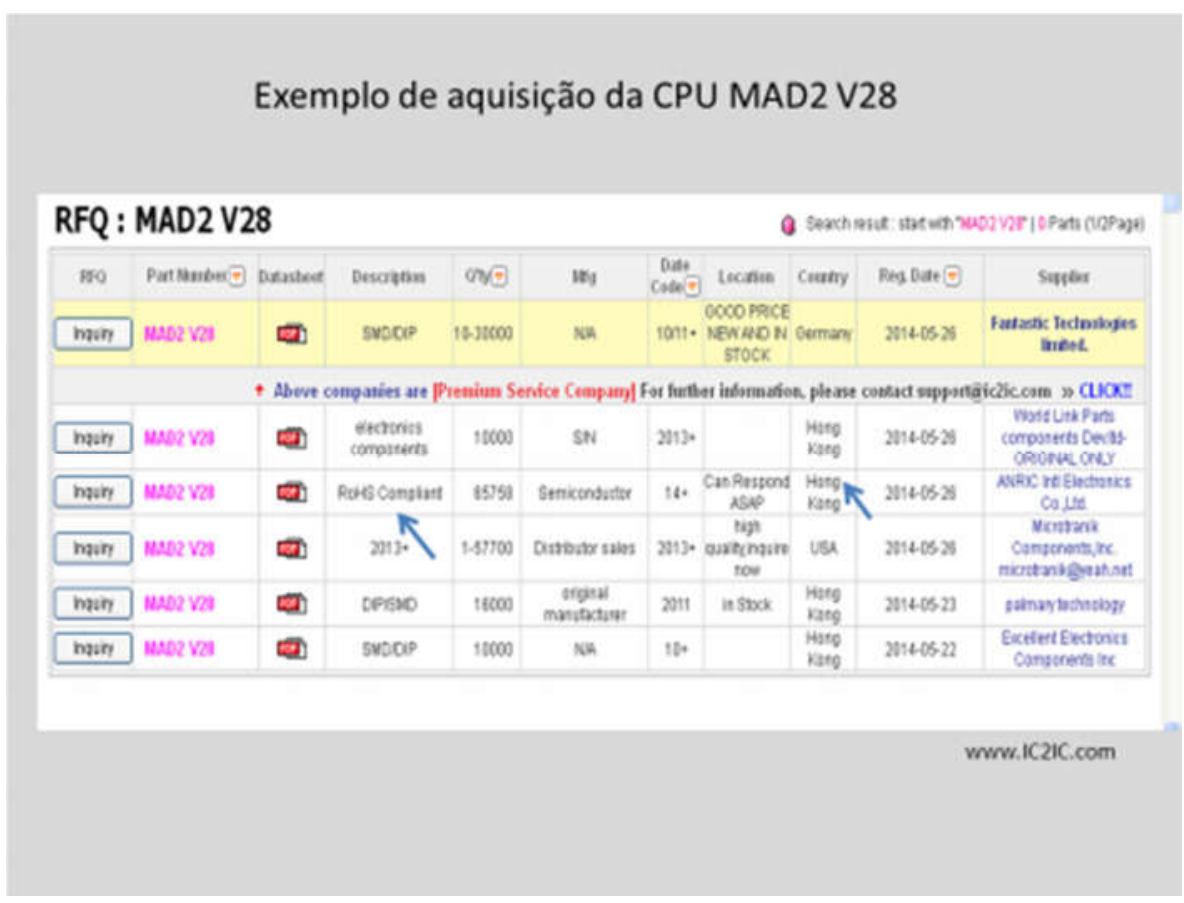

Figura 7 - Exemplo de aquisição da CPU MAD2 V28. Fonte: página na web da empresa IC2IC, 2014.

Mediante escopo tão abrangente e inúmeras exceções, a Diretiva RoHS apresenta datas limites para atendimento à Diretiva para categorias específicas de equipamentos eletroeletrônicos, permitindo que os produtores de EEE pudessem se adaptar às restrições da $R o H S$.

Vários itens utilizados junto a EEE, como cabos, componentes eletrônicos podem estar cobertos, ou não, pela Diretiva RoHS. Cabos e sobressalentes para reparo, melhoria de funcionalidade ou melhoria de capacidade de um específico produto deve seguir as mesmas datas limites das categorias dos produtos aos quais estão vinculados.

Da mesma forma, segundo o princípio de repair as produced sobressalentes para produtos colocados no mercado antes das datas limites estipulados pela Diretiva estão excluídos da RoHS.

EEE com múltiplo ou dual uso podem estar no escopo da Diretiva. Diferentemente da Diretiva WEEE, a Diretiva RoHS não faz distinção entre o uso pessoal ou profissional do equipamento. Equipamentos de múltiplo uso como os de segurança estão inseridos na Diretiva RoHS.

Em julho de 2011 a Diretiva $R o H S$ foi atualizada pela Diretiva 2011/65/EC, esta passando a ser denominada RoHS2. 
As categorias dos EEE cobertas pela Diretiva são as mesmas da Diretiva 2002/95/EC, bem como as substâncias químicas limitadas pela Diretiva.

Conforme documento "RoHS2 FAQ” (EC, 2012, p. 5), os motivos da atualização da Diretiva RoHS1 para RoHS2 foram:

$\checkmark$ Tornar a Diretiva mais simples, de fácil entendimento, tornando-a mais efetiva possivel;

$\checkmark$ Mais clareza e certeza do ponto de vista legal;

$\checkmark$ Adaptar a Diretiva ao avanço técnico e científico, principalmente em relação a equipamentos médicos e instrumentos de controle;

$\checkmark$ Harmonizar a implementação da Diretiva nos diferentes membros da UE;

$\checkmark$ Alinhar a diretiva RoHS com outras legislações da UE, com o intuito de reduzir custos administrativos e diminuir o custo efetivo do produto coberto pela Diretiva;e

$\checkmark$ Prevenir riscos à saúde e ao meio-ambiente, em particular, à saúde dos trabalhadores envolvidos na coleta dos resíduos eletroeletrônicos.

O mesmo documento (EC, 2012, p. 5-6) resume as diferenças entre a Diretiva RoHS, agora denomina RoHS1, e a RoHS2:

Escopo:

- Revê definições (artigo 3);

Define termos ou expressões que constam da Diretiva, como a definição das categorias dos EEE que fazem parte da norma.

- Propõe revisão do escopo da Diretiva até julho de 2014;

O artigo 6(1) da RoHS2 estipula verificações/atualizações periódicas, inclusive antes de 2014,

- Estende os requisitos da Diretiva para todos os EEE, inclusive cabos e sobressalentes, exceto para as exceções determinadas no artigo 2(4), até julho de 2019.

Restrição de novas substâncias:

- Garante aos Estados membros da UE restrições às novas substâncias;

- Prevê a revisão da lista de substâncias tóxicas até julho de 2014 e determina de revisões periódicas; 
Exceções:

- Estabelece regras mais claras e transparentes para conceder, renovar ou excluir exceções;

- Determina a obrigação dos fabricantes em realizar avaliações necessárias dos EEE, quando da solicitação de exclusão da Diretiva.

* Coerência com outras legislações européias.

\subsection{1}

\section{Exceções da Diretiva RoHS2}

Em relação às exigências para obtenção de dispensa de atendimento à Diretiva $R o H S$, diferentemente da $R o H S 1$, a RoHS2 analisa o impacto global da substituição de uma substância em atendimento à Diretiva. Se negativo, pode justificar a inclusão do EEE na Diretiva como exceção. Na Diretiva RoHS2, segundo o documento Guidance document on RoHS 2 (Deubzer et al., 2012), quatro parâmetros devem considerados na avaliação da inclusão do EEE como exceção: disponibilidade de substitutos para a substância química, impacto sócioeconômico da substituição, impactos da inovação e avaliação do ciclo de vida sob o impacto atribuído à exceção. A tabela 14 resume os parâmetros que devem ser levados em consideração na avaliação da inclusão do EEE como exceção da Diretiva RoHS2.

Tabela 14 - Parâmetros a serem considerados na avaliação de exceções da Diretiva RoHS 2

\begin{tabular}{|l|l|}
\hline \multicolumn{1}{|c|}{ Parâmetro } & \multicolumn{1}{|c|}{ Justificativa } \\
\hline Impactos socioeconômicos da substituição & $\begin{array}{l}\text { A substituição de substâncias nocivas em EEE } \\
\text { pode ter efeitos adversos sobre a competitividade e } \\
\text { isso pode, por sua vez, afectar o emprego em } \\
\text { algumas regiões. }\end{array}$ \\
\hline Disponibilidade de substâncias substitutas & $\begin{array}{l}\text { A disponibilidade de uma substância em } \\
\text { substituição à substância originalmente utilizada } \\
\text { no EEE pode não ser imediata, acarretando atrazos } \\
\text { na produção do produto, ou a permanência do } \\
\text { mesmo no mercado. }\end{array}$ \\
\hline $\begin{array}{l}\text { Avaliação do ciclo de vida mediante o } \\
\text { impacto das exceções }\end{array}$ & $\begin{array}{l}\text { Avaliar os impactos decorrentes de possíveis } \\
\text { substância substitutas nos vários estágios do EEE: } \\
\text { produção, distribuição, uso e gerenciamento dos } \\
\text { REEE no fim do ciclo de vida do produto. }\end{array}$ \\
\hline Impactos das exceções & $\begin{array}{l}\text { Avaliação necessária para detectar se os impactos } \\
\text { que a duração de uma exceção pode ter sobre os } \\
\text { esforços futuros para o desenvolvimento de } \\
\text { possiveis substâbncias substitutas. }\end{array}$ \\
\hline
\end{tabular}

Fonte: Baseado Adaptado da Guidance document on RoHS 2 (Deubzer et al., 2012) 
Conforme o documento Guidance document on RoHS 2, (Deubzer et al., 2012) as exceções são agora concedidas por um período máximo de tempo, podendo ser renovado a pedido, somente após avaliação. A tabela 15 resume as exceções da Diretiva RoHS2.

Tabela 15 - Resumo das exceções da Diretiva RoHS2

\begin{tabular}{|c|c|c|}
\hline Itens RoHS & Equipamentos & Exemplos \\
\hline $2(4)(a)$ & $\begin{array}{l}\text { Militares e equipamentos de } \\
\text { segurança. }\end{array}$ & Mísseis, sistemas de combate. \\
\hline $2(4)(b)$ & $\begin{array}{l}\text { EEE projetados para serem enviados } \\
\text { ao espaço. }\end{array}$ & Satélites. \\
\hline $2(4)(c)$ & $\begin{array}{l}\text { Parte de equipamentos não incluídos } \\
\text { no escopo da Diretiva. }\end{array}$ & $\begin{array}{l}\text { Sistemas computacionais, } \\
\text { especialmente projetados para serem } \\
\text { instalados em aeronaves. }\end{array}$ \\
\hline $2(4)(d)$ & Ferramentas industriais fixas. & Guindastes. \\
\hline $2(4)(e)$ & Instalações fixas. & Elevadores. \\
\hline $2(4)(f)$ & Meios de transporte. & $\begin{array}{l}\text { Carros, veículos comerciais, } \\
\text { aeronaves, trens e navios. }\end{array}$ \\
\hline $2(4)(g)$ & Maquinários móveis. & Escavadeiras hidráulicas. \\
\hline $2(4)(h)$ & Dispositivos médicos para implantes. & Marcapassos. \\
\hline 2(4)(i) & Painéis Fotovoltaicos. & Painéis solares. \\
\hline $2(4)(j)$ & Pesquisa e desenvolvimento & Instrumentos de medições. \\
\hline
\end{tabular}

Fonte: Guidance document on RoHS 2 (Deubzer et al., 2012)

Em atendimento à Diretiva $\mathrm{RoHS} 2$ a restrição de substâncias nocivas em EEE será gradualmente estendida aos novos produtos de certas categorias conforme detalhado na tabela 16 .

Tabela 16 - Resumo de datas limites para adequação à Diretiva RoHS2.

\begin{tabular}{|c|c|c|}
\hline \multicolumn{3}{|c|}{ Datas Limites } \\
\hline 22 de julho de 2016 & 22 de julho de & 23 de julho de \\
& 2017 & 2019 \\
\hline Categoria 8 & Categoria 9 & Todos os EEE, exceto \\
os explicitamente \\
Instrumentação & Instrumentação de & Controle e \\
excluídos da Diretiva \\
diagnóstico in vitro & Monitoramento & \\
& Industrial & \\
\hline
\end{tabular}

Fonte: Guidance document on RoHS 2 (Deubzer et al., 2012) 


\section{1 .2}

\section{Certificações de EEE}

Segundo informações contidas no documento RoHS2 FAQ (EU, 2012, p. 20) vinculado na página da web da União Europeia:

"A Diretiva RoHS 2 prevê que EEE tem de cumprir os requisitos da directiva. Dado que o equipamento é constituido por componentes diferentes, o próprio EEE só pode cumprir as exigências de restrição se todos os seus componentes e peças atendem aos requisitos de restrição da RoHS 2, incluindo componentes não eletrônicos ou não-elétricos como fixadores ou o gabinete de um computador desktop. Portanto, componentes que estão sendo utilizados no EEE acabado ou para reparo ou em caso de modernização de EEE usados, que estão no âmbito da RoHS 2 devem satisfazer as restrições quanto às substâncias restritas de acordo com o Art. 4, mas não precisam de marcação CE. Os componentes vendidos como componentes avulsos, ou se produzidos para serem usados em um produto exceção da RoHS não devem ter a marca CE, e não tem que cumprir com os requisitos da Diretiva."

Tradução: autor.

O mesmo documento ressalta a importância da Declaração de Conformidade e do Selo de Conformidade com a marca $C E$ conforme estabelecido pela Decisão N ${ }^{\circ} 765 / 2008 / \mathrm{EC}$ (EC, 2008) da Comunidade Européia, que estabelece os requisitos de acreditação e verificação de mercado relativos à comercialização de produtos. A Declaração e o Selo de Conformidade são necessários para remover os obstáculos à livre circulação de produtos e criar um quadro jurídico europeu eficaz e coerente visando à comercialização de produtos no bloco europeu.

A Declaração de Conformidade deve assegurar que os requisitos da Diretiva RoHS2 tenham sido satisfeitos, isto é, que os equipamentos eletroeletrônicos estejam de acordo com as restrições impostas pela Diretiva.

Quanto ao Selo CE, todos os EEE que atendam à Diretiva $\mathrm{RoH} 2 \mathrm{~S}$ devem possuir o selo, e a Declaração de Conformidade do produto deve fazer referência a Diretiva RoHS2. Deve-se salientar que o artigo 15 da $R o H S$ estipula que o Selo CE deve ser aplicado ao produto final.

No âmbito internacional, a International Electrotechnical Commission (IEC) é a responsável pela elaboração e publicação de normas para equipamentos eletroeletrônicos, inclusive para verificação de conformidade à Diretiva RoHS2.

A norma IEC que apresenta a metodologia para verificação do nível das substâncias químicas regulamentadas pela RoHS é a IEC 62321 (IEC, 2008). 
Pela IEC 62321, as metodologias para determinar os níveis das substâncias controladas pela Diretiva RoHS2 estão agrupadas em dois grupos: testes analíticos e testes laboratoriais, estes não cobertos pela norma IEC.

Várias empresas internacionais, algumas com representação no Brasil, como a Veritas Bureau e a SGS, efetuam ensaios para comprovação de conformidade à Diretiva RoHS2.

No Brasil, o Órgão responsável pela Acreditação de Institutos e Laboratórios é o INMETRO (Instituto Nacional de Metrologia, Qualidade e Tecnologia). Dentre algumas empresas que se propõem a testar materiais que atendam à Diretiva RoHS2, o Instituto de Pesquisa Tecnológico (IPT) de São Paulo que desponta como instituição de excelência na avaliação de materiais que compõem os EEE tendo como referência a RoHS2. O IPT disponibiliza em sua página na web a metodologia que emprega na análise química das substâncias que fazem parte da Diretiva RoHS2.

A tabela17 lista os equipamentos utilizados pelo Laboratório de Análise Química do IPT para determinar a presença das substâncias químicas limitadas pela Diretiva RoHS2 Já a tabela 18 apresenta os valores limites de aceitabilidade de substâncias químicas em EEE em atendimento à Diretiva RoHS2 estipulados pelo IPT.

Segundo o IPT (2011), os casos mais frequentes de reprovação em sua avaliação química são: soldas à base de chumbo, tintas e corantes em geral, colas e adesivos em geral, polímeros (PVC, poliamida, etc.) e chumbo em placas cerâmicas de circuitos impressos.

Tabela 17 - Relação de equipamentos utilizados na detecção de substâncias químicas

\begin{tabular}{|l|l|}
\hline \multicolumn{1}{|c|}{ Substância } & \multicolumn{1}{c|}{ Equipamento } \\
\hline Cromo VI & $\begin{array}{l}\text { Espectrometria de fluorescência de raios X. } \\
\text { Espectrofotometria UV visível. }\end{array}$ \\
\hline Cádmio, Mercúrio e Chumbo & $\begin{array}{l}\text { Espectrometria de emissão atômica de plasma. } \\
\text { Espectrofotometria de absorção atômica. }\end{array}$ \\
\hline PBB e PBDE & $\begin{array}{l}\text { Cromotografia gasosa acoplada a espectrômetro de } \\
\text { massa. } \\
\text { Espectrometria de fluorescência e Raios X. }\end{array}$ \\
\hline
\end{tabular}

Fonte: IPT, 2011 
Tabela 18- Valores limites de aceitabilidade de substâncias químicas em EEE em atendimento à RoHS estipulados pelo IPT-SP

\begin{tabular}{|c|c|c|c|c|}
\hline Elemento & $\begin{array}{c}\text { Limite } \\
\text { Máximo }\end{array}$ & Aprovado & Não conclusivo & Reprovado \\
\hline Cádmio $(\mathrm{Cd})$ & $100 \mathrm{mg} / \mathrm{kg}$ & $0<\mathrm{Cd}<70$ & $70<\mathrm{Cd}<130$ & $\mathrm{Cd}>130$ \\
\hline Chumbo $(\mathrm{Pb})$ & $\begin{array}{c}1000 \\
\mathrm{mg} / \mathrm{kg}\end{array}$ & $0<\mathrm{Pb}<700$ & $700<\mathrm{Pb}<1300$ & $\mathrm{~Pb}>1300$ \\
\hline Mercúrio $(\mathrm{Hg})$ & $\begin{array}{c}1000 \\
\mathrm{mg} / \mathrm{kg}\end{array}$ & $0<\mathrm{Hg}<700$ & $700<\mathrm{Hg}<1300$ & $\mathrm{Hg}>1300$ \\
\hline Cromo & $\begin{array}{c}1000 \\
\mathrm{mg} / \mathrm{kg}\end{array}$ & $0<\mathrm{Cr}$ total $<700$ & $\mathrm{Cr}$ total $>700$ & \\
\hline Cr hexavalente $)$ & 1000 & $0<$ Brtotal $<350$ & $\mathrm{Br}$ total $>350$ & \\
\hline PBB e PBDE & $\mathrm{mg} / \mathrm{kg}$ & & & \\
\hline
\end{tabular}

Fonte: Informativo do IPT-SP.

\subsection{3}

\section{Primeira atualização da Diretiva RoHS2}

A Diretiva RoHS2, conforme previsto na norma, foi revista, sendo verificada a necessidade da inclusão de novas substâncias químicas no escopo da norma.

A Diretiva 2015/863, (EU, 2015), altera o Anexo II da Diretiva 2011/65/EU estipulando a inclusão das substâncias Bis (2-ethylhexyl) phthalat (DEPHP), Butyl benzyl phthalate (BBP), Dibutyl phthalat (DBP) e Diisobutyl phthalate (DIBP), plasticidas utilizados em PVC para torna-los mais flexíveis, no escopo da Diretiva RoHS2, exceto os brinquedos que são normatizados para as mesmas substâncias pelo item 51 do anexo XVII da norma N¹907 de 2006 da EU.

A substância DEPHP pode acarretar danos aos testículos e rins. Se a contaminação ocorrer durante a gravidez pode ocasionar a danos ao feto. As substâncias BBP e DBP podem causar danos ao trato respiratório. Em relação ao meio ambiente, a maior preocupação de contaminação por BBP e DBP ocorre quando do processo de tratamento de REEE. Já a substância DIBP, além de plasticida, é utilizado na produção de vernizes, colas e tintas. Pode ocasionar infertilidade e danos aos recém-nascidos. Quanto ao meio ambiente, causa à longo prazo, efeitos adversos ao meio ambiente aquático.

Conforme determinado para as outras 6 substâncias da Diretiva RoHS2 a concentração máxima tolerada por peso em material homogêneo é $0,1 \%$ para as 4 novas substâncias inseridas na Diretiva. Os Estados Membros da União Europeia devem adotar, e promulgar, a Diretiva 2015/863/EU, até 2016. Além disso, a data 
limite para os EEE atenderem a Diretiva 2015/863/EU é 22 de julho de 2019, sendo que a restrição imposta pela norma não se aplica à cabos, ou sobressalentes para reparo, reuso, ou melhorias, na funcionalidade e capacidade de EEE colocados no mercado antes de 22 de julho de 2019. Já para os dispositivos médicos, instrumentos de controle e monitoramento, inclusive instrumentos de controle e monitoramento industriais a data limite é 22 de julho de 2021 (EU, 2015).

Devido à sua recente promulgação e à data limite para que os EEE atendam a Diretiva 2015/863/EU, este estudo não abrangerá a análise dos impactos decorrentes da inclusão das substâncias DEPHP, BBP, DBP e DIBP na Diretiva RoHS2, ficando este estudo restrito as substâncias chumbo, mercúrio, cádmio, cromo hexavalente, polibromato bifenil (PBB) e éter difenil polibromato (PBDE).

A Diretiva 2015/863 não é aplicada a brinquedos, os quais já estão sujeitos à restrição às substâncias DEPHP, BBP, DBP e DIBP pelo item 51 do anexo XVII da norma 1907/2006/EC.

Para fins do estudo em curso a Diretiva em análise será denominada apenas por Diretiva RoHS.

\section{2}

\section{Adoção da Diretiva RoHS fora da União Europeia}

O alinhamento à Diretiva RoHS por vários países de fora da UE visa, além de prevenir e remediar impactos ambientais negativos, principalmente, fomentar o comércio. A RoHS Europeia é considerada, por alguns, barreira alfandegária, que impede o comércio justo de eletroeletrônicos. Portanto, alinhar-se à Diretiva $R o H S$ possibilita transpor barreiras comerciais. A tabela 19 apresenta as principais características das Diretivas em análise.

\subsection{1}

\section{RoHS China}

Semelhante à Diretiva $R o H S$ da $\mathrm{CE}$, a legislação chinesa para controle de substâncias tóxicas em equipamentos eletroeletrônicos, restringe as substâncias químicas $\mathrm{Pb}, \mathrm{Cd}, \mathrm{Hg}, \mathrm{Cr6}+$, PBBs e PBDEs em EEE nos valores máximos de 1000 ppm para todas as substâncias da Diretiva, exceto o Cd cujo limite é de 100 ppm. 
Os EEE que fazem parte do escopo da RoHS China devem estar incluídos na lista oficial, Electronic Information Products (EIP) Classification (EU SME, 2011), que determina quais os produtos, distribuídos por categorias, que devem atender às restrições às substâncias tóxicas. A RoHS China restringe-se aos equipamentos à venda na China, não é aplicável a produtos destinados à exportação, matériasprimas relacionadas, peças e componentes importados para montagem e exportação final.

Como exemplo de EEE que devem atender à RoHS China, pode-se citar: equipamentos médicos, equipamentos de controle e monitoramento, baterias e outros.

Vários documentos compõe a RoHS China:

1. Management Methods for Controlling Polution by Electronic Information Products (Ministry of Information order \#39), 2006 (American Electronics Association, 2015) - visa o controle e a redução de poluentes no meio ambiente causada pelo descarte de EEE, bem como promover a fabricação e a venda de EEE com menor poder poluente e ainda salvaguarda o meio ambiente e à saúde humana;

2. Requirements for Concentration Limits for Certain hazardous Substances in Electronic Information Products SJ/11363, 2006 (EU SME, 2011) estabelece os valores máximos permitidos para as substâncias da $R o H S$ China;

3. People's Republica of China Electronic Industry Standard SJ/T 11364, 2006 (EU SME, 2011) - foca na identificação e indicação de produtos submetidos à legislação RoHS China visando o controle da poluição causada por EEE;

4. Testing Methods for Hazardous Substances in Electronic Information Producs - SJ/T 11365, 2006 (EU SME, 2011) - determina a metodologia para identificar as substâncias tóxicas em EEE em atendimento à RoHS China;

5. Determination of Regulated Substances (Lead, Mercury and cadium) in Electrical and Electronic Equipment- GB/Z 21274,2007 (EU SME, 2011) fornece orientações para determinar as substâncias da Diretiva nos equipamentos eléctricos e electrónicos 
Conforme o artigo Eco-Info \& Lead-free (Pb-free): China RoHS and Chasing Arrow Information (Texas Instrumments, 2015) equipamentos que possuam níveis de substâncias RoHS acima de valores limites permitidos, a RoHS China exige que seja definido o tempo que a substância se mantém inócua. O período é definido pela função Environmentally Friendly Use Period (EFUP). O período EFUP inicia-se na produção do produto.

No mesmo artigo, a empresa Texas Instruments estima que seja de até 50 anos o tempo de EFUP de circuitos integrados, incluindo os que contem chumbo, sendo utilizados com temperatura e umidade típicos de um ambiente de escritório.

\section{2 .2}

\section{RoHS Coreia}

A UE e a Coreia do Sul são fortes parceiros comerciais. Desde 1962, a UE é o maior investidor na Coreia do Sul. Segundo o documento 6319/09 (CEU, 2009) a Coreia do Sul é a oitava maior parceira da UE, já a UE tornou-se o segundo maior destino para exportação dos produtos coreanos.

Neste contexto, a Coreia do Sul se alinhou à UE em relação à sua política ambiental e elaborou a norma The Act of Resource Recycling of Electrical and Electronic Equipment and Vehicles (KLRI, 2007).

Equipamentos Eletroeletrônicos na RoHS Coreia são definidos como equipamento e dispositivos que funcionam por corrente elétrica ou campo magnético. A definição de veículos é adotada do artigo 2(1) do Automobile management Act (KLRI, 2010).

Pelo artigo Summary of Korea RoHS (RSJ Technical Consulting, 2007) a RoHS Coreia limita, o uso de substâncias tóxicas em EEE na mesma concentração da $R o H S$ da UE, além de incluir veículos em seu escopo. Exceções são permitidas quando não existirem substâncias que substituam as banidas, ou se a eliminação da substância tóxica for de extrema dificuldade.

O mesmo artigo aponta o grande diferencial da RoHS Coreia: a preocupação quanto ao design do produto. $\mathrm{O}$ design for the environment tem como base a busca por melhorias contínuas do projeto do produto, e também, por novas tecnologias de 
reciclagem que sejam ambientalmente amigáveis e economicamente viáveis. $\mathrm{O}$ Design deve simplificar a separação das partes e subpartes dos EEE, favorecendo a reciclagem e o descarte dos REEE, permitindo a segregação de unidades que contenham, sabidamente, substâncias tóxicas.

RSJ Technical Consulting informa ainda em seu artigo que além de restrição às substâncias tóxicas em EEE, e a preocupação com o design dos produtos, a $R o H S$ Coreia regulamenta a coleta seletiva e a quantidade de REEE a serem reciclados pelos produtores e importadores, normatizando a responsabilidade dos produtores e importadores.

Seguindo a Diretiva RoHS da Coreia, os produtores e importadores de EEE devem apresentar declaração de conformidade do produto à RoHS Coreia tanto em relação aos limites da concentração de substâncias tóxicas quanto em relação aos requisitos para reciclagem de EEE.

\subsection{3 \\ RoHS Califórnia (USA)}

Embora os EUA e a UE sejam os maiores parceiros comerciais bilaterais do mundo, sendo que juntos são responsáveis por aproximadamente dois quintos do comércio mundial, os USA não se alinharam à política ambiental da Comunidade Europeia quanto à restrição de substâncias tóxicas em equipamentos eletroeletrônicos.

Sem uma Lei Federal similar à RoHS europeia, vários Estados Americanos veem se empenhando em desenvolverem legislações similares à RoHS da UE.

Seguindo essa linha de ação, o Estado da Califórnia aprovou em 2003 a Lei considerada a RoHS Califórnia The Electronic Waste Recycling Act (EWRA, Senate Bill n²0 ) (California, 2003). Trata-se de Lei Estadual que regulariza a redução das substâncias tóxicas, cádmio, cromo hexavalente, chumbo e mercúrio em dispositivos eletrônicos. Aplica-se a qualquer pessoa que venda ou oferte para venda dispositivos eletrônicos no Estado da Califórnia. Inclui produtores, distribuidores, atacadistas e varejistas. 
Semelhante à RoHS da UE, cobre, porém, um escopo menor de equipamentos, apenas dispositivos eletrônicos. A concentração máxima dos metais em substâncias homogêneas é de $0,1 \%$ por peso de chumbo, mercúrio e Cr6, e de $0,01 \%$ por peso de cádmio.

No Estado da Califórnia as substâncias PBBs e PBDEs em EEE estão proibidas desde 2006. As RoHS diferem, também, quanto ao momento que os EEE atender às normas. Para a RoHS Europeia, o EEE está submetido à Diretiva quando colocado no mercado, após a Diretiva ter entrado em vigor. A RoHS Califórnia, entretanto, aplica-se aos dispositivos eletrônicos fabricados após a $R o H S$ ter entrado em vigor.

A RoHS Califórnia pode ser resumida pelos projetos de lei Senate Bill n ${ }^{\circ} 20$ (California, 2003) e Senate Bill n50 (California, 2004). O primeiro restringe substâncias tóxicas em telas de vídeo CRT, LCD e de plasma maiores do que 4 polegadas medidas na diagonal, enquanto que o segundo expandiu a cobertura do Sente Bill $n^{\circ} 20$ para produtos remodelados.

Em 2009, o Projeto de Lei H.R. 2420, The environment Design of Electrical Equipment Act (USA, 2009) foi apresentado à Câmera dos deputados dos EUA. O Projeto de Lei estabelece restrição às concentrações maiores de $0,1 \%$ por peso de mercúrio, chumbo, cromo hexavalente e $0,01 \%$ por peso de cádmio, em substâncias homogêneas. Uma das razões para a elaboração do Projeto de Lei H.R. 2420 foi de prevenir disparidades entre os 50 Estados dos EUA. O Projeto de Lei H.R. 2420 não foi promulgado até a elaboração deste estudo.

\section{2 .4}

\section{RoHS Japão}

Uma das maiores economias do mundo, o Japão é o quinto principal parceiro comercial da UE, e a UE o terceiro principal parceiro comercial do Japão.

"A relação da UE com o Japão é fundamentada por ambos os lados serem democracias avançadas, industrializadas que compartilham muitos interesses $e$ valores em comum. A cooperação entre a UE e o Japão ocorre em todos os niveis, seja na política externa, relações econômicas e comerciais e os desafios regionais e 
globais. Além disso, participam ativamente de diálogos setoriais, como por exemplo, de aspectos ambientais, ciência e tecnologia, comércio, serviços financeiros, as políticas macroeconômicas e de política industrial".

Fonte: CEU (2009, p. 5), traduzido pelo autor.

Alinhado economicamente à União Europeia, e compartilhando dos mesmos valores para preservação ambiental, o Japão promulgou em 1991, última revisão em 2000, o documento The Law for Promotion of Effective Utilization of Resources (Japão, 2000) que versa sobre a indústria de construção civil e elétrica quanto ao desenvolvimento sustentável.

Conscientes de sua dependência em importar a maior parte de importantes insumos, e preocupados com o grande volume de resíduo produzido, sem aproveitamento para reciclagem e reuso, The Law for Promotion of Effective Utilization of Resources promulgada pelo Japão garante:

“[..].utilização eficaz dos recursos para reduzir a geração de lixo, e para contribuir para a proteção do meio ambiente; o objetivo desta lei é fornecer o mecanismo básico necessário para promover a redução da geração de bens usados $e$ subprodutos e da utilização os recursos recicláveis e pelas reutilizáveis, e assim contribuir para a promoção do desenvolvimento saudável da economia do país." (Japão, 2000. Tradução: autor).

A Lei regulamenta, ainda, as responsabilidades do consumidor, do fabricante e do vendedor quanto ao reuso e reciclagem do produto adquirido, selo da norma e punições.

As substâncias tóxicas contidas em partes e materiais a serem controladas de EEE foram concentradas pela Organização não Governamental The Japan Green Procurement Survey Standardization Initiative (JGPSSI) no documento Material Composition Survey and Response Manual (JGPSSI, 2012). Dentre as substâncias químicas normatizadas pela JGPSSI estavam as seis substâncias tóxicas incluídas na RoHS europeia, além de substancias radioativas, e outras. A JGPSSI restringia, como a Diretiva RoHS da UE, aos limites de $0,01 \%$ para cádmio e de $0,1 \%$ para chumbo, mercúrio, cromo hexavalente, polibromato bifenil e éter difenil polibromato (PBDE) em EEE. Para declaração da composição química dos materiais que compõem os EEE suas subpartes, materiais e acessórios, a JGPSSI estabeleceu o documento Joint Industry Guide (JIG-101) (Consumer Technology Association, 2012). 
Entretanto, em 2012 a JGPSSI foi dissolvida, e o JIG-101 não mais atualizado. Em substituição ao JIG-101, a Internatonal Electrotechnical Commission (IEC) elaborou o documento IEC 62474 -Material Declaration for Products of and for the Electrotechnical Industry (IEC, 2015) que em substituição ao JIG-101 é composta de duas partes: requisitos de declaração de material e de um banco de dados com quatro tipos de informação: classes do material, substâncias de referência, substâncias e grupos de substâncias. Desde então, o documento IEC 62474 é a norma de referência para a declaração de substâncias existentes nos EEE, recomendada pela JGPSSI e associações representativas de indústrias de tecnologia digital e de usuários de EEE. 


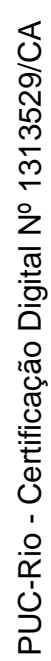

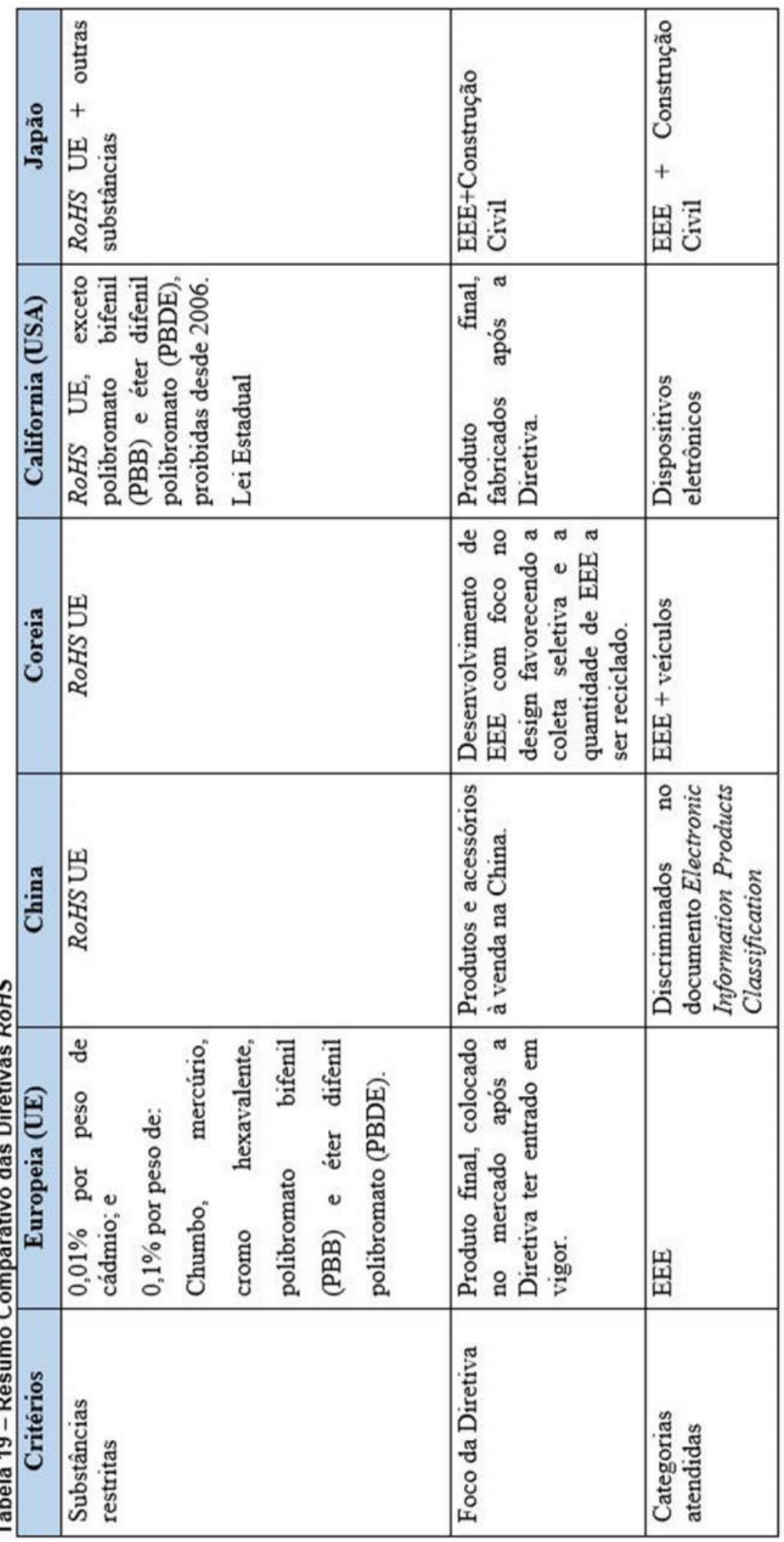




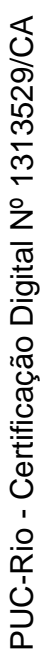

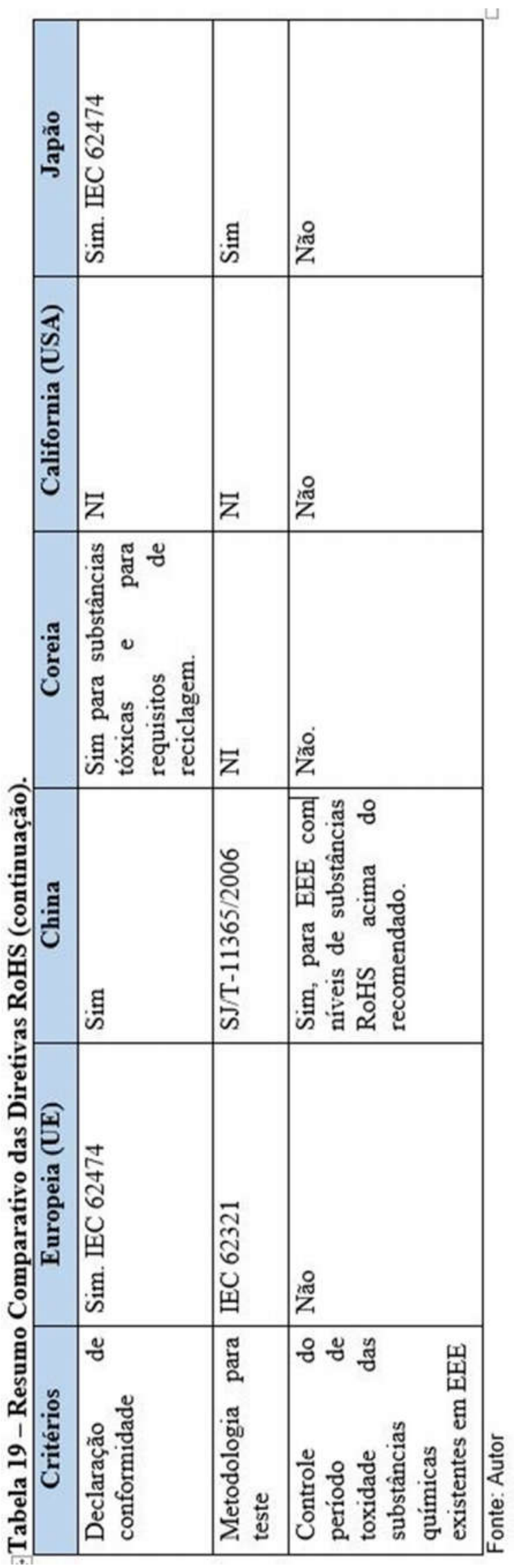




\section{4 \\ Metodologia para a análise da viabilidade técnica e econômica}

A análise da viabilidade técnica e econômica da implementação da diretiva RoHS na Organização Militar da Marinha do Brasil será realizada mediante o emprego do modelo militar de decisão do Estado Maior da Armada, EMA-332 (EMA, 2015), precedido por análise baseada no procedimento analítico SWOT (Strengths, Weaknesses, Opportunities, Threats), ou FOFA, (Forças, Fraquezas, Oportunidades e Ameaças), que permitirá a definição do cenário estratégico para identificação de fatores condicionantes que auxiliarão na busca por linhas de ação em resposta ao problema apresentado.

\section{1}

\section{Modelo militar de decisão - EMA-332}

A metodologia descrita na publicação EMA-332 (EMA, 2015) apresenta o Modelo Militar de decisão que possibilita o levantamento de possíveis soluções para um problema apresentado, orientando o decisor na "seleção $e$ na implementação de soluções efetivas para os problemas que se deve resolver" (EMA, 2015, p. 3-1).

O problema analisado neste trabalho, o de verificar se a adoção da diretiva RoHS na aquisição de EEE por Organização Militar da Marinha do Brasil, órgão responsável por aquisição de equipamentos eletroeletrônicos das áreas de navegação, acústica e de detecção radar, assegura confiabilidade técnica/operativa dos EEE dentro de faixa de preços aceitáveis, foi submetida a testes baseados no modelo de decisão do Estado Maior da Armada, EMA-332 (EMA, 2015).

As soluções ou Linhas de Ações (LA) definidas para solucionar o problema foram submetidos a testes de avaliação: adequabilidade, exequibilidade e aceitabilidade (AEA). Os testes de adequabilidade e exequibilidade são testes 
rígidos e com aspectos eliminatórios, sendo cada teste, condicional para que seja submetido a exame posterior.

A solução proposta para atender o critério de adequabilidade deve satisfazer à critérios rígidos quanto à sua pertinência, à integridade, este dividido em três critérios (atingimento, fidelidade e condicionamento) e campo da abordagem, este dividido em 4 critérios (nível, amplitude, alcance e oportunidade). Todos os critérios devem ser atendidos para que a solução seja considerada adequada, e possa ser submetida ao teste de exequibilidade.

Os critérios para verificação da adequabilidade da solução são definidos como (EMA, 2015, p. 4-23 e 4-24):

Pertinência - solução relacionada diretamente do problema, contribuindo para que seu propósito seja alcançado;

Integridade:

$\checkmark$ Atingimento dos propósitos fixados;

$\checkmark$ Fidelidade às premissas que levaram à proposição da ação estratégica;

$\checkmark$ Condicionamento - se a ação estratégica considera os requisitos e as limitações que lhe são impostas;

\section{Campo da Abordagem:}

$\checkmark$ Nível da Abordagem - implica considerar se a ação estratégica proposta encontra-se inscrita no limite de competência ou autoridade do Decisor responsável por sua execução;

$\checkmark$ Amplitude da Abordagem - corresponde à abrangência dos aspectos fundamentais do tema em estudo pela Equipe de Planejamento, devendo ser deixados de lado os fatores irrelevantes ou incontroláveis; $\mathrm{e}$

$\checkmark$ Alcance da Abordagem - corresponde à avaliação da compatibilidade entre o grau de profundidade da Ação Estratégica proposta e a sua amplitude.

$\checkmark$ Oportunidade - avaliar o momento adequado para execução da linha de ação e o intervalo de tempo para a sua execução.

Já o teste de exequibilidade permite maior flexibilidade.

"Uma solução é exequível quando, qualquer que seja seu custo, pode ser executada dentro das restrições impostas pelo desenvolvimento da ciência, da tecnologia e pela disponibilidade de "know-how" e dos meios existentes. O conceito de custo deverá 
ser o considerado em seu sentido mais amplo possivel (material, vidas, moral, risco, etc.) e não apenas em termos de valores monetários. " (EMA, 2015, p. 4-24)

O teste de exequibilidade baseia-se na possibilidade da LA ser executada face à disponibilidade de recursos humanos, à disponibilidade de recursos materiais, à disponibilidade de recursos financeiros, à disponibilidade de recursos tecnológicos e à disponibilidade de tempo.

Assim, para verificarmos que a solução é exequível deve-se fazer os seguintes questionamentos (EMA, 2015, p.4-25 e 4-26):

\footnotetext{
* Recursos humanos: quantidade suficiente? Qualidade satisfatória?

* Disponibilidade de recursos financeiros: recursos suficientes?

* Recursos tecnológicos: a solução é compatível com estado da arte? A tecnologia é dominada pelos executores da tarefa?

* Disponibilidade de tempo: qual o período previsto de implantação da solução?
}

A aceitabilidade não constitui um critério rígido para avaliação de soluções, sendo condicionada a parâmetros previamente estabelecidos e ao custo da implementação das soluções adequadas e exequíveis. Neste trabalho o critério de aceitabilidade será avaliada academicamente, embora esteja fora da esfera de decisão da Organização Militar da MB.

\section{2}

\section{Fatores da Matriz SWOT}

\subsection{1}

\section{Ambiente Externo}

Num mundo cada vez mais globalizado, porém segmentado em blocos políticos e econômicos, a análise do Ambiente Externo irá influenciar diretamente as decisões no Ambiente Interno. $\mathrm{O}$ isolamento, seja ele ao nível econômico, político, tecnológico, militar ou científico acarretará vários prejuízos à Nação.

Assim, conforme manual de métodos e planejamento da ESG: (ESG, 2009, p. 16):

"[...] deve-se buscar a identificação, na realidade internacional, dos fatores capazes de vir a influenciar, positiva ou negativamente, à ação política nacional. Deve-se captar a complexa interação por intermédio da qual atuam e defrontam-se na cena mundial as diversas nações. 
O manual de métodos e planejamento da ESG menciona ainda (ESG, 2009, p. 17):

"No plano das relações internacionais, cabe identificar as áreas estratégicas e de interesse mais relevantes para o país, atuais e potenciais, geograficamente próximas ou remotas, que possam exercer influência sobre o problema abordado. "'

A análise do ambiente externo englobará as ameaças, forças não controláveis pelo agente analisador que podem inviabilizar o sucesso de determinada linha ação e, as oportunidades, que são os fatores que irão apresentar ao decisor como, e porque, de atingir os objetivos com mais eficiência.

\subsection{2}

\section{Ambiente Interno}

No Ambiente Interno a avaliação das Forças e Fraquezas deve permitir que seja estabelecido o grau de interação junto às oportunidades e ameaças identificadas no Ambiente Externo. A partir desta identificação, os itens identificados como Força devem ser capazes de analisar a possibilidade de aproveitamento das oportunidades e verificar como superar as ameaças.

Conforme ESG, na análise do ambiente interno:

"[...]busca-se o conhecimento dos aspectos estruturais e conjunturais da realidade do país e suas interrelações no âmbito internacional, devendo ser consideradas as tendências de sua evolução. Deve ser caracterizado pela descrição da situação atual em seus diferentes aspectos, pela previsão de sua evolução e dos seus desdobramentos."

Fonte: (ESG, 2009, p. 18)

Conforme detalhado no item 2.1.3 do manual de métodos e planejamento da ESG (2009) na análise estrutural deve-se observar a organização institucional da realidade nacional e seus recursos. $\mathrm{Na}$ análise conjuntural observa-se o desempenho da organização e suas características mais significativas e na análise prospectiva o processo pelo qual são desenvolvidas pesquisas a respeito de fenômenos técnicos, tecnológicos, científicos, econômicos, sociais, etc., que procuram prever a evolução futura das sociedades.

$\mathrm{Na}$ análise estrutural, em relação ao desenvolvimento sustentável, podemos afirmar que embora o Brasil esteja alinhado aos anseios ambientais, e tenha legislado em favor da proteção ambiental, falta entrosamento e comunicação entre 
os Órgão do Governo e perfeito esclarecimento quanto à prática do que seja sustentável.

Tendo-se como referência na análise conjuntural a Organização Militar da MB, pode-se afirmar que a mesma tende a acompanhar a evolução tecnológica mundial em todas as suas áreas de atuação, tendo pessoal qualificado e capacitado para acompanhar a evolução da sociedade. Entretanto, ainda não se alinhou ao desenvolvimento sustentável proposto pelo Governo. Portanto, não possui pessoal técnico e administrativo capacitado na área ambiental.

Por exemplo, fraquezas internas para países em desenvolvimento, estão associadas à falta de capacitação técnica e institucional das organizações (Ansanelli, 2008, p.32-33).

Dentre as fraquezas internas descritas por Ansanelli destacam-se ainda:

1. Fraca infraestrutura técnica e de instrumental cientifico atualizado, de recursos, de pessoal especializado e informações nos laboratórios de testes por parte das agências de avaliação da conformidade;

2. Pouco avanço na realização de acordos de harmonização, equivalência técnica e reconhecimento mútuo;

3. Fraca participação na elaboração e desenvolvimento das exigências externas, de modo que muitos países em desenvolvimento se tornam tomadores de requisitos internacionais; $e$

4. Dificuldades de recuperar os custos adicionais de produção decorrentes da adequação às exigências, quando o padrão de concorrência de certos setores está baseado em baixos preços.

\section{3}

\section{Definição da Matriz SWOT e sua análise}

Os fatores identificados para definição do cenário estratégico, que facilitará a tomada de decisão para a adoção da Diretiva RoHS por Organização Militar da MB estão discriminados na tabela 20. 
Tabela 20 - Matriz SWOT

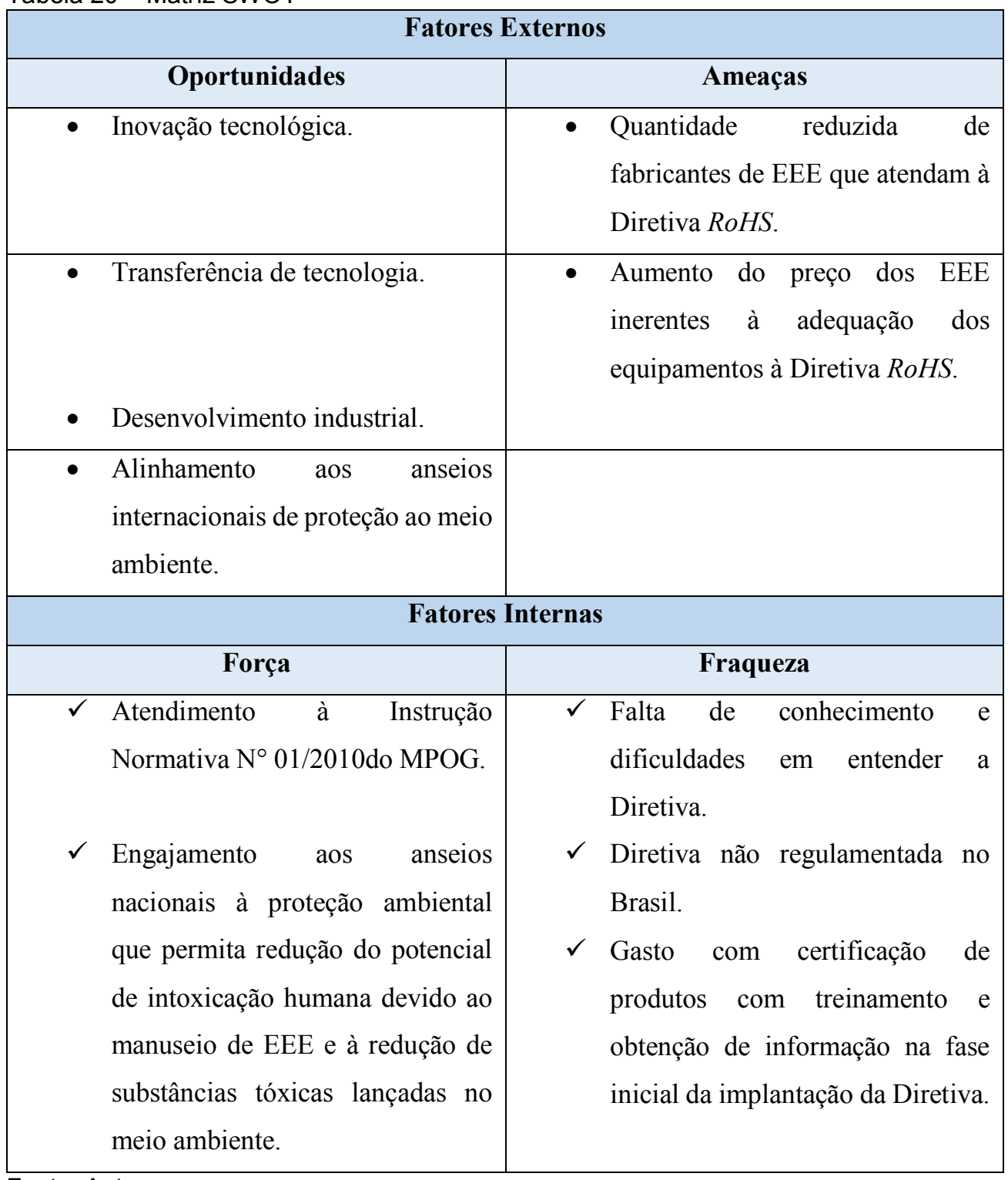

Fonte: Autor 


\subsection{1}

\section{Análise dos Fatores Externos}

\section{A. Oportunidades}

- Inovação tecnológica, Transferência de tecnologia, Desenvolvimento industrial.

A Diretiva RoHS permitiu que as empresas investissem em pesquisas e desenvolvimento buscando novas oportunidades de mercado enfrentado, contudo, desafios e limitações no desenvolvimento de equipamentos, principalmente, quanto à performance e ao design do produto. As empresas que já investiam em produtos sustentáveis facilmente se adaptaram às necessidades e exigências das agências reguladoras.

De acordo com Porter \& van der Linde (1995) apud Ansanelli (2008, p.15):

"[...] regulamentações mais rigorosas impulsionam o desenvolvimento ou adaptações de processos e produtos".

Afirma ainda:

"[...] as medidas ambientais estimulam inovações que podem compensar, parcial ou totalmente, os custos de adequação ambiental de modo que o custo inicial pode se reverter em benefício líquido. Isto porque a poluição é vista como sinal de ineficiência e desnecessária utilização dos recursos.

Fonte: Porter \& van der Linde (1995,1990) apud Ansanelli (2008, p.17).

Ansanelli atesta, também, que inovação ambiental, resultante da pressão ambiental, pode gerar vantagens competitivas.

Outras considerações dos trabalhos de Ansanelli (2008) são mencionadas a seguir:

1. [...] em alguns casos somente a expectativa da regulação já garante a mudança do comportamento da firma, embora não isente a necessidade da mesma. Informa ainda, que subsídios para propósitos ambientais são mais atrativos politicamente, mas possuem limitados impactos sobre as decisões de inovação, pois as empresas desenvolvem inovações mais voltadas às necessidades do mercado. Neste caso, subsídios para investimentos e Pesquisa \& Desenvolvimento são mais úteis, pois são mais bem usados em 
situações de incerteza sobre a solução tecnológica em longo prazo. Kemp (2000) apud Ansanelli (2008, p.15).

2. Alerta que as firmas podem influenciar detalhes da política ambiental, justificando a impossibilidade técnica de sua adequação. Em seu estudo constata que há uma tendência de que quanto mais rigorosos os instrumentos, mais inovadores serão os resultados. Afirma que a força dos instrumentos em relação ao grau de mudança tecnológica, também, depende das características da indústria, estrutura de mercado e da trajetória tecnologia. (Ansanelli 2008, p.37).

3. Sugere parcerias e formação de redes tecnológicas entre diferentes agentes em favor do desenvolvimento de inovação radical, tecnologias limpas, informação e soluções eficientes, medidas de comunicação para divulgação das ações, resultados, como fontes eu adicionais de informação e pressão. (Kemp (2000) apud Ansanelli (2008, p.16).

- Alinhamento aos anseios internacionais de proteção ao meio ambiente

Cada vez mais o mundo se preocupa com as questões ambientais. Inúmeras conferencias foram realizadas e tratados assinados e acordos firmados entre as Nações. O Brasil é signatário de vários tratados e como participante atuante do cenário regulador mundial, sediou a Rio-92 e a Rio+20, ambas possuidoras de pauta que fomentavam o desenvolvimento sustentável.

Internamente, o Brasil tem legislado em favor do meio ambiente e promulgou várias leis, decretos e normas com o intuito de proteger o bem maior de uma nação: seu povo e seus recursos naturais.

Com regulamentações mais restritivas voltadas cada vez mais à ações preventivas do que punitivas, as normas ambientais atuais visam reduzir a contaminação ambiental na origem, ou seja, no desenvolvimento dos EEE, impondo limitações ao uso de substâncias tóxicas em sua fabricação.

Por isso, a importância do atendimento do Brasil à Diretiva RoHS, pois sua internalização no Setor Público vai de encontro às orientações internacionais de desenvolvimento sustentável, onde, atualmente, as regulamentações ambientais 
servem de estímulo às inovações tecnológicas, de novas tecnologias limpas, que possibilitem a redução de impactos ambientais negativos.

\section{B. Ameaças}

- Quantidade reduzida de fabricantes de EEE que atendam à Diretiva RoHS.

Alguns fatores são responsáveis pela reduzida quantidade de fabricantes de EEE: desconhecimento da norma, dificuldade de compreensão da Diretiva, falta de recursos para adequar-se à norma, e ainda, à baixa demanda de mercado.

O risco por parte dos fabricantes de EEE de investimento voluntário no desenvolvimento de novas tecnologias ambientais é grande, embora o custo do investimento possa ser compensado, em muitos casos, por economia em energia ou por valores indiretos agregados à empresa por estar vinculada ao desenvolvimento sustentável e à proteção do meio ambiente.

Quanto à demanda, Ansanelli (2008, p, 11) informa que: “[...]pode haver insegurança e incerteza por parte dos usuários potenciais das tecnologias ambientais, por causa dos riscos econômicos e de obsolescência técnica envolvidos [...]"

Assim, o Estado é essencial como orientador nas aquisições sustentáveis, incentivando que mais produtores de EEE se alinhem com a política ambiental mundial.

\section{- Aumento do preço dos EEE inerentes à adequação dos equipamentos à Diretiva RoHS.}

A adequação da indústria de EEE à Diretiva $R o H S$ requer investimentos em toda a cadeia produtiva do equipamento, desde a fase de pesquisa e desenvolvimento do produto, passando por investimentos em capacitação de pessoal e certificação do produto, até chegar à fase de divulgação do EEE. Existe em alguns casos, dependendo do processo de produção, gasto maior com energia.

Gordon et al. (2008) estima que US\$ 32 bilhões foram gastos mundialmente para adequar as empresas à Diretiva, sendo US\$ 3,7 bilhões destinados anualmente para atualização dos EEE à Diretiva. 
Para recuperar os custos do investimento, os fabricantes recorrem prioritariamente, ao aumento do valor de venda do equipamento, seguido pela inserção de novos produtos no mercado e à demissão de empregados. Alguns fabricantes não repassam o recurso investido aos consumidores, preferindo agregar valor à marca.

No Brasil, o Instituto de Pesquisas Tecnológicas de São Paulo (IPT-SP,2015) estima que o acréscimo observado nos custos em adaptações tecnológicas de produtos à adequação dos EEE à Diretiva RoHS em torno de $20 \%$ a $30 \%$.

\subsection{2}

\section{Análise dos Fatores Internos}

\section{A. Força}

\section{$\checkmark \quad$ Atendimento à Instrução Normativa $n^{\circ}$ 01/2010 do MPOG}

A Instrução Normativa $n^{\circ}$ 01/2010 do MPOG, apoiada pelas leis que regulamentam as contratações públicas sustentáveis, é agente estimulador da inserção de critérios de sustentabilidade em requisitos para a aquisição de itens, serviços ou obras pelo Governo, agregando valores sustentáveis aos bens adquiridos.

Como fator verificador do incentivo provocado pela Instrução Normativa, pode-se avaliar os dados disponibilizados no informativo sustentável divulgado pelo MPOG (2014), com dados extraídos do Portal de Compras do Governo Federal que participa que as compras públicas sustentáveis feitas no primeiro trimestre de 2014 representaram $0,06 \%$ das licitações públicas, movimentando R \$ 7,9 milhões na aquisição de bens. Na comparação desse período com o ano de 2013, verifica-se um crescimento de $66 \%$ nas aquisições sustentáveis do governo federal. O mesmo informativo acrescenta que de 2010 até 2013 as contratações sustentáveis tiveram crescimento de $200 \%$, passando de $\mathrm{R} \$ 13,5$ milhões para $\mathrm{R} \$ 40,4$ milhões.

O informativo do MPOG relata, conforme discriminado nas tabelas 22 e 23 que os materiais mais licitados são os vinculados a materiais de escritório. Em relação aos materiais de Tecnologia de Informação (TI), os equipamentos mais adquiridos são os computadores pessoais. 
Tabela 21 - Relação de materiais sustentáveis mais licitados por órgãos públicos, em porcentagem

\begin{tabular}{|l|r|}
\hline \multicolumn{1}{|c|}{ Descrição do Material } & $\%$ \\
\hline Papel A4 & 31 \\
\hline Aparelho de Ar Condicionado & 16 \\
\hline Copo descartável & 12 \\
\hline Detergente & 9 \\
\hline Caneta esferográfica & 4 \\
\hline Outros & 28 \\
\hline
\end{tabular}

Fonte: Comprasnet-janeiro a março(MPOG, 2014)

Tabela 22 - Relação de materiais sustentáveis mais licitados por órgãos públicos, em reais

\begin{tabular}{|l|c|}
\hline \multicolumn{1}{|c|}{ Descrição do Material } & R\$ \\
\hline Papel A4 & $2.806 .446,71$ \\
\hline Aparelho de Ar Condicionado & $1.060 .185,00$ \\
\hline Microcomputador pessoal & $1.053 .406,75$ \\
\hline Caneta esferográfica & $516.796,00$ \\
\hline Limpador base ácida & $397.496,10$ \\
\hline Outros & $2.018 .282,38$ \\
\hline
\end{tabular}

Fonte: Comprasnet-janeiro a março (MPOG, 2014)

Pelos dados acima disponibilizados pode-se observar que as leis ambientais foram vitais para promover o incentivo à aquisição de itens ambientalmente amigáveis, inclusive para os EEE.

\section{$\checkmark \quad$ Engajamento aos anseios nacionais à proteção ambiental visando a redução do potencial de intoxicação humana devido ao manuseio de EEE e à redução de substâncias tóxicas lançadas no meio ambiente.}

Embora o Brasil esteja legislando em favor da proteção do meio ambiente e da saúde humana, principalmente em relação ao descarte de resíduos, a prevenção, ainda é a melhor alternativa para a proteção. Neste sentido, a Diretiva $R o H S$, não regulamentada no Brasil, permite um controle eficaz conforme verificado no relatório final $\mathrm{N}^{\circ}$ 30-CE-0095296/00-09 (Bogaert et al., 2008) que conclui que a adoção da Diretiva RoHS na fabricação de equipamentos eletroeletrônicos reduz a quantidade de substâncias tóxicas disponibilizadas no meio ambiente. Conforme este relatório, é estimado que anualmente a quantidade de substâncias tóxicas não dispostas no meio ambiente, após a adoção da Diretiva $R o H S$ pela UE, é de 89800 toneladas de chumbo, 12600 toneladas de Octa-BDE, 4300 toneladas de cádmio e 22 toneladas de mercúrio. Percentualmente, 20\% de mercúrio, 56\% de Cádmio, $59 \%$ de chumbo, $68 \%$ de Octa-BDE e $71 \%$ de cromo (VI) não são lançados no meio 
ambiente (do total das substâncias RoHS presentes nos produtos selecionados para a análise da Diretiva: refrigeradores, PCs, Laptops, impressoras, copiadoras, celulares, televisões, relógios, lâmpadas fluorescentes, vídeo games e vídeo games portáteis).

O mesmo relatório estima que o impacto da Diretiva em termos da quantidade relativa evitada em relação ao potencial de toxidade humana, tendo como referência a quantidade total de substâncias antes da $R o H S$ nos equipamentos analisados acima detalhados é de $100 \%$ para Cr (VI), $85 \%$ para chumbo, $82 \%$ para cádmio e $27 \%$ para o mercúrio, sendo aproximadamente $70 \%$ das substâncias no total. Os dados acima detalhados corroboram o alto nível de proteção ambiental alcançados com a adoção da Diretiva $R o H S$, principalmente na salvaguarda da saúde humana. Neste sentido, o Brasil alinhando-se à Diretiva estará protegendo o meio ambiente e a saúde de sua população.

\section{B. Fraqueza}

\section{Falta de conhecimento e dificuldades em entender à Diretiva $R o H S$ e Gasto com treinamento, obtenção de informação e certificação de produtos na fase inicial da implantação da Diretiva}

A Diretiva $R o H s$ não é de fácil entendimento. Inclui várias exceções, tendo sido atualizada em 2011 e em 2015.

O desconhecimento da Diretiva RoHS na área de Defesa está vinculado ao fato dos equipamentos militares constarem das exceções da Diretiva. Entretanto, das exceções constam equipamentos de uso estritamente militar como os armamentos e sistemas táticos. Porém, equipamentos de uso dual, utilizados tanto para fins militar quanto para finns civis são cobertos pela Diretiva. As exceções da Diretiva são, reconhecidamente, fator predominante das dificuldades de entendimento da norma. Existem várias exceções na Diretiva, que devem ser analisadas para o bom entendimento da mesma. Algumas exceções têm datas limite para serem extintas, conforme detalhado no item 3.1.1 e 3.1.3 deste estudo.

O custo maior na adoção da Diretiva RoHS recai sobre obtenção de informações referentes à Diretiva e ao treinamento de pessoal, além dos gastos com 
a certificação dos produtos. Mais de $90 \%$ dos recursos destinados à treinamento e coleta de dados são gastos com pessoal. (Bogaert et al., 2008).

O investimento inicial com treinamento de pessoal, coleta e revisão de dados, análise de exceções e perdas financeiras para atendimento à Diretiva RoHS é de $67 \%$ do custo total da adequação à Diretiva, sendo $33 \%$ destinados à adequação técnica. Os custos com a certificação do produto estão no montante dos gastos dedicados ao atendimento técnico da norma (Bogaert et al. 2008).

Das Diretivas RoHS mundiais analisadas, a Diretiva RoHS China é a mais difícil, e a mais cara para ser implementada (Gordon et al., 2008)

Pelo o acima exposto, é fato que a adequação à Diretiva $R o H S$ poderá acarretar em aumento no preço final do produto a ser adquirido, bem como de EEE em desenvolvimento que deverão ser certificados.

Desta maneira, o alinhamento à RoHS custará à Organização Militar despesas com treinamento de pessoal, obtenção de informação e com cerificação de produtos.

\section{- Diretiva não regulamentada no país.}

Embora, conforme apresentado no capítulo 2 deste estudo, o Brasil possua legislação ambiental dedicada a vários setores, abrangendo inclusive restrição à substância constante da Diretiva $R o H S$, como o mercúrio, não existe legislação ambiental brasileira específica dedicada à restrição de substâncias tóxicas existentes em EEE.

A Diretiva $R o H S$ é regulamentada pela UE, não tendo força de lei em território nacional. Embora a IN 01/2010 determine atendimento à Diretiva RoHS, não existem referências legais que permitam a exigência de cumprimento ao determinado pela $R o H S$ pelas empresas brasileiras.

As empresas brasileiras, visando acompanhar a tendências nacional ao consumo sustentável, vêm tentando se adaptar às exigências da Diretiva, harmonizando seus produtos à RoHS, aspirando, inclusive, à inserção de seus produtos no Mercado Comum Europeu.

Conforme Ansanelli (2008, p.20), "[ ] caso a exigência ambiental constitua um padrão de produto internacionalmente aceito, haverá impactos nos fluxos de comércio que podem ser positivos ou negativos, dependendo dos custos da adequação". Neste sentido, é essencial que as empresas brasileiras se adaptem às exigências da Diretiva RoHS para que possam competir no mercado nacional e internacional. 


\section{4 \\ Fatores Condicionantes (FC)}

Para definição das linhas de ação a serem analisadas faz-se necessário analisar os fatores condicionantes ao problema em análise.

Fatores condicionantes são fatores relevantes e pertinentes, relacionados diretamente ao problema e que influenciam na solução do problema. Alguns fatores já foram mencionados e analisados na tabela SWOT, quando da análise do cenário para a adoção da Diretiva $R o H S$.

Foram identificados os seguintes fatores condicionantes à adoção da Diretiva RoHS:

\section{$\checkmark \quad$ Atendimento às legislações ambientais}

A legislação considerada neste estudo inclui as normas nacionais e internacionais ambientais analisadas nos capítulos 2 e 3, destacando-se a Lei dos Resíduos Sólidos, a Instrução Normativa $\mathrm{N}^{\circ} 01$ de 2010 do MPOG e a Diretiva RoHS. Foi levada em consideração a Política Governamental para contratações Públicas Sustentáveis através da Lei 12.349/2010 e o Guia Prático da CJU/SP/2013.

\section{$\checkmark$ Características técnicas de equipamentos em uso na MB}

Os equipamentos em uso na $\mathrm{MB}$ são adquiridos conforme especificações técnicas elaboradas por Diretorias Especializadas. As especificações incluem características técnicas, funcionais e operativas, as quais devem ser atendidas pelos equipamentos a serem adquiridos.

\section{$\checkmark$ Fabricantes de EEE RoHS}

Para o desenvolvimento deste estudo foram pesquisadas pela web possíveis empresas fornecedoras de equipamentos que atendam a Diretiva $R o H S$ nas áreas em análise. Foram verificadas as empresas Furuno, Northrop Grumman, Sagem, IXsea, a Raytheon Anschütz e a Marine Data Systems.

\section{$\checkmark$ Confiabilidade técnica}

A substituição do mercúrio por outros metais nas ligas de solda, devido à restrição imposta pela Diretiva RoHS tem levantado questionamentos quanto à confiabilidade técnica dos EEE, principalmente quanto ao uso de ligas sem chumbo 
na indústria produtoras de eletroeletrônicos. No momento, várias ligas, com diferentes substâncias, estão sendo testadas sendo que algumas já estão no mercado.

\subsection{1.}

\section{Análise dos fatores condicionantes}

\section{$\checkmark$ Atendimento às legislações ambientais}

Dentre as legislações nacionais e internacionais estudadas destacamos a Diretiva $R o H S$ europeia que veio como resposta ao desenvolvimento sustentável proposto, atuando na prevenção do dano ambiental ocasionado pelo tipo de resíduo sólido urbano que mais cresce no mundo: o resíduo eletrônico. A Diretiva RoHS reconhece a necessidade do controle de substâncias nocivas em EEE.

A Lei Nacional dos Resíduos Sólidos determina a adoção de tecnologias limpas e de insumos de menor agressividade ao meio ambiente, indo de encontro das recomendações das Diretivas RoHS e WEEE.

A Instrução Normativa $N^{\circ}$ 01/2010 (MPOG, 2010) determina a inclusão de critérios ambientais na aquisição de bens na Administração Pública Federal, recomenda explicitamente o atendimento a Diretiva. Sendo os critérios ambientais fator de ponderação na classificação e aceitação das propostas para aquisição de bens e serviços.

Ratificando a inclusão de critérios de sustentabilidade ambiental em aquisições públicas, a Lei Federal 12.349 (Brasil, 2010) define como não restritivo ao princípio constitucional da isonomia nas contratações públicas, a inclusão de critérios de desenvolvimento sustentável nas licitações públicas.

Portanto, a inclusão de critérios de sustentabilidade ambiental para aquisição de Bens por Órgãos Públicos é legalmente correta e incentivado pelo Poder Público.

\section{$\checkmark$ Características técnicas de equipamentos em uso na MB}

A Marinha utiliza vários modelos de equipamentos nas áreas de navegação, de acústica e de detecção radar em seus meios. Grande parte dos equipamentos são itens de "prateleira", ditos comerciais, isto é, equipamentos não dedicados, que utilizam itens COTs. As características técnicas de equipamentos em uso na MB 
servirão de referência para a análise da viabilidade técnica em atendimento à Diretiva RoHS.

As tabelas 23 a 27 apresentam características técnicas padrão mínimas para os equipamentos Electronics Chart Display System (ECDIS), Global Position System (GPS), radar de navegação, giro satélite e repetidoras digitais, respectivamente, que devem ser atendidas em caso de aquisição de EEE das áreas em estudo.

Tabela 23 - Características Técnicas de um ECDIS

\begin{tabular}{|c|l|}
\hline Parâmetro & \multicolumn{1}{|c|}{ Característica } \\
\hline Função & $\begin{array}{l}\text { Apresentação de informação de sensores, como os de navegação, } \\
\text { radar e AIS para auxílio à navegação, além de informações de } \\
\text { alvos detectados, sobre cartas de navegação digitais para } \\
\text { compilação de dados de navegação. }\end{array}$ \\
\hline Padrão da carta digital & Raster, S57, S63 \\
\hline Interface & RS 422, NMEA 0183 \\
\hline Dimensão monitor & $19 *$ mínimo \\
\hline Modos de apresentação & Verdadeira, Relativa \\
\hline Informações & Acompanhamento de alvos, curso e rota do navio, alarmes, \\
disponibilizadas & derrota estimada, homem-ao-mar, marcação do navio, posição. \\
\hline Integração & Agulha giroscópica, hodômetro, AIS, radar e GPS \\
\hline
\end{tabular}

Fonte: autor, a partir de dados disponibilizados no site da empresa Furuno Japão.

Tabela 24 - Características Técnicas de um GPS

\begin{tabular}{|c|l|}
\hline Parâmetro & \multicolumn{1}{|c|}{ Característica } \\
\hline Função & $\begin{array}{l}\text { Apresentação de informação de posicionamento geográfico do } \\
\text { navio. }\end{array}$ \\
\hline Precisão & $10 \mathrm{~m}, 5 \mathrm{~m}$ com DGPS \\
\hline Canais & 12 canais de satélite \\
\hline Interface & RS 422, NMEA 0183 \\
\hline Dimensão monitor & $4,5 \%$ mínimo \\
\hline Frequência & $1.575,42$ MHz \\
\hline Informações & Marcação, balanço, caturro, latitude, longitude, velocidade. \\
\hline disponibilizadas & \\
\hline
\end{tabular}

Fonte: autor, a partir de dados disponibilizados no site da empresa Furuno Japão. 
Tabela 25 - Características Técnicas de um Radar de navegação

\begin{tabular}{|c|l|}
\hline Parâmetro & \multicolumn{1}{c|}{ Característica } \\
\hline Potência & Depende de requisitos operativos. \\
\hline Alcance & Variável, depende da potência. \\
\hline Função & $\begin{array}{l}\text { Posição do navio e distância e marcações em relação às outras } \\
\text { embarcações. }\end{array}$ \\
\hline Interface & NMEA 0183 \\
\hline Dimensão monitor & Mínimo 4" LCD. \\
\hline Modos de apresentação & Vídeo Radar \\
\hline Informações & Dados de Navegação, velocidade e curso. \\
\hline disponibilizadas & \\
\hline Frequência de operação & 8 a 12 GHz (Banda X) \\
\hline
\end{tabular}

Fonte: autor, a partir de dados disponibilizados no site da empresa Furuno Japão.

Tabela 26 - Características Técnicas de uma Giro-Satélite

\begin{tabular}{|c|c|}
\hline Parâmetro & Característica \\
\hline Função & $\begin{array}{l}\text { Apresentação de informação de marcação do meio utilizando } \\
\text { dados satélite. }\end{array}$ \\
\hline Precisão & $10 \mathrm{~m}, 5 \mathrm{~m}$ com DGPS \\
\hline Canais & 12 canais de satélite \\
\hline Interface & RS 422, NMEA 0183 \\
\hline Dimensão monitor & 4,5”'“ mínimo \\
\hline Frequência & $1.575,42 \mathrm{MHz}$ \\
\hline $\begin{array}{c}\text { Informações } \\
\text { disponibilizadas }\end{array}$ & Marcação, balanço, caturro, latitude, longitude, velocidade. \\
\hline Modos de Apresentação & Navegação, manobra e rosa dos ventos \\
\hline
\end{tabular}

Tabela 27-Características Técnicas de uma Repetidora Digital

\begin{tabular}{|c|l|}
\hline Parâmetro & \multicolumn{1}{|c|}{ Característica } \\
\hline Função & $\begin{array}{l}\text { Apresentação de informação dos sensores, como os de } \\
\text { navegação, radar e acústica. }\end{array}$ \\
\hline Interface & RS 422, NMEA 0183 \\
\hline Dimensão monitor & $4,5^{*}$ mínimo \\
\hline Integração & Agulha giroscópica, hodômetro, AIS, radar e GPS \\
\hline
\end{tabular}

Fonte: autor, a partir de dados disponibilizados no site da empresa Furuno Japão. 


\section{$\checkmark$ Fabricantes de EEE RoHS}

Foram verificadas as páginas na WEB de prováveis empresas fornecedoras de equipamentos que atendam à Diretiva RoHS nas áreas de interesse da Marinha. Foram verificadas as empresas Furuno (www.furunousa.com), Northrop Grumman (www.northropgrumman.com), Sagem (www.sagem.com), IXsea (www.ixsea.com), Raytheon Anschütz (www.raytheon-anschuetz.com) e Marine Data Systems (www.marine-data.co.uk).

Dentre as empresas verificadas, as empresas Sagem, IxSea and Northrop Grumman não disponibilizam em suas páginas na web dados quanto ao comprometimento em relação a critérios de sustentabilidade na produção e comercialização de seus produtos.

A empresa Raytheon Anschütz afirma atendimento à Diretiva REACH (EU, 2006), e informa que embora não seja afetado pela Diretiva RoHS por produzir equipamentos de navegação, declara que um terço dos produtos vendidos pela empresa já atendem à Diretiva. Como exemplo, pode-se mencionar as agulhas giroscópicas da Anchütz que são fabricadas sem mercúrio há 100 anos. "Green passaports", certificados de conformidade ambiental, são disponibilizados se requisitados.

A empresa Furuno declara em sua página na web que se empenha em assegurar que seus produtos atendam a Diretiva RoHS. Quando confirmado, uma declaração de conformidade é disponibilizada na página dedicada ao produto na página na WEB da empresa (anexos 01 e 02). Além disso, a empresa Furuno através do documento "Green Procurement Standards for parts and materials" (Furuno, 2014) apresenta os critérios ambientais para a produção de EEE ambientalmente amigáveis.

A empresa Marine Data Systems, fabricante de equipamentos da área de navegação, apresenta em sua página na WEB produtos que atendem à Diretiva RoHS.

Pelo exposto, pode-se observar a limitação, mesmo no mercado internacional, de empresas que forneçam EEE nas áreas em análise. No Brasil, não foram identificadas empresas que forneçam EEE nas áreas em análise com critérios ambientais. 


\section{$\checkmark$ Confiabilidade técnica}

A principal dúvida técnica identificada face às restrições impostas pela Diretiva $R o H S$, durante este estudo, foco de preocupação de usuários de sistemas digitais da área de Defesa, foi quanto à restrição ao uso de chumbo nas ligas de solda para aplicação em eletrônica. O chumbo é utilizado nas soldas tradicionais na proporção de $63 \%$ e $37 \%$ (63Sn 37Pb) ou $62 \% \mathrm{Sn} 36 \% \mathrm{~Pb} 2 \% \mathrm{Ag}$ (62 Sn 36Pb $2 \mathrm{Ag}$ ), sendo $\mathrm{Sn}, \mathrm{Pb}$ e $\mathrm{Ag}$ as siglas para estanho, chumbo e prata, respectivamente.

Com a implementação da Diretiva $R o H S$, o chumbo não foi banido apenas das ligas de soldas. As placas de circuito integrado (PCI) tiveram que ter sua metodologia de acabamento reavaliada para atender à Diretiva. As trilhas de cobre necessárias à interligação dos vários componentes das placas, que eram protegidas contra oxidação com uma camada da liga SnPB, tiveram que ser alteradas.

A maior preocupação do banimento do chumbo das ligas de solda é a formação da migração eletroquímica visualizada nas figuras 8 e 9 .

Conforme Mendes (2009, p.V):

"O processo de migração eletroquímica ocorre quando temos metal, isolante e metal, em ambientes de alta umidade sobre polarização elétrica, o metal deixa a posição inicial em forma de ions e se deposita sobre o isolante. Em uma placa de circuito impresso, dois terminais adjacentes podem tornar-se eletrodos, dessa forma dendritos crescem do catodo para o anodo. Podem aparecer diferentes morfologias com diferentes elementos envolvidos no processo de migração, dependendo da composição da pasta de solda ou acabamento da placa de circuito impresso."

As dimensões de um filamento decorrente de formação de migração eletrônica são da ordem de $1 \mu \mathrm{m}$. (NASA, 2015). 


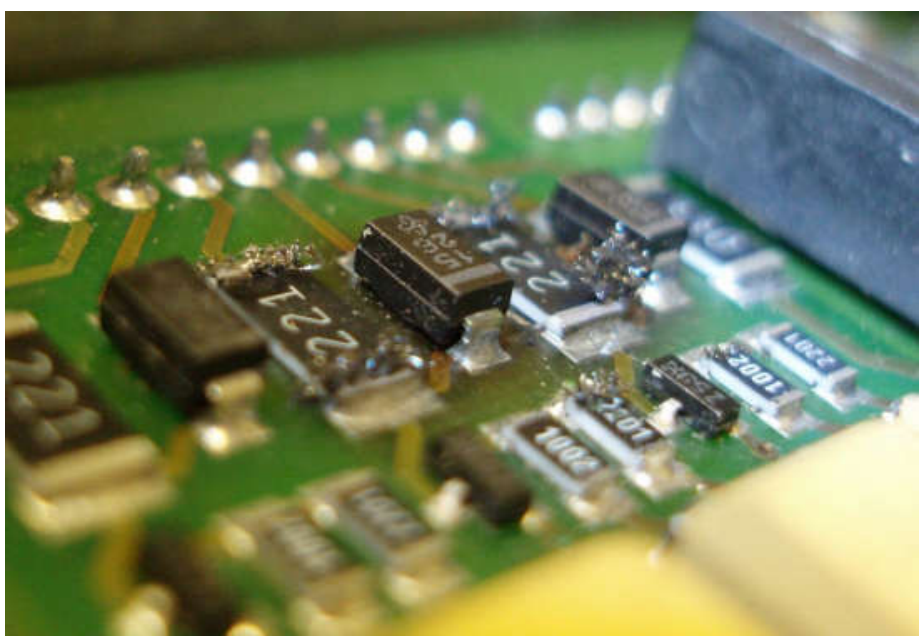

Figura 8: Apresentação de formação de migração eletrônica. Fonte: wikipedia, 2015.

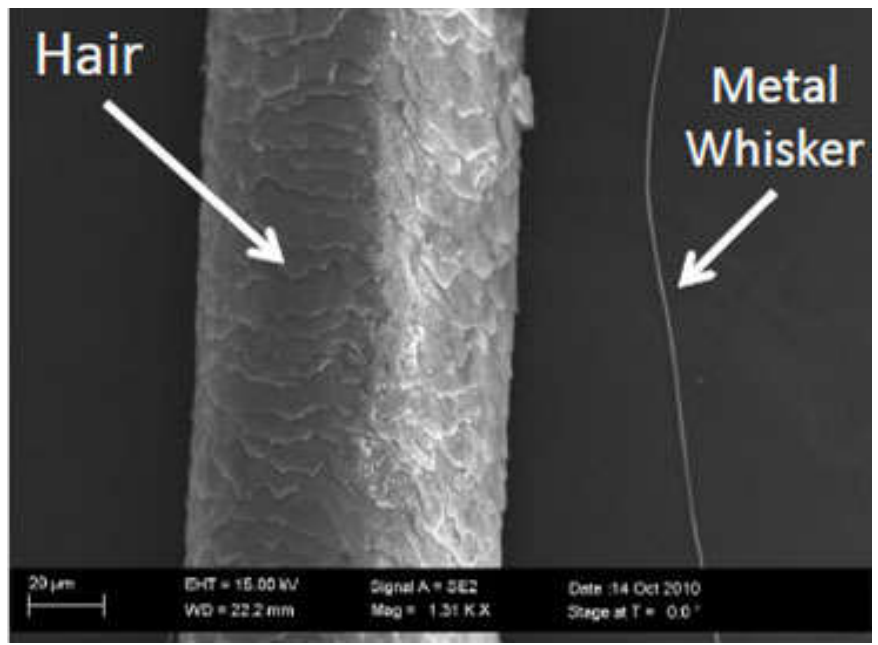

Figura 9: apresentação das dimensões de um filamento decorrente de migração eletrônica frente a um fio de cabelo Fonte: NASA, 2015.

Historicamente, a migração eletrônica das soldas de estanho foi mitigada com a adição de chumbo ao processo de galvanização do estanho. Desde então, a liga $\mathrm{SnPb}$ ou $\mathrm{SnPbAG}$, apresenta excelente produto final, utilizada com sucesso pela indústria eletrônica.

A liga $63 \mathrm{Sn} 37 \mathrm{~Pb}$ apresenta baixo ponto de fusão, $183^{\circ} \mathrm{C}$, boa resistência mecânica e ótima molhabilidade (habilidade de um líquido em manter contato com uma superfície sólida) e agrega maior confiabilidade aos EEE Perassi (1994) apud Almeida et al (2013). Em contrapartida, as novas ligas de solda apresentam temperatura de fusão maior do que das ligas tradicionais consumindo mais energia. Devido aos novos pontos de fusão das ligas de soldas, os componentes eletrônicos devem suportar temperaturas de até $40^{\circ} \mathrm{C}$ maiores do que suas temperaturas típicas 
atuais. A tabela 28 apresenta algumas ligas de solda sem chumbo e suas temperaturas de fusão.

Algumas empresas já se adaptaram às novas exigências ambientais e disponibilizam no mercado soldas sem chumbo. Como exemplo de ligas de solda disponibilizadas no mercado, a tabela 29 apresenta alguns tipos de soldas sem chumbo comercializadas pela empresa Indium Corporation (2015) disponibilizadas no site da empresa.

Tabela 28 - Composição de soldas sem chumbo.

\begin{tabular}{|c|c|c|}
\hline Liga & Composição & $\begin{array}{l}\text { Temperatura de } \\
\text { fusão }\left({ }^{\circ} \mathrm{C}\right)\end{array}$ \\
\hline $\begin{array}{l}\text { Estanho-cobre } \\
(\mathrm{SnCu})\end{array}$ & $99.2 \mathrm{Sn} 0,8 \mathrm{Cu}$ & 227 \\
\hline $\begin{array}{l}\text { Bismuto-Estanho- } \\
\text { Prata (BSA) }\end{array}$ & 57Bi $42 \mathrm{Sn} 1.0 \mathrm{Ag}$ & 138 \\
\hline $\begin{array}{l}\text { Estanho-prata- } \\
\text { cobre (SAC) }\end{array}$ & $95,5 \mathrm{Sn} 3,9 \mathrm{Ag} 0,6 \mathrm{Cu}$ & 218 \\
\hline $\begin{array}{l}\text { Estanho-prata- } \\
\text { bismuto-cobre } \\
\text { (SABC) }\end{array}$ & $96 \mathrm{Sn} 2,5 \mathrm{Ag} 1,0 \mathrm{Bi} 0,5 \mathrm{Cu}$ & 215 \\
\hline
\end{tabular}

Fonte: adaptada de US EPA, (2005) apud Bogaert et al. (2008, p. 85)

Segundo Almeida et al. (2013) com a produção de liga de solda livre de chumbo haveria redução de aproximadamente $85 \%$ nos gastos com a saúde humana e com hospitalizações, tendo como base a produção de $946 \mathrm{t}$ de solda tradicional produzida pela empresa Cast Metais por ele estudada (Almeida et al., 2013). Analisando o ciclo de vida da produção das soldas, com e sem chumbo, Almeida et al (2013) concluiu que a cadeia produtiva das soldas livres de chumbo é menos eficiente em relação aos recursos naturais não renováveis e danos à saúde humana na etapa de extração do minério. Entretanto, na etapa de manufatura a liga de solda sem chumbo é mais benéfica em relação à saúde humana. $\mathrm{O}$ indicador da redução da expectativa de vida, anos perdidos por inaptidão ou por morte prematura (Daly -Disability Adjusted Life Years) é de 2,9 anos para soldas com chumbo e de 0,4 anos para as soldas livres de chumbo.

No estudo da Bogaert et al. (2008) são apresentados os resultados do impacto do ciclo de vida das ligas de solda sem chumbo, tendo como referência a solda $\mathrm{SnPb}$. Foram verificadas várias categorias de impactos ambientais e impactos sobre 
a saúde humana. Das ligas sem chumbo estudadas, a BSA foi a que apresentou melhor impacto sobre a saúde humana e o meio ambiente. Para Almeida et al. (2013) os grandes fabricantes de EEE (UE e Japão) decidiram pela solda mais antropocêntrica, ou seja, pela preservação da saúde humana em detrimento à preservação de recursos minerais não renováveis.

Tabela 29 - Relação de ligas de soldas sem chumbo produzidas pela empresa Indium Corporation.

\begin{tabular}{|c|c|c|}
\hline Solda & Composição & Ponto de Fusão $\left({ }^{\circ} \mathrm{C}\right)$ \\
\hline InSn & $\mathrm{InSn} 52.0 \mathrm{In} / 48.0 \mathrm{Sn}$ & 118 \\
\hline $\mathrm{BiSn}$ & $58.0 \mathrm{Bi} / 42.0 \mathrm{Sn}$ & 138 \\
\hline BiSnAg & $57.0 \mathrm{Bi} / 42.0 \mathrm{Sn} / 1.0 \mathrm{Ag}$ & 140 \\
\hline Indalloy 254 & $86.9 \mathrm{Sn} / 10 \mathrm{In} / 3.1 \mathrm{Ag}$ & 205 \\
\hline $\mathrm{SnBiAg}$ & $91.8 \mathrm{Sn} / 4.8 \mathrm{Bi} / 3.4 \mathrm{Ag}$ & 213 \\
\hline SAC405 & $95.5 \mathrm{Sn} / 4.0 \mathrm{Ag} / 0.5 \mathrm{Cu}$ & 218 \\
\hline SAC387 & $96.5 \mathrm{Sn} / 3.8 \mathrm{Ag} / 0.7 \mathrm{Cu}$ & 219 \\
\hline SAC305 & $96.6 \mathrm{Sn} / 3.0 \mathrm{Ag} / 0.5 \mathrm{Cu}$ & 220 \\
\hline $\mathrm{SACm}^{\mathrm{TM}}$ & $98.5 \mathrm{Sn} / 0.5 \mathrm{Ag} / 1.0 \mathrm{Cu}+\mathrm{Mn}$ & 225 \\
\hline SAC0307 & $99.0 \mathrm{Sn} / 0.3 \mathrm{Ag} / 0.7 \mathrm{Cu}$ & 227 \\
\hline $\mathrm{SnCu}$ & $99.3 \mathrm{Sn} / 0.7 \mathrm{Cu}$ & 227 \\
\hline Sn992 & $99.2 \mathrm{Sn} / 0.5 \mathrm{Cu}+\mathrm{Bi}+\mathrm{Co}$ & 227 \\
\hline "J" alloy & $65.0 \mathrm{Sn} / 25.0 \mathrm{Ag} / 10.0 \mathrm{Sb}$ & 223 \\
\hline Indalloy133 & $95.0 \mathrm{Sn} / 5.0 \mathrm{Sb}$ & 240 \\
\hline Indalloy 259 & $90.0 \mathrm{Sn} / 10.0 \mathrm{Sb}$ & 272 \\
\hline
\end{tabular}

Fonte:Dados obtidos da página na WEB da empresa Indium Corporation,2015. (tabela adaptada)

Vários pesquisadores consideram importante analisar o ciclo de vida das soldas sem chumbo com outros metais, para uma avaliação mais precisa quanto ao impacto final do banimento do chumbo das ligas de solda. Na literatura específica há avaliações complementares e antagônicas quanto a utilização, ou não, de chumbo nas ligas de solda a serem utilizadas em EEE.

Alguns estudos mencionam que as soldas sem chumbo são mais seguras em termos de toxidade e impacto ambiental. (Ku, (2003) apud Almeida et al. (2013). Outros questionam o quanto efetivo é o banimento de chumbo em ligas de solda, conforme Itsubo et al. (2003) apud Almeida et al. (2013), que calcula que para cada quilo de solda produzida são necessários apenas 0,68 gramas do metal. 
O estudo de Almeida e al. (2013) sobre os efeitos na saúde do trabalhador, e no meio ambiente, decorrente da substituição das soldas de estanho-chumbo por outras conclui, mediante cálculo de emergia ${ }^{1}$ de 3 tipos diferentes de solda (63Sn $37 \mathrm{~Pb}, 96,5 \mathrm{Sn} 3 \mathrm{Ag} 0,5 \mathrm{Cu}$ e $99 \mathrm{Sn} 0,3 \mathrm{Ag} 0,7 \mathrm{Cu}$ ) fabricadas pela empresa brasileira Cast Metais e Soldas Ltda, que mais recursos são utilizados para produzir uma tonelada de solda livre de chumbo do que para produzir a tradicional solda estanhochumbo. Em seu artigo Almeida et al. (2013, p.52) informa que "no total do ciclo de vida, as fabricações de soldas livres de chumbo consomem 3,2 vezes mais recursos não renováveis que a solda tradicional que contém chumbo”.

O Japão foi o país pioneiro em estudos para obtenção de soldas livres de chumbo. Estabeleceu extensa rede de colaboradores, tanto no meio acadêmico, quanto no setor industrial e no setor público, promovendo, e incentivando, a inovação tecnológica. A bem-sucedida parceria, e os bons resultados obtidos pelo Japão influenciaram a elaboração das medidas restritivas ao uso de chumbo em EEE impostas pela Diretiva RoHS (Masaru, 2006). As figuras 10 e 11 apresentam, respectivamente, os levantamentos realizados por Masaru (2006) das patentes americanas e dos artigos técnicos sobre liga de solda sem chumbo registrado e publicado nos Estados Unidos, Japão e Europa.

Pelas figuras 10 e 11 observa-se que o pico de inovação indicado pela quantidade de patentes registradas, e artigos científicos publicados, foi antes da entrada em vigor da Diretiva RoHS.

${ }^{1}$ Emergia - energia necessária para que um ecossistema possa produzir um recurso. 


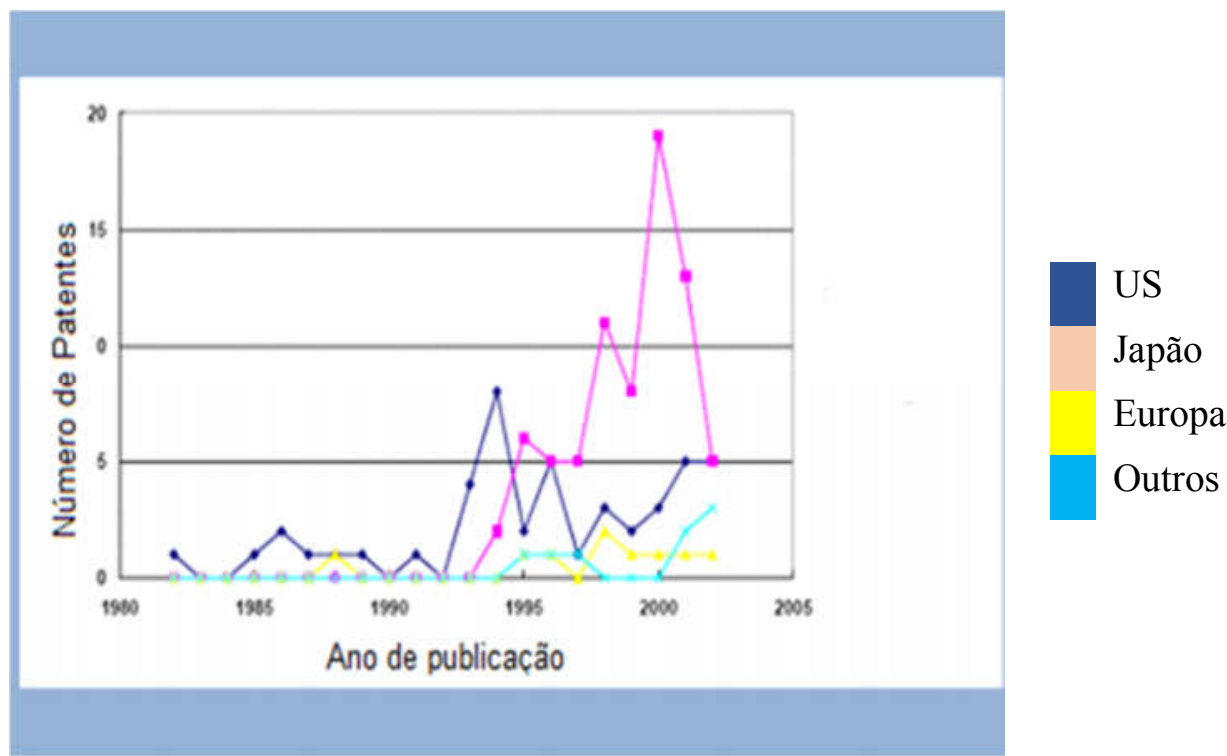

Figura 10 - Patentes americanas de soldas livres de chumbo registradas nos Estados Unidos, Japão e Europa.

Fonte: Masaru (2006).

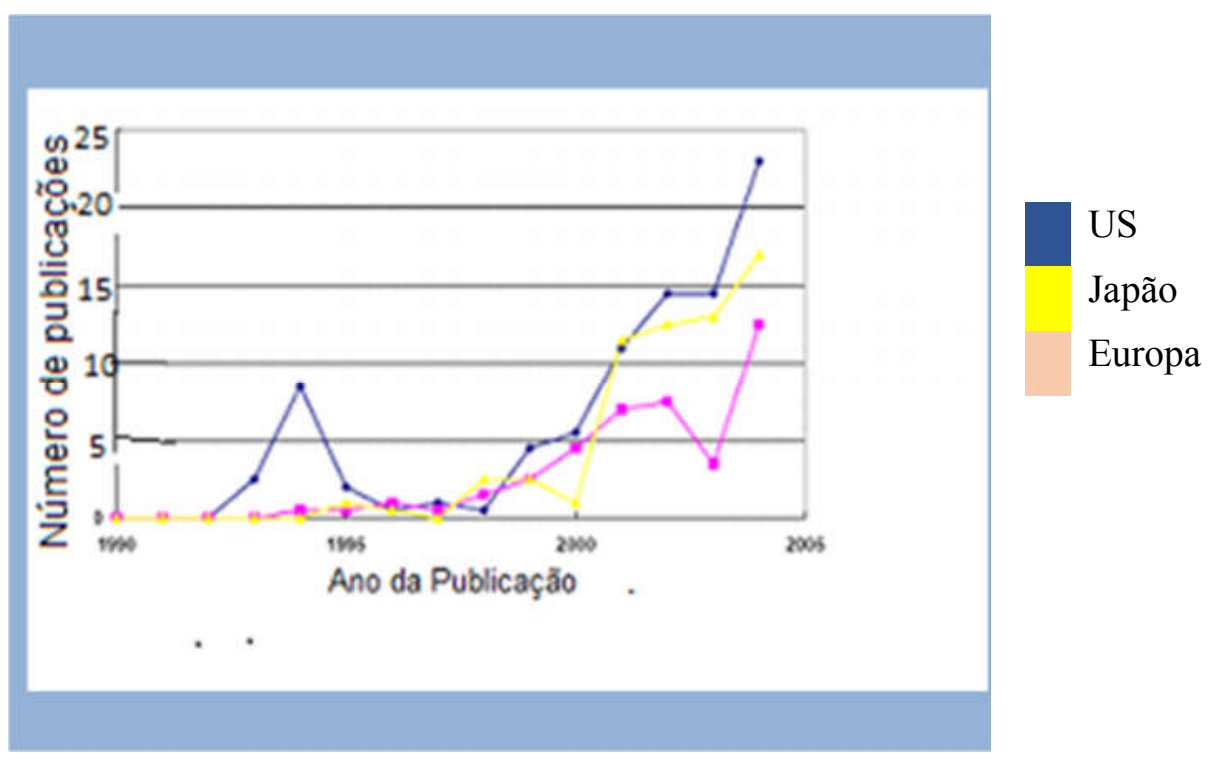

Figura 11 - Artigos científicos sobre solda livre de chumbo publicado nos Estados Unidos, Europa e Japão (1990 - 2004).

Fonte: Masaru (2006).

Embora a exclusão do chumbo das ligas de solda seja motivo de dúvidas e preocupações, principalmente na área de Defesa, empresas já fabricam equipamentos que atendem plenamente à Diretiva $R o H S$, inclusive com ligas de solda sem chumbo. 
5

Avaliação de propostas para adoção da Diretiva RoHS

As propostas cogitadas para verificar a viabilidade técnica e econômica da adoção de EEE que possuam critérios de sustentabilidade ambiental RoHS por Organização Militar da Marinha do Brasil, na aquisição de equipamentos de uso dual (civil e militar), foram:

\author{
A) Desenvolvimento de EEE com critérios da Diretiva RoHS no Brasil; \\ B) Aquisição de EEE com os critérios da Diretiva $R o H S$ no mercado \\ internacional.
}

5.1.

Desenvolvimento de EEE com os critérios da Diretiva RoHS no Brasil

Pertinência $-o$ desenvolvimento de EEE que atendam aos requisitos técnicos básicos relacionados no item 4.4.1 e à Diretiva $R o H S$ permitirá que sejam avaliadas as viabilidades técnicas e econômicas de EEE que atendam à critérios de sustentabilidade, sendo possível, posteriormente, verificar as respostas operacionais. Portanto esta linha de ação é pertinente.

\title{
Integridade
}

$\checkmark$ Atingimento $-\mathrm{o}$ desenvolvimento de EEE também permitirá a verificação da viabilidade técnica e econômica da inclusão dos critérios de sustentabilidade mediante a adoção da Diretiva RoHS pela Organização Militar da MB. Portanto, atinge o objetivo deste estudo.

$\checkmark$ Fidelidade - como o item atingimento, o desenvolvimento de EEE permitirá que a viabilidade técnica e econômica da adoção da Diretiva RoHS, seja verificada. Neste sentido, a linha de ação é fiel à proposta.

$\checkmark$ Condicionamento -Os EEE a serem desenvolvidos deverão atender aos requisitos mínimos listados no item 4.4.1, exceto pelos fabricantes de EEE RoHS não pertinente nesta solução. 


\section{Campo da Abordagem}

$\checkmark$ Nível da abordagem - A proposta está inscrita no limite de competência, ou seja, competência técnica da autoridade responsável pela sua execução, a aquisição de EEE das áreas de navegação, acústica e detecção radar.

$\checkmark$ Amplitude da abordagem - A solução visa ratificar que os EEE a serem desenvolvidos podem agregar valores de sustentabilidade ambiental sendo confiáveis técnica e operativamente a um custo justo. Portanto, abrange os aspectos principais a serem verificados.

$\checkmark$ Alcance da Abordagem - Existe compatibilidade entre o nível e a amplitude da abordagem posto que a solução se encontra dentro da competência da Organização Militar responsável pela execução da solução.

$\checkmark$ Oportunidade - Mesmo que a solução seja implementada de imediato, o tempo de desenvolvimento de projetos dos EEE mais o tempo de adequação de componentes à $R o H S$ é considerado demasiadamente longo para uma conclusão que permita avaliar a viabilidade técnica e econômica em atendimento a Instrução Normativa $N^{\circ}$ 01/2010 do MPOG. O estudo de Bogaert et al. (2008) expõe que há empresas que não souberam avaliar o custo em pesquisa e desenvolvimento da implementação de solda sem chumbo, já que o custo do desenvolvimento foi decorrente de 7, ou até 9 anos de desenvolvimento para a adequação de EEE ao determinado pela Diretiva $R o H S$.

Pelo exposto, fica claro que a solução de se adquirir EEE a serem desenvolvidos no Brasil com os critérios da Diretiva RoHS não é oportuna neste momento devido ao tempo estimado para desenvolvimento de EEE que atendam à Diretiva RoHS. Para que seja implementado o determinado pelo MPOG é necessário que a avaliação de viabilidade seja realizada com brevidade para que, no caso de a adoção da Diretiva RoHS ser viável técnica e economicamente, haja, posteriormente, investimentos em desenvolvimento de equipamentos eletroeletrônicos que atendam a Diretiva RoHS.

Concluindo, a solução de Desenvolver no Brasil EEE com os critérios da Diretiva RoHS para verificar a viabilidade técnica e econômica da adoção de critérios de sustentabilidade por Organização Militar da MB é INADEQUADA. 
5.2.

Adquirir EEE com os critérios da Diretiva RoHS no mercado internacional.

Pertinência - existem empresas no mercado internacional que desenvolvem equipamentos de navegação em atendimento RoHS europeia, ou à outras Diretivas semelhantes, como a RoHS Japão. Como exemplo, podemos citar a empresa Furuno fabricante de equipamentos em uso na MB. A empresa é fabricante dos equipamentos que atendem a critérios de sustentabilidade, conforme detalhado na tabela 30. Quando certos do atendimento, emitem certificado com o logo da Comunidade Europeia CE com a declaração de atendimento a Diretiva 2011/65/EU, a Diretiva RoHS.

A empresa Furuno está representada por suas subsidiárias em vários países da Europa, Estados Unidos, Korea, Shangai, Hong Kong e Singapura. No Brasil, o representante técnico da Furuno é a empresa Radiomar (www.radiomar.com.br)

Portanto, a linha de ação proposta de se adquirir EEE com critérios da Diretiva RoHS no mercado internacional é pertinente, pois há no mercado internacional EEE que permitem que sejam verificadas a viabilidade técnica e econômica da adoção de EEE que atendam à Diretiva $R o H S$ pela Organição Militar da MB.

\section{Integridade}

$\checkmark$ Atingimento - a solução proposta atinge ao propósito fixado. Ou seja, o de verificar a viabilidade técnica em adotar-se a Diretiva $R o H S$ na aquisição de equipamentos de navegação de uso dual por Organização Militar da MB. Para exemplificar, equipamento de Navegação Satélite como o GP-150 fabricado pela empresa Furuno, atende às características técnicas detalhadas na tabela 24 e atende à Diretiva RoHS, exceto pela quantidade de chumbo na liga da solda utilizada nas PCI (anexo 03), está instalado em vários meios da MB. O GPS GP-170, substituto do GP-150, já atende plenamente a Diretiva RoHS. 
Tabela 30 - Equipamentos Furuno que atendem à Diretiva RoHS

\begin{tabular}{|c|c|c|c|}
\hline Equipamento & Função & Equipamento & Função \\
\hline FR-8045 & \multirow[t]{3}{*}{ Radar } & GS-100 & Hodômetro Satélite \\
\hline FR-8065 & & PG-500 & \multirow[t]{2}{*}{ Sensor } \\
\hline FR-8125 & & PG-700 & \\
\hline GP-170 & \multirow[t]{7}{*}{ GPS } & FI-150 & $\begin{array}{l}\text { Indicador de } \\
\text { Direção e } \\
\text { intensidade do } \\
\text { Vento }\end{array}$ \\
\hline GP-3500 & & RD-33 & \multirow[t]{11}{*}{ Repetidora } \\
\hline GP-32 & & RD-20 & \\
\hline GP-33 & & RD-50 & \\
\hline GP-330B & & MU-190 & \\
\hline GP-1670 & & MU-190V & \\
\hline GP-1870 & & MU-231 & \\
\hline SC-50 & \multirow[t]{2}{*}{ Giro Satélite } & MU-150 HD & \\
\hline SC-110 & & MU-190 HD & \\
\hline FMD-3100 & \multirow[t]{3}{*}{ ECDIS } & MFD-8 & \\
\hline FMD-3200 & & MFD12 & \\
\hline FMD-3300 & & MFDBB & \\
\hline
\end{tabular}

$\checkmark \quad$ Fidelidade - Foi verificado que existem equipamentos de navegação, embora poucos, que incluam critérios de sustentabilidade em suas características técnicas. Por exemplo, vários equipamentos fabricados pela Furuno agregam valores ambientais em seu desenvolvimento, mediante o determinado pelo documento Green Procurement Standards for Parts and Materials, (Furuno, 2014) que restringe, semelhante a Diretiva $R o H S$, a quantidade das substâncias nocivas em eletroeletrônicos. Portanto, a linha de ação é fiel a proposta do estudo.

$\checkmark$ Condicionamento - A solução atende aos fatores condicionantes listados no item 4.4.1. 


\section{Campo de Abordagem}

$\checkmark \quad$ Nível da abordagem - Como para a solução anterior, esta proposta está inscrita no limite de competência, ou seja, competência técnica da autoridade responsável pela sua execução, a aquisição de EEE por Organização Militar da MB responsável pela aquisição de EEE das áreas de navegação, acústica e detecção radar.

$\checkmark$ Amplitude da abordagem - A solução proposta abrange os aspectos fundamentais do estudo, ratifica a viabilidade técnica na aquisição de EEE que atendam critérios de sustentabilidade RoHS fornecidos por empresas de competência reconhecida no mercado internacional. A solução visa atestar a existência de EEE RoHS sustentáveis disponíveis no mercado internacional.

$\checkmark$ Alcance da Abordagem - conforme abordado na solução anterior, existe compatibilidade entre o nível e a amplitude da abordagem posto que a solução se encontra dentro da competência da Organização responsável pela execução da solução.

$\checkmark$ Oportunidade - Tecnicamente, a execução desta solução pode ser imediata, já que existe empresa que fornece atualmente EEE, e itens de reposição, em atendimento a Diretiva $R o H S$, alguns em uso pela MB. A empresa identificada é capaz de fornecer os seguintes equipamentos com critérios de sustentabilidade: GPS, radar de navegação, repetidoras, ECDIS e giro satélite. A tabela 31 apresenta exemplo de equipamentos que também atendem à Diretiva $R o H S$ fabricados pela empresa Marine Data Systems

Assim, na perspectiva apresentada nos itens acima é correto afirmar que a solução de se adquirir EEE das áreas analisadas no mercado internacional é ADEQUADA. 
Tabela 31 - Exemplo de EEE RoHS fabricados pela empresa Marine-Data Systems

\begin{tabular}{|l|l|}
\hline \multicolumn{1}{|c|}{ Equipamento } & \multicolumn{1}{|c|}{ Descrição } \\
\hline MD 4RDI / MD74RDI/W & $\begin{array}{l}\text { Repetidora com apresentação digital de } \\
\text { indicação de manobras. }\end{array}$ \\
\hline MD77RDI Analogue Rudder Angle Indicator & $\begin{array}{l}\text { Repetidora com apresentação analógica de } \\
\text { indicação de manobras. }\end{array}$ \\
\hline MD77ROT Analogue Rate of Turn Indicator & $\begin{array}{l}\text { Repetidora com apresentação de taxa de } \\
\text { guinada (grau/minuto). }\end{array}$ \\
\hline MD67HR Dial Heading Repeater & Repetidora com indicação de marcação. \\
\hline MD68HR Dial Scale Steering Repeater & Repetidora de indicação de marcação \\
\hline MD77HR Dial Digital Heading Repeater & Repetidora com indicação de marcação. \\
\hline MD71HR Digital Heading Repeater & Repetidora digital de marcação. \\
\hline MD75HR Large Format Digital Heading & $\begin{array}{l}\text { Repetidora com indicação digital de } \\
\text { marcação. }\end{array}$ \\
\hline Repeater & $\begin{array}{l}\text { Repetidora com indicação digital de marcação } \\
\text { com indicação a LED de guinada. }\end{array}$ \\
\hline MDdicator & \begin{tabular}{l} 
Interface sincro-digital. \\
\hline
\end{tabular}
\end{tabular}

Fonte: Autor, baseado nos dados disponibilizados na página na WEB da empresa MarineData (2015).

Alguns equipamentos listados na tabela 30 estão instalados e operando satisfatoriamente em meios da MB. É o caso do equipamento GPS GP-32 que atende as características técnicas da tabela 24, e da agulha satélite SC-50 que atende as características técnicas da tabela 26.

A tabela 32 relaciona os meios e Organizações da MB que possuem equipamentos fabricados pela empresa Furuno que atendem aos critérios de sustentabilidade ambiental da Diretiva RoHS Japão ou à Diretiva RoHS Europeia. 
Tabela 32 Relação de equipamentos Furuno que atendem a critérios de sustentabilidade por meios/OM da MB.

\begin{tabular}{|c|c|}
\hline \multicolumn{2}{|c|}{ GPS GP 32} \\
\hline Monitor "Parnaíba" & Comando da Flotilha da Amazônia 05 \\
\hline $\begin{array}{c}\text { Aviso Transporte Tropas Fluvial } \\
\text { "Piraim" }\end{array}$ & Comando da Flotilha da Amazônia 02 \\
\hline $\begin{array}{l}\text { Navio Assistência Hospitalar } \\
\text { "Tenente Maximiano" }\end{array}$ & Comando da Flotilha da Amazônia 01 \\
\hline Navio Patrulha "Poti" & $\begin{array}{c}\text { Delegacia Capitania dos Portos RJ em } \\
\text { Angra dos Reis }\end{array}$ \\
\hline Navio Patrulha "Pirajá" & Comando da Flotilha do Amazonas \\
\hline Navio Patrulha "Piratini" & $\begin{array}{l}\text { Navio Polar "Almirante } \\
\text { Maximiano" }\end{array}$ \\
\hline Navio Patrulha “Penedo’ & $\begin{array}{l}\text { Navio Patrulha Fluvial } \\
\text { "Amapá" }\end{array}$ \\
\hline $\begin{array}{c}\text { Navio Patrulha Fluvial "Raposo } \\
\text { Tavares" }\end{array}$ & $\begin{array}{l}\text { Lancha Patrulha Naval } \\
\text { "Guerreira" }\end{array}$ \\
\hline \multicolumn{2}{|c|}{ GPS GP-33 } \\
\hline \multicolumn{2}{|c|}{ Base de Hidrografia da Marinha em "Niterói’ } \\
\hline \multicolumn{2}{|c|}{ GPS GP-150D } \\
\hline \multicolumn{2}{|c|}{ Navio Escola "Brasil" } \\
\hline \multicolumn{2}{|c|}{ Navio Balizador Comandante "Manhaes" } \\
\hline \multicolumn{2}{|c|}{ Navio Balizador Comandante "Varella" } \\
\hline \multicolumn{2}{|c|}{ Navio Patrulha "Benevente" } \\
\hline \multicolumn{2}{|c|}{ Navio Pesquisa "Aspirante Moura" } \\
\hline \multicolumn{2}{|c|}{ Navio Hidroceanográfico Fluvial " Rio branco" } \\
\hline \multicolumn{2}{|c|}{ Navio Hidroceanográfico Fluvial "Rio Tocantins" } \\
\hline \multicolumn{2}{|c|}{ Navio Hidroceanográfico Fluvial "Rio Xingu" } \\
\hline \multicolumn{2}{|c|}{ Navio Hidroceanográfico Fluvial "Rio Solimões" } \\
\hline \multicolumn{2}{|c|}{ Navio Hidroceanográfico Fluvial "Rio Negro" } \\
\hline \multicolumn{2}{|c|}{ GPS GP-170 } \\
\hline \multicolumn{2}{|c|}{ Base de Hidrografia da Marinha em "Niterói" } \\
\hline \multicolumn{2}{|c|}{ Giro Satélite SC-50 } \\
\hline Aviso Pesquisa "Aspirante Moura" & $\begin{array}{l}\text { Navio Hidroceanográfico Fluvial "Rio } \\
\text { Branco" }\end{array}$ \\
\hline $\begin{array}{l}\text { Navio de Assistência Hospitalar 'Soares } \\
\text { de Meirelles' }\end{array}$ & Navio Apoio Fluvial "Potengi" \\
\hline Navio Auxiliar "Pará" & $\begin{array}{l}\text { Navio Transporte Fluvial "Almirante } \\
\text { Leverger" }\end{array}$ \\
\hline
\end{tabular}




\begin{tabular}{|c|c|}
\hline Navio Patrulha "Anequim" & $\begin{array}{l}\text { Navio Transporte Fluvial "Almirante } \\
\text { Leverger" }\end{array}$ \\
\hline Navio Patrulha “Tucunaré' & Navio Transporte Fluvial "Paraguassu" \\
\hline Navio Patrulha 'Parati” & $\begin{array}{l}\text { Navio Hidroceanográfico "Fluvial } \\
\text { Caravelas" }\end{array}$ \\
\hline $\begin{array}{l}\text { Navio Hidroceanográfico Fluvial "Rio } \\
\text { Negro" }\end{array}$ & $\begin{array}{l}\text { Navio Hidroceanográfico Fluvial "Rio } \\
\text { Tocantins" }\end{array}$ \\
\hline $\begin{array}{l}\text { Navio Hidroceanográfico Fluvial "Rio } \\
\text { Xingu" } \\
\text { Navio Hidroceanográfico "Rio } \\
\text { Solimões" }\end{array}$ & $\begin{array}{l}\text { Navio Hidroceanográfico "Rio } \\
\text { Solimões" }\end{array}$ \\
\hline \multicolumn{2}{|c|}{ Giro Satélite SC-110 } \\
\hline \multicolumn{2}{|c|}{ Navio Assistência Hospitalar "Tenente Maximiano" } \\
\hline \multicolumn{2}{|c|}{ Repetidora RD 33} \\
\hline \multicolumn{2}{|c|}{ Navio Patrulha "Maracanã' } \\
\hline \multicolumn{2}{|c|}{ Navio Patrulha "Mangaratiba" } \\
\hline \multicolumn{2}{|c|}{ Sensor PG 500} \\
\hline \multicolumn{2}{|c|}{ Comando da Flotilha do Amazonas } \\
\hline \multicolumn{2}{|c|}{ Navio de Assistência Hospitalar "Soares de Meirelles" } \\
\hline \multicolumn{2}{|c|}{ Aviso Pesquisa "Aspirante Moura” } \\
\hline \multicolumn{2}{|c|}{ Aviso Hidroceanográfico Fluvial "Rio Tocantins" } \\
\hline \multicolumn{2}{|c|}{ Aviso Hidroceanográfico Fluvial "Rio Xingu" } \\
\hline \multicolumn{2}{|c|}{ Aviso Hidroceanográfico Fluvial "Rio Solimôes" } \\
\hline \multicolumn{2}{|c|}{ Radar FR-8062 } \\
\hline \multicolumn{2}{|c|}{ Aviso Hidroceanográfico Fluvial "Rio Negro" } \\
\hline \multicolumn{2}{|c|}{ Navio Hidroceanográfico Fluvial "Rio Branco" } \\
\hline \multicolumn{2}{|c|}{ Navio de Assistência Hospitalar "Soares de Meirelles" } \\
\hline \multicolumn{2}{|c|}{ Navio Patrulha Fluvial 'Pedro Teixeira" } \\
\hline \multicolumn{2}{|c|}{ Navio Patrulha Fluvial "Roraima” } \\
\hline \multicolumn{2}{|c|}{ Navio Assistência Hospitalar "Carlos Chagas" } \\
\hline \multicolumn{2}{|c|}{ Radar FR-8062 } \\
\hline \multicolumn{2}{|c|}{ Navio Assistência Hospitalar "Tenente Maximiano" } \\
\hline \multicolumn{2}{|c|}{ Aviso Hidroceanográfico Fluvial 'Rio Tocantis" } \\
\hline Aviso Hidroceanográfi & o Fluvial "Rio Xingu" \\
\hline
\end{tabular}

Fonte: Autor, adaptado do Relatório de Informações Gerenciais do Abastecimento da MB.(MB, 2015) 
As figuras 12 a 17 apresentam alguns exemplos de equipamentos Furuno que atendem à Diretiva RoHS.

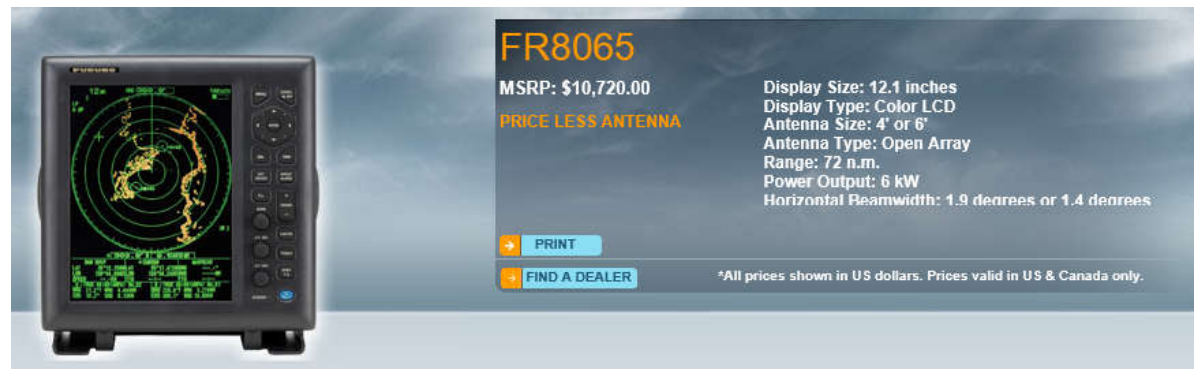

Figura 12 - Radar FR8065.

Fonte: Página na WEB da empresa Furuno USA, 2015.

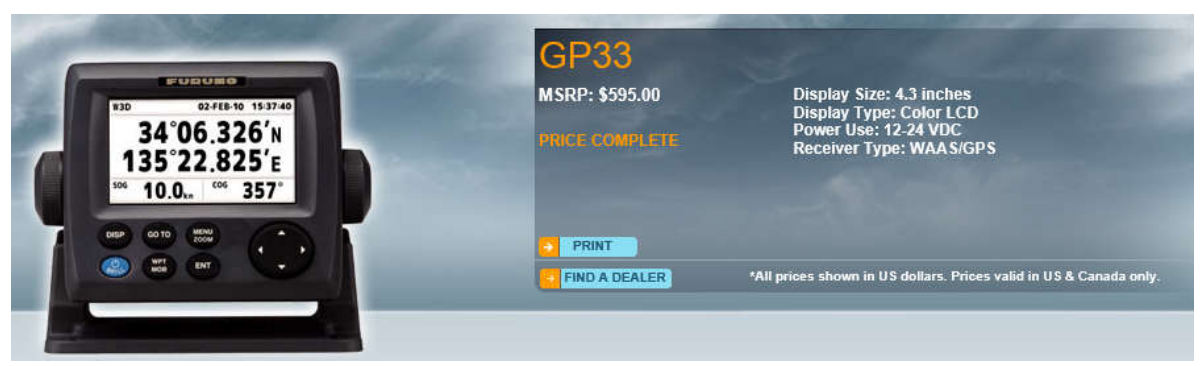

Figura 13 - GPS GP33.

Fonte: Página na WEB da empresa Furuno USA, 2015.

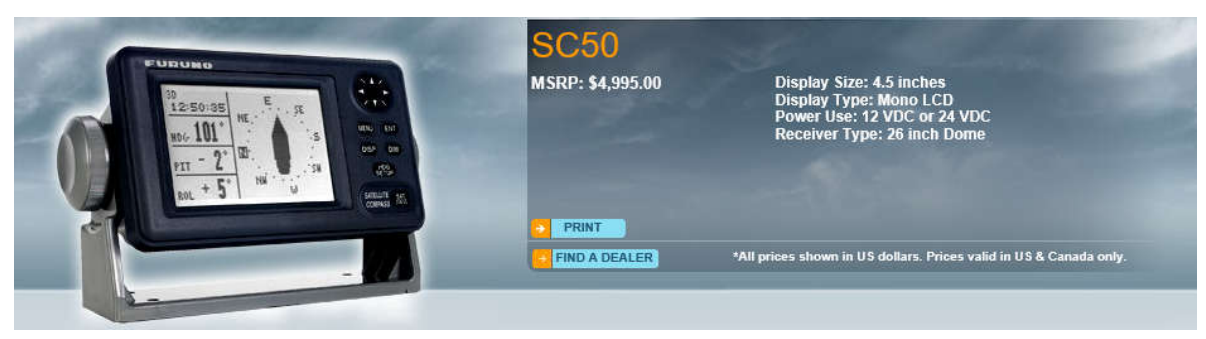

Figura 14 - Giro satélite SC-50.

Fonte: Página na WEB da empresa Furuno USA, 2015. 


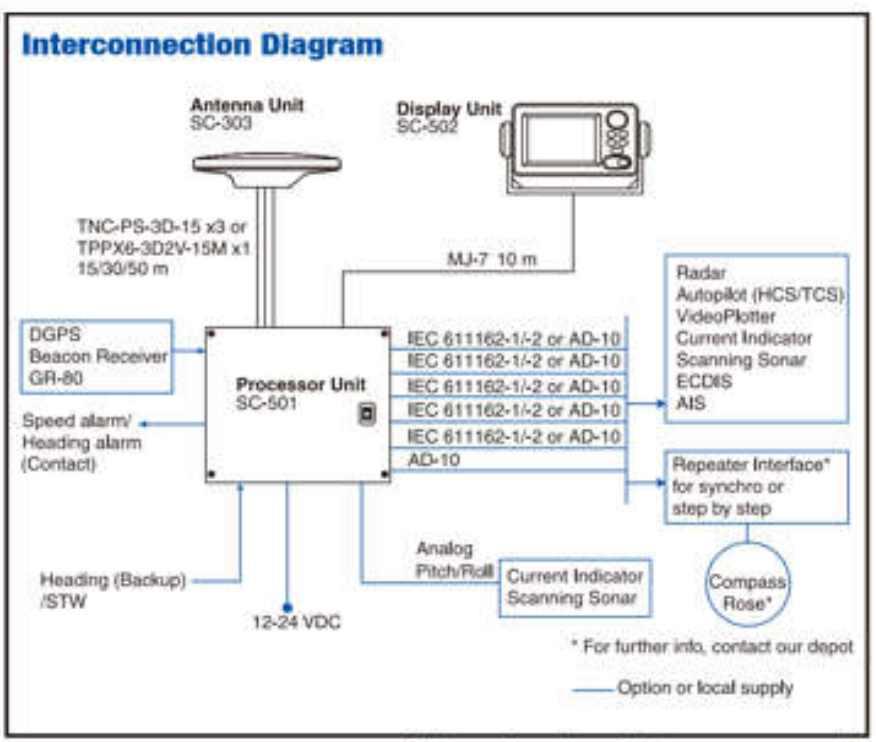

Figura 15 - Configuração básica de interligação das unidades do giro satélite SC-50.

Fonte: Página na WEB da empresa Furuno USA, 2015.

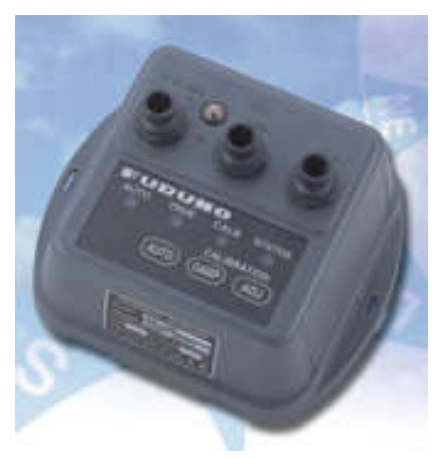

Figura 16 -Sensor PG-500.

Fonte: Página na WEB da empresa Furuno USA, 2015.
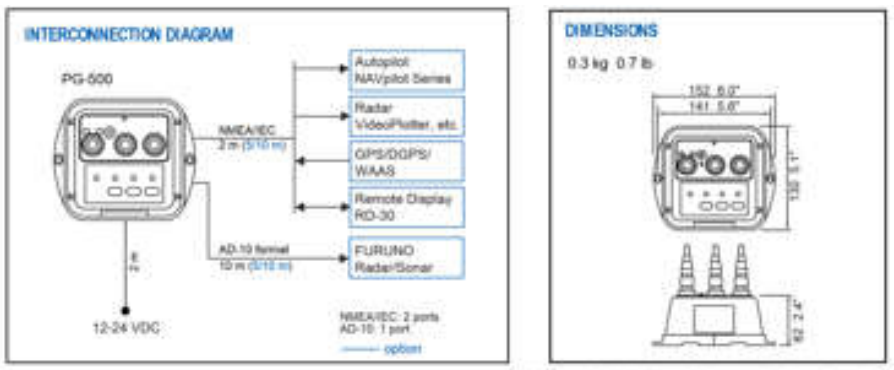

Figura 17 - Configuração básica de integração ao sensor PG-500. Fonte: Página na WEB da empresa Furuno USA, 2015. 


\section{- EXEQUIBILIDADE}

Sendo considerada adequada, a solução considerada adequada será avaliada quanto a sua exequibilidade, analisando-se fatores como disponibilidade de recursos humanos, recursos materiais, tecnológicos e financeiros, bem como disponibilidade de tempo na implementação das soluções consideradas adequadas.

Assim, a linha de ação considerada adequada, adquirir EEE com os critérios da Diretiva RoHS no mercado internacional, será avaliada quanto a sua exequibilidade.

Recursos Humanos - A Organização Militar na aquisição de EEE das áreas em análise possui equipe técnica, militares e civis, composta por engenheiros e técnicos eletrônicos, sendo um engenheiro em fase de conclusão do mestrado em engenharia ambiental, em quantidade e qualificações satisfatória para implantar a solução proposta.

O Centro de Manutenção de Sistemas da Marinha (CMS), órgão responsável pela instalação e manutenção de EEE da MB possui oficinais dedicadas às áreas de navegação, acústica e detecção radar.

O CMS possui ainda, engenheiros com mestrado em engenharia ambiental que auxiliam na gestão ambiental do Centro, principalmente quanto à reciclagem. Além disso, o CMS possui experiência com os equipamentos citados na tabela 32 , não tendo sido detectado pelos técnicos consultados do CMS necessidades diferentes daquelas utilizadas para instalação ou manutenção dos EEE em decorrência de atenderem à Diretiva RoHS.

Disponibilidade de Recursos Materiais e Tecnológicos - A solução proposta não necessita de recursos tecnológicos, como equipamentos de teste ou ferramentas especiais diferentes das usadas na instalação e manutenção de equipamentos que não atendam a critérios de sustentabilidade. Os equipamentos que atendem à Diretiva RoHS já instalados nos meios da $\mathrm{MB}$ (tabela 32) não exigiram recursos diferentes em suas instalações, dos usualmente empregados pelo CMS.

Disponibilidade de Recursos Financeiros no processo de aquisição - A implementação da solução não implica em custos financeiros adicionais no processo de aquisição de EEE que atendam a RoHS. O mesmo processo, licitação pública (técnica + menor preço), para aquisição de EEE não sustentáveis será 
utilizado para aquisição de equipamentos eletroeletrônicos que atendam à Diretiva RoHS.

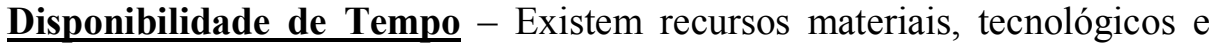
humanos para implementação da solução. Portanto, a variável tempo não assume papel restritivo na exequibilidade da solução O tempo previsto para a execução da solução é nulo, já que a aquisição de EEE com critérios de sustentabilidade pode ser imediata.

Mediante os critérios analisados pode-se concluir que a solução pode ser implementada não havendo sido detectada restrições à sua execução. Neste sentido, a solução é EXEQUÍVEL.

\section{- CUSTO}

Não existem dados conclusivos quanto ao aumento atribuído à adaptação dos EEE à Diretiva RoHS. Conforme apresentado na análise das ameaças externas, o acréscimo no custo dos equipamentos em decorrência da $R o H S$ fica em torno de $30 \%$. Vale salientar, que variações no custo de alguns equipamentos pode ter ocorrido devido às inovações tecnológicas.

Para as empresas da União Europeia o custo inerente à adaptação dos produtos à Diretiva RoHS teve seu pico até 2006. Após 2006 os custos declarados pelas empresas caíram vertiginosamente. As empresas americanas e japonesas tiveram o custo de harmonização à Diretiva reduzida também a partir de 2006, entretanto não na mesma intensidade.

Gordon et al. (2008), baseada nos dados obtidos juntos a 171 companhias europeias, estima que a média, por empresa, do custo inicial para atender à Diretiva RoHS foi de US\$2,640,000. Estima, também, que o custo total mundial de harmonização inicial à $R o H S$, conforme já informado, foi de aproximadamente US\$ 32 bilhões, $1,1 \%$ da receita das empresas demonstrando o quanto significativo foram os negócios realizados pelas indústrias da UE.

Bogaert et al. (2008) apresenta o estudo realizado junto a 30 empresas e informa que o maior investimento das empresas esta na coleta e revisão de informações, tanto na fase inicial da harmonizão à Diretiva quanto em previsão futura: $49 \%$ e $68 \%$, respectivamente. Estes dados demonstram a necessidade constante da indústria em manter-se atualizada quanto à Diretiva $R o H S$. 
Para este estudo a comparação do custo de antes/após RoHS foi realizada entre equipamentos que possuem as mesmas funcionalidades e características técnicas similares, e quando possível, do mesmo fabricante. Os dados de custos de antes da Diretiva $R o H S$ apresentados na tabela 33 foram obtidos de estudos e pareceres técnicos elaborados pela Organização Militar da MB que apresentam a análise da viabilidade de substituição de equipamentos eletroeletrônicos obsoletos. Os valores apresentados nos estudos e pareceres são aproximados, considerados como referentes ao custo do equipamento, sem considerar manutenção e instalação. Os estudos são de sigilo reservado, restritos à Organização Militar da MB. Já os valores de EEE com critérios de sustentabilidade foram obtidos da página na web da empresa Furuno USA (www.furuno.com). O valor de ajuste considerado como limite de acréscimo no preço dos EEE foi de 30\%, utilizando-se os valores em dólar, não convertidos para o real.

$$
\begin{aligned}
& \text { Vd }(\mathrm{US} \$) \leq(\mathrm{X}) \times \mathrm{V}, \text { valor após a Diretiva RoHS } \\
& \mathrm{V}(\mathrm{US} \$)=\text { Valor antes da Diretiva } R o H S \\
& \mathrm{X}=\text { valor de ajuste } \\
& \mathrm{X} \leq 30 \%
\end{aligned}
$$

Todos os equipamentos Furuno devem atender aos critérios de sustentabilidade previstos no documento Green Procurement Standards for Parts and Materials, que inclui as restrições impostas pela Diretiva RoHS. Entretanto os certificados de conformidade RoHS (Furuno, 2014) não estão disponibilizados para todos os seus equipamentos. Neste sentido, para a avaliação da viabilidade econômica, serão considerados, também, equipamentos Furuno que atendam critérios de sustentabilidade ambiental embora não possuam certificado de conformidade $\mathrm{RoHS}$.

A tabela 33 relaciona os preços de equipamentos das áreas de navegação, acústica e detecção radar de antes da Diretiva RoHS. Já a tabela 34 lista preços de equipamentos Furuno pós-Diretiva de 2015. As Tabelas 35 e 36 apresentam, respectivamente, as características técnicas de radares de navegação analisados até 2003, antes da RoHS entrar em vigor, e modelos atuais, disponíveis para comercialização. 
Vale salientar que o radar $1942 \mathrm{MK} 2$ possui as características técnicas principais, potência, alcance, interfaces e tipo de antena iguais às do radar 1942, ambos obsoletos. Entretanto, o radar 1942MK2 possui cotação na página da WEB da Furuno USA. Neste sentido, a comparação de preço será entre os radares 1942 e 1942MK2, e este com o radar 1945, radares com as mesmas características técnicas. Não foram identificadas informações de sustentabilidade para o radar 1945MK2, entretanto, os manuais do equipamento disponibilizados na página na WEB da empresa Furuno USA são datados de 1998, antes da Diretiva RoHS entrar em vigor.

Tabela 33 - Relação de preços de equipamentos até 2003

\begin{tabular}{|c|c|c|}
\hline Equipamento & Preço (US\$) & Ano \\
\hline Radar de Navegação 1831 & $4,500.00$ & 1999 \\
\hline Radar de Navegação 1942 & $5,000.00$ & 1999 \\
\hline Radar de Navegação 1 & $20,000.00$ & 2001 \\
\hline Radar de Navegação 2 & $11,500,00$ & 2001 \\
\hline Radar de Navegação FR-8100DS & $11,400.00$ & 2001 \\
\hline Radar de Navegação 3 & $11,500.00$ & 2001 \\
\hline Radar de Navegação 4 & $15,000.00$ & 2001 \\
\hline Radar de Navegação 5 & $13,000.00$ & 2002 \\
\hline Radar de Navegação 6 & $13,000.00$ & 2002 \\
\hline Radar de Navegação 7 & $13,000.00$ & 2003 \\
\hline Ecobatímetro 1 & $8,000.00$ & 2002 \\
\hline Ecobatímero FE-700 & $7,000.00$ & 2003 \\
\hline GPS 1 & $2,000.00$ & 2001 \\
\hline
\end{tabular}

Fonte: Autor, baseado em estudos elaborados pela Organização Militar da MB.

Tabela 34 - Relação de preços de equipamentos fabricados pela empresa Furuno em 2015

\begin{tabular}{|c|c|c|}
\hline Equipamento & Preço & Ano \\
\hline Radar 1623 & US\$1.795.00 & \multirow[t]{13}{*}{2015} \\
\hline Radar 1715 & US\$2.195.00 & \\
\hline Radar 1835 & US\$ 4.895 .00 & \\
\hline Radar 1942MK2 & US\$ 6.995,00 & \\
\hline Radar 1945 & US\$ 7.895.00 & \\
\hline Radar FR 8065 & US\$ 11.895.00* & \\
\hline Radar FR 8125 & US\$ $12.895 .00^{*}$ & \\
\hline $\begin{array}{l}\text { Ecobatímetro FE - } 700 \text {, } \\
\text { sem transdutor }\end{array}$ & US\$ 5.495 & \\
\hline Ecobatímetro FE-800 & US\$ 5,495.00 & \\
\hline GP 150 & US\$ 2.295 & \\
\hline GP 150D & US\$ 2.295 & \\
\hline GP-33 & US\$ 595,00 & \\
\hline GP-170 & US\$ 2,295.00 & \\
\hline
\end{tabular}

Fonte: Autor, baseado em dados disponibilizados na página na web da empresa Furuno USA (www.furunousa.com) *- antena incluída. 
Tabela 35 - Características técnicas de radares de navegação avaliados até 2003

\begin{tabular}{|c|c|c|c|}
\hline Equipamento & Potência & Banda & Alcance \\
\hline Radar 1831 & $3 \mathrm{KW}$ & $\mathrm{X}$ & $24 \mathrm{~nm}$ \\
\hline Radar 1942 & $6 \mathrm{KW}$ & $(8 \mathrm{a} 12 \mathrm{GHz})$ & $64 \mathrm{~nm}$ \\
\cline { 1 - 2 } & & & $72 \mathrm{~nm}$ \\
\hline Radar FR-8100DS & $10 \mathrm{KW}$ & \\
\hline
\end{tabular}

Tabela 36 - Características técnicas de radares de navegação à venda em 2015

\begin{tabular}{|c|c|c|c|}
\hline Equipamento & Potência & Banda & Alcance \\
\hline Radar 1623 & $2,2 \mathrm{KW}$ & \multirow{7}{*}{$\begin{array}{c}\mathrm{X} \\
(8 \mathrm{a} 12 \mathrm{GHz})\end{array}$} & $16 \mathrm{~nm}$ \\
\hline Radar 1715 & $2,2 \mathrm{KW}$ & & $24 \mathrm{~nm}$ \\
\hline Radar 1835 & $4 \mathrm{KW}$ & & $36 \mathrm{~nm}$ \\
\hline Radar 1945 & \multirow[t]{2}{*}{$6 \mathrm{KW}$} & & \multirow[t]{2}{*}{$64 \mathrm{~nm}$} \\
\hline Radar 1942 MK2* & & & \\
\hline Radar FR 8065 & $6 \mathrm{KW}$ & & $72 \mathrm{~nm}$ \\
\hline Radar FR 8125 & $12 \mathrm{KW}$ & & $72 \mathrm{~nm}$ \\
\hline
\end{tabular}

Apesar do número de equipamentos analisados ser reduzido, pode-se observar pelas tabelas 37 a 39 que os mesmos tiveram percentual de variação no preço na faixa limite de 30\%, em dólar. Analisando o preço de venda em 2015 do equipamento obsoleto e cujo projeto é anterior à Diretiva RoHS, o radar 1942MK2, em relação ao similar em característica técnica, o radar 1945, pode-se notar reduzido percentual de variação no preço, 12,8\%. Alguns equipamentos, como os ecobatímetros, o radar de 24 n.m. de alcance e o obsoleto, porém a venda, GPS GP-33 tiveram o percentual de variação de preço negativo.

O maior percentual na variação de preço detectado entre o radar 1942 e o radar 1942MK2 pode ser creditado ao fator de obsolescência deste, e consequente dificuldade de obtenção de itens para produção dos mesmos. 
Tabela 37 - Percentual de variação no preço de radares

\begin{tabular}{|c|c|c|c|c|c|c|c|}
\hline \multicolumn{3}{|c|}{ Radares até 2003} & \multicolumn{4}{|c|}{ Radares 2015} & \multirow{2}{*}{$\begin{array}{l}\text { Percentual } \\
\text { variação } \\
\text { no preço }\end{array}$} \\
\hline Potência & Alcance & Preço & Potência & Alcance & \multicolumn{2}{|c|}{ Preço (US\$) } & \\
\hline \multirow[t]{2}{*}{$3 \mathrm{KW}$} & \multirow[t]{2}{*}{$24 \mathrm{~nm}$} & \multirow[t]{2}{*}{4.500} & $2.2 \mathrm{KW}$ & $24 \mathrm{~nm}$ & 1715 & 2.195 & $-49 \%$ \\
\hline & & & $4 \mathrm{KW}$ & $36 \mathrm{~nm}$ & 1835 & 4.895 & $9 \%$ \\
\hline \multirow[t]{2}{*}{$6 \mathrm{KW}$} & \multirow[t]{2}{*}{$64 \mathrm{~nm}$} & \multirow[t]{2}{*}{5.000} & \multirow[t]{2}{*}{$6 \mathrm{KW}$} & \multirow[t]{2}{*}{$64 \mathrm{~nm}$} & 1942MK2 & 6.995 & $39,9 \%$ \\
\hline & & & & & 1945 & 7.895 & $12,8 \%$ \\
\hline $10 \mathrm{KW}$ & $72 \mathrm{~nm}$ & 11.400 & $12 \mathrm{KW}$ & $72 \mathrm{~nm}$ & FR8125 & 12.895 & $13 \%$ \\
\hline
\end{tabular}

Fonte: Autor

Tabela 38 - Percentual de variação no preço de ecobatímetros

\begin{tabular}{|c|c|c|c|}
\hline Ecobatímetro até 2003 & \multicolumn{2}{|c|}{ Ecobatímetro 2015 } & $\begin{array}{c}\text { Percentual de } \\
\text { variação no } \\
\text { preço }\end{array}$ \\
\hline Preço (US\$) & \multicolumn{2}{|c|}{ Pres) } & $-22 \%$ \\
\hline $7.000,00$ & FE-700 & $5.495,00$ & \\
\hline & FE-800 & & \\
\hline
\end{tabular}

Fonte: Autor

Tabela 39 - Percentual de variação no preço de GPS

\begin{tabular}{|c|c|c|c|}
\hline GPS de até 2003 & \multicolumn{2}{|c|}{ GPS 2015 } & $\begin{array}{c}\text { Percentual de } \\
\text { variação no } \\
\text { preço }\end{array}$ \\
\hline \multirow{2}{*}{$2.000,00$} & \multicolumn{2}{|c|}{ Preço (US\$) } & $15 \%$ \\
& $\begin{array}{c}\text { GP-150 } \\
\text { (Obsoleto à venda) }\end{array}$ & $2.295,00$ & \\
\cline { 2 - 2 } & GP-170 & & $-70,25 \%$ \\
\cline { 2 - 3 } & $\begin{array}{c}\text { GP-33 } \\
\text { (obsoleto à venda) }\end{array}$ & 595,00 & \\
\hline
\end{tabular}

Fonte: Autor

Mesmo considerando que variações no preço do produto podem ser devido às inovações, ou restrições tecnológicas, podemos observar pelo sumário apresentado pela tabela 40 que o atendimento à Diretiva $R o H S$ não acarreta acréscimo considerável no preço dos equipamentos junto ao consumidor. Portanto, a solução de adquirir-se EEE com os critérios da Diretiva RoHS no mercado internacional é economicamente viável. 


Tabela 40 - Resumo do percentual de variação no preço dos
equipamentos analisados.
\begin{tabular}{|c|c|}
\hline Equipamentos & $\begin{array}{c}\text { Percentual de } \\
\text { variação no preço }\end{array}$ \\
\hline Ecobatímetro & $-22 \%$ \\
\hline Navegador Satélite & $15 \%$ \\
\hline Radar 2,2 KW/24 m.n & $-49 \%$ \\
\hline Radar 4 KW/36 m.n & $9 \%$ \\
\hline Radar 6 KW/64 m.n & $12,8 \%$ \\
\hline Radar 10KW-12 KW/72 m.n & $13 \%$ \\
\hline Radar 6KW/64 m.n. & $39,9 \%$ \\
$($ Obsoleto $)$ & \\
\hline
\end{tabular}

Fonte: Autor

\section{- ACEITABILIDADE}

Conforme o documento EMA-332, no teste de aceitabilidade deve ser verificado a relação custo-benefício da solução pretendida, justificando sua implementação.

Embora o critério de aceitabilidade esteja fora da esfera de decisão da Organização Militar, para fins acadêmicos foi considerado o critério de aceitabilidade. Verificando os dados apresentados nas análises de adequabilidade e exequibilidade, uma vez que a MB já possui equipamentos que atendem a critérios de sustentabilidade operando satisfatoriamente em seus meios navais, e que os custos dos equipamentos RoHS analisados ficaram, em comparação aos equipamentos de antes da diretiva, com percentual de variação de preços compatível com os $30 \%$, previstos para adequação de equipamentos à $R o H S$, a solução de adquirir-se EEE RoHS de empresas no mercado internacional é considerada ACEITAVEL.

Desta maneira, a solução proposta para verificar-se a viabilidade técnica e econômica da adoção da Diretiva RoHS por Organização Militar da MB utilizandose de EEE sustentáveis disponibilizados no mercado internacional apresentou-se ADEQUADA, EXEQUÍVEL E ACEITÁVEL. 


\section{6}

\section{Conclusões e sugestões de trabalhos futuros}

\section{1}

\section{Conclusões}

Durante a pesquisa foi observado que a adequação das indústrias à Diretiva RoHS é possível, sendo os maiores custos de adequação à norma atribuídos ao treinamento, obtenção de informação e certificação. Ficou evidenciado no estudo que a Diretiva RoHS é capaz de auxiliar na redução do nível de contaminação humana e ambiental geradas pelas substâncias focadas pela Diretiva.

Foi verificado que a China, Japão e Coréia, além do estado da Califórnia nos EUA, se alinharam aos conceitos ambientais da Diretiva RoHS. A Diretiva Coréia enfatiza o design ambientalmente amigável. Já a Diretiva China inova quando determina que para equipamentos que possuam níveis de substâncias $R o H S$ acima de valores limites, seja definido o tempo que as substâncias se mantêm inócuas.

Para o Brasil, que não possui lei que normatize a quantidade de substâncias químicas nocivas em EEE, sugere-se a adoção da Diretiva RoHS, agregando-se os benefícios verificados nas RoHS Coréia e China.

O foco deste trabalho, entretanto, foi apresentar a análise da viabilidade técnica e econômica da Organização Militar da MB em adotar equipamentos eletroeletrônicos sustentáveis que atendam a Diretiva $R o H S$. No estágio econômico e técnico brasileiro atual, a pesquisa evidenciou que não era viável desenvolver-se equipamentos RoHS no país para verificar a viabilidade técnica e econômica da adoção da Diretiva pela MB. No entanto, verificou-se que os EEE das áreas em análise disponibilizados no mercado internacional eram suficientes para a análise desejada, sendo, portanto, a solução de se adquirir EEE no mercado internacional considerada adequada e exequível. Durante o estudo, foi observado que a Organização Militar analisada já possui equipamentos $R o H S$ instalados em seus 
meios navais operando satisfatoriamente, ratificando a confiabilidade técnica da Diretiva.

Quanto aos custos, em comparação aos equipamentos anteriores à diretiva, os equipamentos RoHS analisados apresentaram acréscimo inferior a 30\%, percentual máximo previsto para adequação de equipamentos à RoHS. Apenas um equipamento à venda, porém obsoleto, apresentou custo acima do previsto. $\mathrm{O}$ estudo também atesta que a Organização Militar pode alinhar-se à norma ambiental sem que isso implique em gastos extras em recursos humanos e materiais, bem como operativo, para adequar-se à Diretiva $R o H S$.

Assim, a análise efetuada neste estudo pode ser projetada para a aquisição de EEE RoHS pela Organização Militar da MB, já que foi confirmada a confiabilidade técnica e viabilidade econômica da Diretiva RoHS.

O trabalho evidenciou, também, que dos EEE da Organização Militar da MB analisados, os que apresentam maior taxa de alienação são os equipamentos de teste.

Vale ressaltar, que este trabalho sofreu limitações devido à escassez de dados de sustentabilidade atrelados à área de Defesa, e de dados relativos aos equipamentos eletroeletrônicos colocados no mercado antes da Diretiva $R o H S$ ter entrado em vigor. Ademais, algumas informações consideradas sigilosas não foram vinculadas no trabalho por serem de interesse restrito da área da Defesa.

Mediante os poucos fabricantes de equipamentos eletroeletrônicos das áreas analisadas que atendem à Diretiva, sugere-se que as aquisições de EEE não utilizem 'os critérios de sustentabilidade como fator de exclusão. Para isso, é proposto que sejam utilizados pesos diferenciados, maiores para os equipamentos que atendam a critérios de sustentabilidade, considerando, entretanto, os equipamentos que não sejam ambientalmente amigáveis. Além disso, conforme sugerido para o Brasil, sugere-se que a Organização Militar adote a Diretiva $R o H S$ em suas especificações técnicas, agregando, também, os benefícios verificados nas RoHS Coréia e China.

Ainda, como resultado deste estudo, propõe-se, ainda, os fluxogramas das figuras 18 e 19, respectivamente, para aquisição de equipamentos eletroeletrônicos e de seus componentes e sobressalentes. 


\section{Aquisição de EEE sustentáveis}

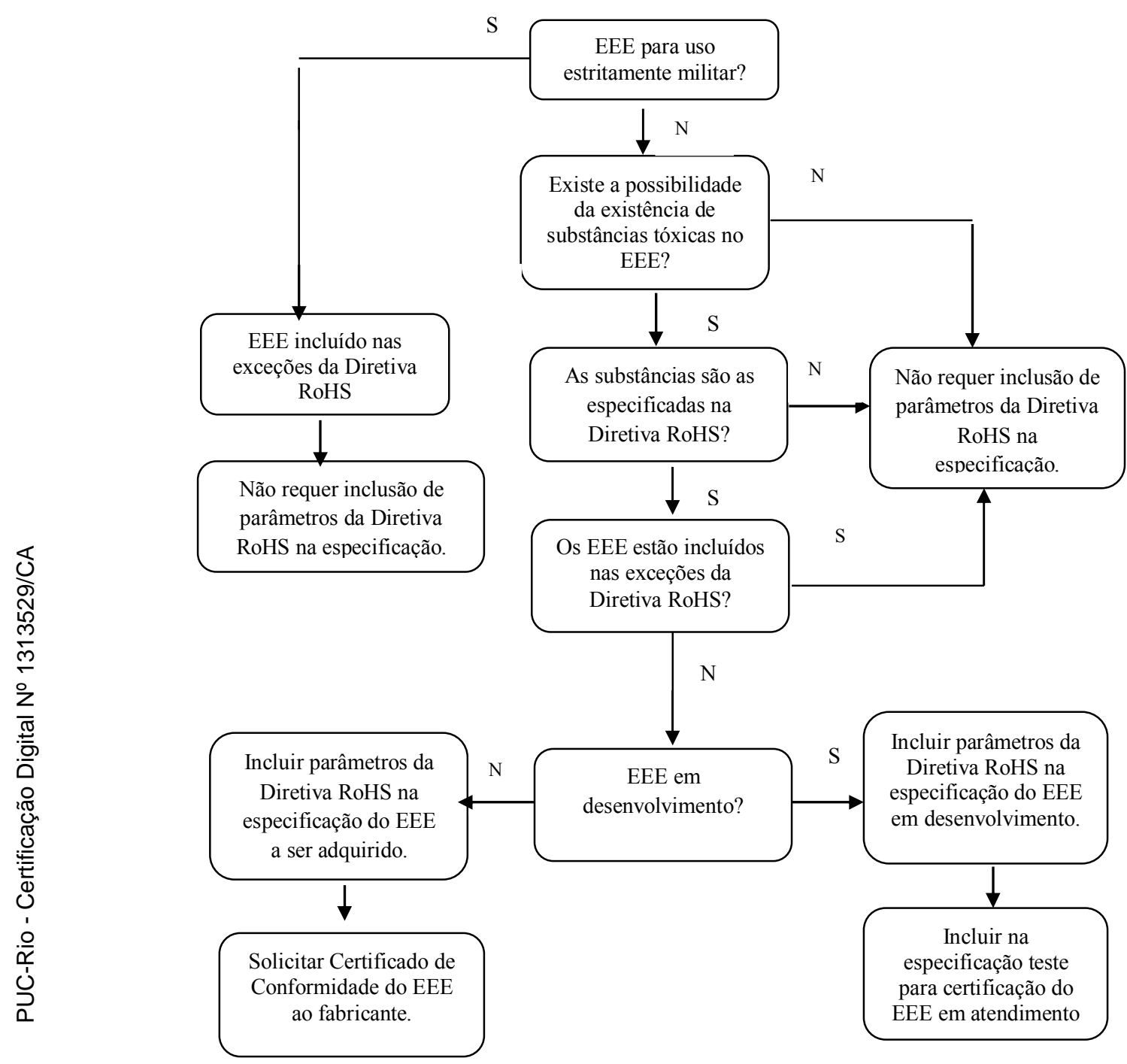

Figura 18 - Aquisição de EEE sustentáveis.

Fonte: Autor

Pelo fluxograma da figura 18 verificamos que numa definição clássica de EEE, os equipamentos eletroeletrônicos de uso estritamente militar fazem parte das exceções da Diretiva e não requerem a inclusão de parâmetros da Diretiva em suas especificações de aquisição,

Para o caso de equipamentos não militares e não incluídos nas exceções da Diretiva $R o H S$, os parâmetros devem fazer parte da especificação de EEE, sendo necessário a solicitação de Certificado de Conformidade ao fabricante. Se forem 
EEE em desenvolvimento, além da inclusão na especificação da norma $R o H S$ a ser atendida, a especificação deverá incluir exigência para a realização de testes para verificação de conformidade à Diretiva RoHS.

Aquisição de componentes e sobressalentes para EEE sustentáveis

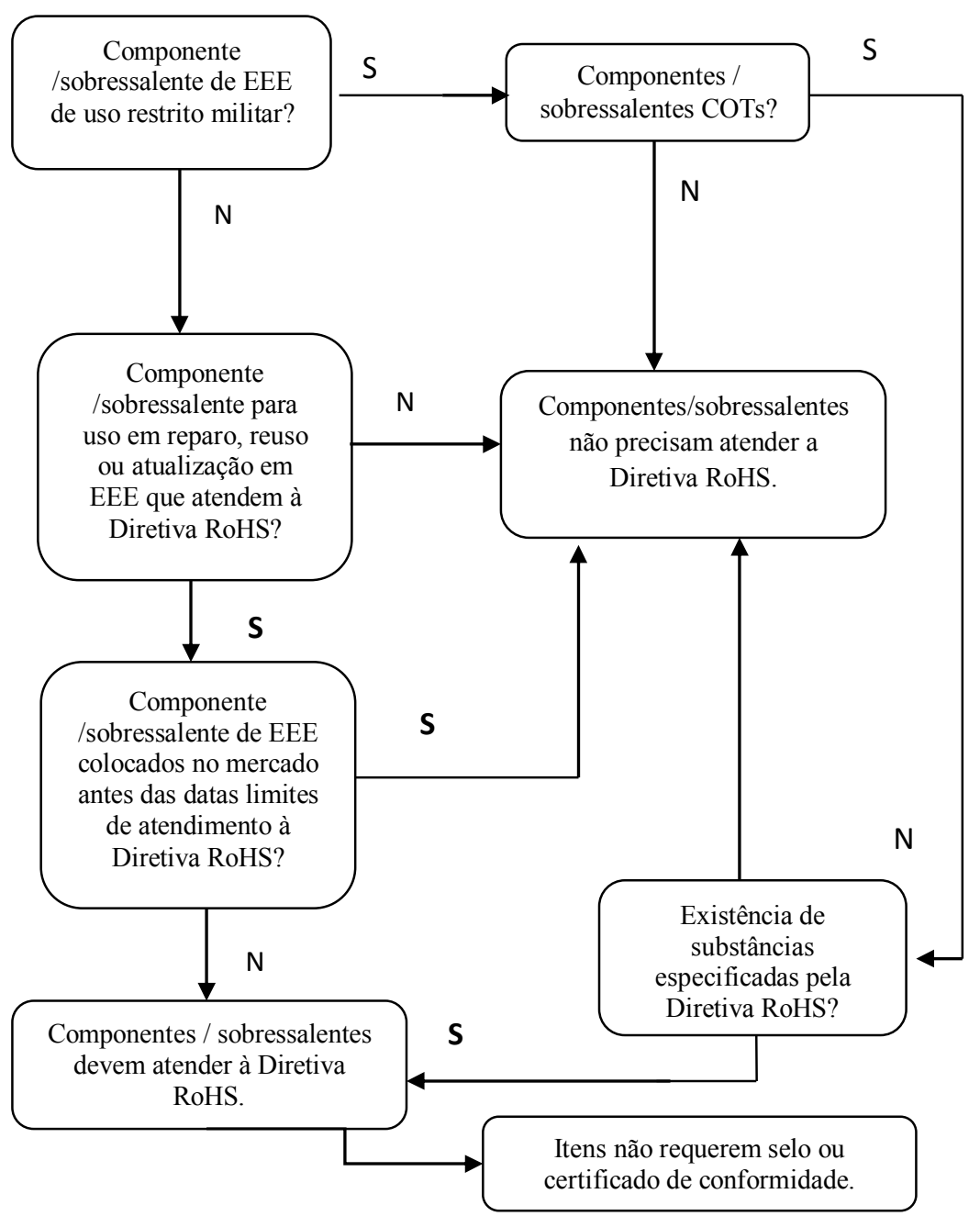

Figura 19 - Aquisição de componentes e sobressalentes para EEE sustentáveis. Fonte: Autor

Com a possibilidade de equipamentos de uso estritamente militar possuírem componentes COTs deve-se atentar para o atendimento ao fluxograma 19. A figura 19 apresenta o fluxograma de decisão para a aquisição de componentes e sobressalentes para EEE sustentáveis. Quando existirem componentes COTs em EEE militares deve-se verificar a existência de substâncias RoHS em suas composições. Se negativo, os componentes e sobressalentes não necessitam de 
atender a Diretiva. Entretanto, se a resposta for positiva os componentes e sobressalentes devem atender à Diretiva, sem a necessidade da exigência de selo ou certificado de conformidade. Para componentes e sobressalentes de EEE de uso não militar colocados no mercado antes das datas limites de atendimento à Diretiva RoHS não necessitam atender à Diretiva. Os itens colocados depois das datas limites devem atender à RoHS. Neste caso, também não requerem selo ou certificado de conformidade.

Finalizando, mesmo com limitações esta pesquisa pôde evidenciar a possibilidade de agregar-se valores de sustentabilidade ambiental a equipamentos comerciais a serem adquiridos por Organização Militar da MB. O fato da MB aliarse à Diretiva RoHS pode influenciar, e tornar-se referência, para outras organizações públicas e privadas. Além disso, a proteção de nossos recursos naturais e de nossa Soberania está atrelada ao poderio naval da MB que depende, notoriamente de seus recursos humanos, mas sobretudo dos EEE que dotam os meios navais

\section{2}

\section{Sugestões de trabalhos futuros}

Como sugestões de trabalhos futuros, novas pesquisas podem ser realizadas para avaliar a percentagem de itens COTs, e consequente impacto ambiental, em equipamentos eletroeletrônicos de uso estritamente militar. Sugere-se, também, pesquisa para se determinar o impacto ambiental, e na saúde humana da utilização de nanotecnologia na fabricação de EEE. Recomenda-se, ainda, que sejam analisados os impactos técnico, ambiental, econômico e social das substâncias inseridas na Diretiva RoHS pela Diretiva 863/2015. 


\section{Referências bibliográficas}

ABNT, 10.004:2004, "Resíduos sólidos classificação". Disponível em: http://www.google.com.br/url?sa=t\&rct=j\&q=\&esrc=s\&source=web\&cd=1\& sqi=2\&ved=0CB0QFjAAahUKEwjsvaGT_s7HAhWBjZAKHRFFAkk\&url=htt p\%3A\%2F\%2Fwww.ccs.ufrj.br\%2Fimages \%2Fbiosseguranca\%2FCLASSI FICACAO_DE_RESIDUOS_SOLIDOS_NBR_10004_ABNT.pdf\&ei=ewLiV ayUPIGbwgSRionIBA\&usg=AFQjCNG0WezhUssn9ij8cmbBu8UQ5TPImg Acesso em: AGO 2015.

ABNT, NBR /ISSO / 14040:2009, "Gestão ambiental - avaliação do ciclo de vida, princípios e estrutura." Disponível em: <http://www.abntcatalogo.com.br/norma.aspx?ID=316462\# > Acesso em: AGO 2015.

ABNT, NBR/ISSO/14044:2009, "Gestão ambiental- avaliação do ciclo de vida - requisitos e orientações". Disponível em: <http://www.abntcatalogo.com.br/norma.aspx?ID=40206> Acesso em: AGO 2015.

ABINEE, "Desempenho setorial abril 2015", 2015. Disponível em: http://www.abinee.org.br/abinee/decon/decon15.htm. Acesso em: jun. 2015.

ABNT, NBR 13.248/2015. "Requisitos de desempenho para cabos de potência e condutores isolados sem cobertura, não halogenados e com baixa emissão de fumaça, para tensões até $1 \mathrm{kV}$ ". Disponível em: $<$ http://www.abntcatalogo.com.br/norma.aspx?ID=323287 $\geq$. Acesso em: set. 2015;

AFONSO. F.C., DSASTUD N 06-004. "Aspectos técnicos e logísticos relativos à aplicação de itens COTS no SICONTA MK II". DSAM. Jun, 2000.

ALLSOPP, M. Santillo, D. \& Johnston, P. "Environmental and Human Health Concerns in the Processing of Electrical and Electronic Waste - GRL-TN-04-2006". Greenpeace Research Laboratories, Departmnet of Biological Sciences, University of Exeter, Exeter EX4 4PS, UK. May, 2006.

ALMEIDA, C. M. V. B., et al., "Substituição das soldas estanho-chumbo na manufatura: efeitos na saúde do trabalhador e no desempenho ambiental. " Gest. Prod., São Carlos, v. 20, n. 1, p 1-13, 2013. Disponível 
em: $\quad<w w w . s c i e l o . b r / s c i e l o . p h p ? s c r i p t=s c i a r t t e x t 8 p i=s 0104-$ 530x2003000100004> Acesso em: 23 dez. 2014.

AMERICAN ELECTRONICS ASSOCIATION, "Management Methods for Controlling Pollution by Electronic Information Products", 11p. Disponível em: <http://www.rsjtechnical.com/images/Documents/China_RoHS_Order39.p d> Acesso em: out. 2015.

ANSANELLI, S. L. M., "Os Impactos internacionais das exigências ambientais da Internacional Workshop Advances in Cleaner Production", São Paulo, 2007, 7p. Disponível em: <www. Advanceincleanerproduction.net/first/ptbr/site/downloads.htm> Acesso em: jan. 2015.

ANSANELLI, S. L. M., "Os Impactos internacionais das exigências ambientais da União Europeia para o Setor de Equipamentos EletroEletrônicos sobre o Brasil", Campinas, SP, 2008, 227p. Tese (Doutorado em Economia Aplicada) - Universidade Estadual de Campinas, Instituto de Economia.

ARAÚJO, M. G. "Modelo de avaliação do ciclo de Vida para a gestão de resíduos e equipamentos eletroeletrônicos no Brasil”. Mar, 2013, Rio de janeiro, UFRJ, COPPE, 217p. Disponível em: $<$ www.ppe.ufrj.br/ppe/production/tesis/marcelo_guimaraes.pdf> Acesso em: 18 set. 2014.

ATSDR, "The ATSDR 2013 substance priority list", 2015. Disponível em: < http://www.atsdr.cdc.gov/spl/index.html> Acesso em: nov. 2015.

BALDÉ, C.P., et al. (2015), "The global e-waste monitor", 2014, 41p. United Nations University.

BETIOL, L. S. et al., "Guia para Compras Sustentáveis - A força do consumo público e empresarial para uma economia verde e inclusiva", 75p, 2012. Realização: Centro de Estudos em Sustentabilidade (GVces) da Escola de Administração de São Paulo da Fundação Getulio Vargas (FGV-EAESP) Disponível em: <http://www.mma.gov.br/responsabilidade-socioambiental/a3p/eixostematicos/licita\%C3\%A7\%C3\%A3o-sustent\%C3\%A1vel > Acesso em: jul. 2015.

BIRKETT, M., "The whisker formation test report”, 2006, TT electronics - Welwyn Components" 9p. Disponível em: $<$ www.mouser.com/pdfdocs/welwyn-wlsn-whisker-report.pdf> Acesso em: 23 dez. 2014.

BOGAERT, S., et al., "Study on RoHS and WEEE Diretives $\mathbf{N}^{\circ}$ 30-CE0095596/00-09 - Final Report". Mar., 2008, 369p. Arcadis \& RPA. Disponível

em: 
<ec.europa.eu/environment/waste/weee/pdf/rpa_study.pdf> Acesso em: out. 2015.

BOMCHECK, "How- does bomcheck manage compliance with RoHS restrictions in china Korea japan?" Disponivel em: https://www.bomcheck.net/RoHS/how-does-bomcheck-managecompliance-with-RoHS-restrictions-in-china-korea-japan > Acesso em: ago. 2015

BRASIL, "Constituição da República Federativa do Brasil de 1988." Disponível em: <http://www.planalto.gov.br/ccivil_03/Constituicao/Constituicao.htm> Acesso em: out. 2015.

BRASIL, "Emenda Constitucional $n^{\circ}$ 42, de 19.12.2003" Disponível em: $<$ http://legislacao.planalto.gov.br/legisla/legislacao.nsf/Viw_Identificacao/e mc\%2042-2003?OpenDocument > Acesso em: jun. 2015.

BRASIL, Lei N 10.257 de 10 de julho de 2001. Regulamenta os arts. 182 e 183 da Constituição Federal, estabelece diretrizes gerais da política urbana e dá outras providências. Disponível em: <ttp://www.planalto.gov.br/ccivil_03/leis/LEIS_2001/L10257.htm> Acesso em: set. 2015.

BRASIL, Lei $\mathbf{N}^{\circ} 12.187$ de 29 de dezembro de 2009. Institui a Política Nacional sobre Mudança do Clima - PNMC e dá outras providências. Disponível em: <http://www.planalto.gov.br/ccivil_03/_ato20072010/2009/lei//12187.htm>. Acesso em: set. 2015.

BRASIL, Lei $\mathbf{N}^{\circ} \mathbf{1 2 . 3 4 9}$ de 15 de dezembro de 2010. Altera as Leis $\mathrm{n}^{\text {os }}$ 8.666, de 21 de junho de 1993, 8.958, de 20 de dezembro de 1994, e 10.973 , de 2 de dezembro de 2004; e revoga o $\S 1^{\circ}$ do art. $2^{\circ}$ da Lei $n^{\circ}$ 11.273, de 6 de fevereiro de 2006. Disponível em: <ttp://www.planalto.gov.br/ccivil_03/_Ato2007-2010/2010/Lei/L12349.htm> Acesso em: out. 2015.

BRASIL, Política Nacional de Resíduos Sólidos; Lei $\mathbf{n}^{0} \mathbf{1 2 . 3 0 5 / 1 0}$, altera a Lei no 9.605, de 12 de fevereiro de 1998; e dá outras providências. Disponível em: <http://www.planalto.gov.br/ccivil_03/_ato20072010/2010/lei//12305.htm>Acesso em: set. 2015.

BRASIL, Lei N 8.666 de 21 de junho de 1993. Regulamenta o art. 37, inciso XXI, da Constituição Federal, institui normas para licitações e contratos da Administração Pública e dá outras providências. Disponível em: <http://www.planalto.gov.br/ccivil_03/Leis/L8666>cons.htm> Acesso em: set. 2015.

BRASIL, Lei $\mathbf{N}^{\circ} 12.462$ de 4 de agosto de 2011. Institui o Regime Diferenciado de Contratações Públicas. Disponível em: 
$<$ http://www.planalto.gov.br/ccivil_03/_ato2011-

2014/2011/Lei/L12462.htm> Acesso em: set. 2015.

BRASIL, Decreto $\mathbf{N}^{\circ} \mathbf{5 . 9 4 0}$ de 25 de outubro de 2006. Institui a separação dos resíduos recicláveis descartados pelos órgãos e entidades da administração pública federal direta e indireta, na fonte geradora, e a sua destinação às associações e cooperativas dos catadores de materiais recicláveis, e dá outras providências. Disponível em: $<$ http://www.planalto.gov.br/ccivil_03/_Ato2004-

2006/2006/Decreto/D5940.htm>. Acesso em: set. 2015.

BRASIL, Decreto $\mathbf{N}^{\circ} \mathbf{7 . 7 4 6}$ de 5 de junho de 2012. Regulamenta o art. $3^{\circ}$ da Lei $n^{\circ} 8.666$, de 21 de junho de 1993, para estabelecer critérios, práticas e diretrizes para a promoção do desenvolvimento nacional sustentável nas contratações realizadas pela administração pública federal, e institui a Comissão Interministerial de Sustentabilidade na Administração Pública CISAP. Disponível em: <http://www.planalto.gov.br/ccivil_03/_ato20112014/2012/decreto/d7746.htm>. Acesso em: set. 2015.

BRASIL, Decreto $N^{\circ} 4.581$ de 27 de janeiro de 2003. Promulga a Emenda ao Anexo I e Adoção dos Anexos VIII e IX à Convenção de Basiléia sobre o Controle do Movimento Transfronteiriço de Resíduos Perigosos e seu Depósito. Disponível

em: <http://www.planalto.gov.br/ccivil_03/decreto/2003/D4581.htm>

BRICK, E. S.; Da Rosa, A. J. "Comparação entre sistemas construídos com tecnologias COTS e proprietária (MIL-SPEC): 0 caso das dotações de sobressalentes das Fragatas Classe "Niterói". Brasil, Disponível em <www.produção.uff.br/conteúdo/rpep/volume12002/relpesq003.htm> Acesso em: 14 set. 2014.

California (USA), "Senate Bill N²0" 2002. <www.leginfo.ca.gov/pub/0304/bill/sen/sb_0001-0050/sb_20_bill_20021202_introduced.pdf > Acesso em: out. $201 \overline{5}$.

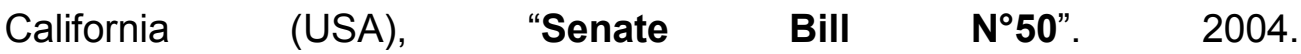
$<\mathrm{ftp}: / /$ www.leginfo.ca.gov/pub/03-04/bill/sen/sb_00010050/sb_50_bill_20040116_amended_sen.pdf > Acesso em: out. 2015.

CARNEIRO, C. A. R. S. C., "Gestão da obsolescência em Sistemas de defesa com recursos a componentes comerciais. "Instituto de Estudos Superiores Militares. Pedrouços, 2010. Disponível em: http://comum.rcaap.pt/handle/123456789/1149 Acesso em: jun. 2015.

$\mathrm{CE}$, "Commission of the European Communities, Summary of the impact assessment." Brussels. Disponivel em: http://ec.europa.eu/environment/water/quantity/pdf/comm_droughts/impact _assessment.pdf. Acesso em: ago. 2015. 
CEA, "Consumer electronics association comments on the review of the Directive 2002/95/EC of the European Parliament and of the Council on EU RoHS", 2008. 2p. Disponível em: < https://circabc.europa.eu/webdav/CircaBC/env/RoHS_2008_review/Librar y/consultation_RoHS/CEA_USA_1.doc > Acesso em: mar. 2015.

CHELALA, Claudia. "Economia verde: desafio para o setor público". Planeta Amazônia. Revista Internacional de Direito Ambiental e Políticas Públicas. Macapá, n. 4, p. 45-59, 2012. Disponível em: https://periodicos.unifap.br/index.php/planeta/article/view/871/ChelalaN4.p df. Acesso em: jun, 2014.

Cidade do Rio de Janeiro, Resolução Conjunta N 003/SMA/SMAC de 26 de agosto de 2013. Institui o Catálogo Sustentável de Bens e Serviços Comuns, ou "Catálogo Verde" a ser adotado nos processos de aquisição de materiais e nas contratações de serviços no âmbito da Prefeitura da Cidade do Rio de Janeiro e dá outras providências. Disponível em: $<$ tttp://www.google.com.br/url?sa=t\&rct=j\&q=\&esrc=s\&source=web\&cd=1 \&ved=0CB0QFjAAahUKEwjuw5a5y-

PHAhUGhJAKHTtVATE\&url=http\%3A\%2F\%2Fsmaonline.rio.rj.gov.br\%2F legis_consulta\%2F44905Res\%2520Conj\%2520SMA_SMAC\%25203_201 3.pdf\&usg=AFQjCNGTQyVHi9KJOReOi62tRS1j2plHWg $>$. Acesso em: set. 2015.

Cidade do Rio de Janeiro, Lei $\mathbf{N}^{\circ} 5.248$ de 27 de janeiro de 2011. Institui a Política Municipal sobre Mudança do Clima e Desenvolvimento Sustentável, dispõe sobre o estabelecimento de metas de redução de emissões antrópicas de gases de efeito estufa para o Município do Rio de Janeiro e dá outras providências. Disponível em: <http://mail.camara.rj.gov.br/APL/Legislativos/contlei.nsf/f25edae7e64db5 3b032564fe005262ef/5cb7185d3c0ecda1832578250070fb60?OpenDocu men>t. Acesso em: set. 2015.

Cidade do Rio de Janeiro, Lei $\mathbf{N}^{\circ} 4.352$ de 30 de junho de 2009. Dispõe sobre o tratamento e a disposição final dos resíduos dos serviços de saúde. Disponível em:

$<$ http://www.google.com.br/url?sa=t\&rct=j\&q=\&esrc=s\&source=web\&cd=1 \&ved=0CB0QFjAAahUKEwjawYvA0OPHAhWCjpAKHQdpASY\&url=http\% $3 \mathrm{~A} \% 2 \mathrm{~F} \% 2 \mathrm{Fwww}$.sinj.df.gov.br\%2FSINJ\%2FArquivo.ashx\%3Fid_norma_c onsolidado\%3D60746\&usg=AFQjCNFfMW3jxcJEMlitQKZ9eDfKflkwVw>. Acesso em: set. 2015.

CLEMENT, S. et al. "Guia de compras públicas sustentáveis. Uso do poder de compra do governo para a promoção de desenvolvimento sustentável". $2^{a}$ Edição. Tradução: Renata Portenoy. Realização: ICLEI Governos Locais pela Sustentabilidade, Secretariado para América Latina e Caribe (LACS) e Centro de Estudos em Sustentabilidade da Escola de Administração de Empresas de São Paulo da Fundação Getulio Vargas (GVces), Rio de Janeiro. 134p. Disponível em: 
<http://www.mma.gov.br/estruturas/a3p/_arquivos/guia_compras_sustenta veis.pdf > Acesso em: jun. 2015.

CONSULTORIA JURÍDICA DA UNIÃO- SP "Guia Prático de Licitações Sustentáveis" Disponível em: <http://www.agu.gov.br/page/content/detail/id_conteudo/138067> Acesso em: jul. 2015.

COMLURB, "Principais características do lixo domiciliar do município do Rio de Janeiro de 1995 - 2013". Disponível em: <armazém de dados.rio.rj.gov.br> Acesso em: 2 jun. 2015.

CONSUMER TECHNOLOGY ASSOCIATION, "Joint Industry Guide (JIG) 101 Transitions to New Material Declaration Standard "Disponível em: <http://www.digitaleurope.org/DocumentDownload.aspx?Command=Core _Download\&Entryld=666>. Acesso em: ago. 2015.

CEU, "6319/09 - Preparatory work on economic and financial aspects of the EU-Third country summits for the first half of 2009" 129,2009 , 26p. Disponivel em: <www.register.consilium.europa.eu/docsrv?l=EN\&f=ST\%206319\%202009 \%20INIT /> Acesso em: 21 fev. 2015.

DAVIDSON A., Johnson J., Rivlin K., "China RoHS is serious business: a discussion of China RoHS and a road map for compliance." 2007. Disponível em: < www.eli.org> Acesso em: mar. 2015.

DA COSTA, C. E. J. As licitações sustentáveis na ótica do controle externo. Distrito Federal, 2011. 56p. Monografia (Especialização em Auditoria e Controle Governamental) - Instituto Serzedello Corrêa, Tribunal de Contas da União.

DANTAS, E. F. S., "O TCU e as licitações sustentáveis" Tribunal de Contas da União", SecexAmbiental. 38 p. 2013. Disponível em: $<$ http://ifc.edu.br/wp-content/uploads/2014/05/Elaine-Dantas-O-TCU-e-aslicita\%C3\%A7\%C3\%B5es-sustent\%C3\%A1veis.pdf> Acesso em: abr. 2015.

DEFESA BR, "Marinha do Brasil - MB Meios Disponíveis e Futuros". Revista eletrônica. Disponível em <http://www.defesabr.com/mb.htm> Acesso em: set. 2015.

DEUBZER, O,.et al.;. "Standard application format and guindance document for RoHS exemption requests on the basis of Article 5(8) Directive 2011/65/EU". EU, 2012. 21p. Disponível em

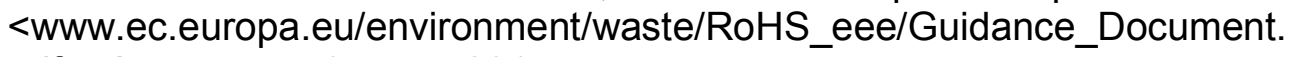
pdf>. Acesso em: 07 ago. 2014. 
DSAM, DSAPART 21-163, (Confidencial). "Proposta de alterdisa para a instalação de um radar de navegação no Navio Faroleiro "Almirante Graça Aranha'”,', fev. 1999.

DSAM, DSAPART 21-167, (Ostensivo). "Análise da proposta de modificação técnica para substituição do radar de navegação das Corvetas “Imperial Marinheiro" e "Bahiana"”, mar. 1999.

DSAM, DSAPART 21-182, (Ostensivo). "Análise da proposta de modificação técnica para instalação de um radar de navegação do Navio Faroleiro “Barão de Teffé”", fev. 2001.

DSAM, DSAPART 21-189a, (Reservado). "Modificação técnica para substituição do radar de navegação do Navio Faloreiro "Graça Aranha"”, mar. 2001.

DSAM, DSAPART 21-193, (Reservado). "Substituição do radar Furuno 1830 no Navio “Ary Parreira””, jul. 2001.

DSAM, DSAPART 21-195, (Reservado). “MODTEC para substituição do radar de navegação para o Navio "Escola Brasil”", jul. 2001.

DSAM, DSAPART 21-197, (Reservado). "Modificação técnica para substituição do DGPS dos Navios Varredores Classe "Aratu"”, mai. 2001.

DSAM, DSAPART 21-199, (Reservado). 'Modificação técnica para substituição do radar de navegação dos Navios Varredores Classe "Aratu"”, mai. 2001.

DSAM, DSAPART 21-201, (Ostensivo). "Análise de MODTEC para substituição dos ecobatímetros dos navios Patrulha Fluvial Classe "Pedro Teixeira"”, mar. 2001.

DSAM, DSAPART 21-206, (Reservado). “Análise de MODTEC para substituição dos radares de navegação para os Rebocadores de AltoMar Classe "Triunfo", nov. 2001.

DSAM, DSAPART 21-209, (Reservado). "Modificação Técnica do radar de navegação para o Navio Balizador “Tenente Castelo"”, nov. 2001.

DSAM, DSAPART 21-214, (Ostensivo). "Modificação Técnica para substituição dos radares de navegação $252 \mathrm{~F}$ dos Rebocadores de Alto-Mar Classe “Guilhem””, ago. 2002.

DSAM, DSAPART 21-225, (Ostensivo). "Substituição dos radares Furuno 1830 em navios subordinados ao Comando da Flotilha do Mato Grosso", dez. 2002. 
DSAM, DSAPART 21-229, (Ostensivo). "Substituição dos ecobatímetros do Navio Escola "Brasil”", fev. 2003.

DSAM, DSAPART 21-231, (Ostensivo). "Substituição dos radares DECCA 1226 nos navios subordinados ao Comando da Flotilha do Amazonas"”, mar. 2003.

DSAM, DSASTUD 21-086, (Ostensivo). "Análise da MODTEC para instalação de um DGPS nos Navios Varredores Classe "Aratu"', abr. 2001.

DSAM, DSASTUD 21-088, (Ostensivo). "Análise da MODTEC para instalação de um radar de navegação nos Navios Varredores Classe “Aratu”", abr. 2001.

DSAM, DSASTUD 21-089, (Ostensivo). "Análise da substituição dos radares Furuno $1830 \mathrm{em}$ navios subordinados ao Comando da Flotilha do Mato Grosso", mar. 2001.

DSAM, DSASTUD 21-094, (Ostensivo). "Análise da substituição dos radares de navegação do Rebocador de Alto-Mar "Almirante Guilhobel"'”, out. 2001.

EMA, "Processo decisório e Estudo de Estado Maior EMA-332", $1^{\circ}$ revisão. (Ostensivo), 2015, Estado-Maior da Armada, Marinha do Brasil, $137 p$.

ESCOLA SUPERIOR DE GUERRA, "Método para o planejamento estratégico/ESG, Manual Básico, Volume IIl”. 2009, Rio de Janeiro, Escola Superior de Guerra, $77 \mathrm{p}$. Disponível em: <http://www.adesgmg.org.br/base/downloads/1355097782.pdf>. Acesso em: out. 2015.

Estado do Rio de janeiro, Decreto $\mathbf{N}^{\circ} \mathbf{4 3 . 6 2 9}$ de 5 de junho de 2012. Dispõe sobre os critérios de sustentabilidade ambiental na aquisição de bens, contratação de serviços e obras pela Administração Pública Estadual Direta e Indireta e dá outras providências. Disponível em: $<$ http://www.legisweb.com.br/legislacao/?id=242066>. Acesso em: set. 2015.

Estado do Rio de janeiro, Lei $\mathbf{N}^{\circ} \mathbf{5 . 6 9 0}$ de 4 de abril de 2010. Institui a política estadual sobre mudança global do clima e desenvolvimento sustentável e dá outras providências. Disponível em: <http://alerjln1.alerj.rj.gov.br/contlei.nsf/f25571cac4a61011032564fe0052c 89c/a9593961f9d00ab28325770a005bd6a4?OpenDocument>. Acesso em: set. 2015.

EU. "Diretive 2002/95/EC of the European Parliament and of the Council on the restriction of the use of certain hazardous substances in electrical and electronic equipment". Official Journal of the European 
Union, jan. 2003. 5p. Disponível em <www.eur-lex.europa.eu/legalcontent/EN/TXT/PDF/?uri=CELEX:32002L0095\&from=EN> Acesso em: 07 ago. 2014.

EU, "Directive 2002/96/EC of the European Parliament and of the Council on Waste Electrical \& Electronic Equipment (WEEE)". Disponivel em: <http://eur-lex.europa.eu/legalcontent/EN/TXT/?uri=CELEX:32002L0096>. Acesso em: jan. 2015.

EU. "Diretive 2011/65/EC of the European Parliament and of the Council on the restriction of the use of certain hazardous substances in electrical and electronic equipment". Official Journal of the European Union, jun. 2011. 23p. Disponível em <www.eur-lex.europa.eu/legalcontent/EN/TXT/PDF/?uri=CELEX:32011L0065\&from=EN> Acesso em: 07 ago. 2014.

EU. "Diretive 2015/863 - amending Annex II to Directive 2011/65/EU of the European Parliament and of the Council as regards the list of restricted substances" Official Journal of the European Union, mar.. 2015. $3 p$. Disponível em <http://eur-lex.europa.eu/legalcontent/EN/TXT/?uri=CELEX:32015L0863>.

Acesso em: out. 2015.

EU. "Frequently asked questions on Directive 2012/19/EU on Waste Electrical and Electronic Equipment (WEEE)". Abr. 2014. Disponível em: $<w w w . e c$.europa.eu/environment/waste/pdf/faq.pdf> Acesso em: 07 ago. 2014.

EU. "ROHS2 FAQ Guidance Document". Dez. 2012. 28p. Disponível em: $<w w w . e c . e u r o p a . e u / e n v i r o n m e n t / w a s t e / R o H S \_e e e / p d f / f a q . p d f>$ Acesso em: 07 ago. 2014.

EU. "Directive 2012/19/EU of the European Parliament and of the Council on Waste Electrical \& Electronic Equipment (WEEE)". Official Journal of the European Union. jul. 2012. 34p. Disponível em: <www.eulex.europa.eu/legal-

content/EN/TXT/PDF/?uri=CELEX:32012L0019\&from=EN> Acesso em: 07 ago. 2014.

EU. "Regulation (EC) No 1907/2006: Registration, Evaluation, Authorisation and Restriction of Chemicals (REACH)". Disponível em: http://ec.europa.eu/environment/chemicals/reach/legislation_en.htm\#legal. Acessado em: OUT. 2015.

EU, "Regulation 765/2008 of the European Parliament and the council setting out the requirements for accreditation and Market surveillance relating to the marketing of products and repealing regulation EEC N³39/93."34p. jul. 2008.Disponível em: $<$ http://www.google.com.br/url?sa=t\&rct=j\&q=\&esrc=s\&source=web\&cd=1 \&cad=rja\&uact $=8 \&$ ved $=0$ ahUKEwiD5e_YhY_LAhVJIZAKHbuDJcQFggcMAA\&url=http $\% 3 \mathrm{~A} \% 2 \mathrm{~F} \% 2 \overline{\mathrm{F} e u r}-$ 
lex.europa.eu\%2FLexUriServ\%2FLexUriServ.do\%3Furi\%3DOJ\%3AL\%3A 2008\%3A218\%3A0030\%3A0047\%3Aen\%3APDF\&usg=AFQjCNG84mW5 KQNkIP5eRNdxIPruv5VOFQ> Acesso em: abr.2015.

EU SME, "China RoHS label". 2011. 5p. Disponível em: $<$ http://www.ccilc.pt/sites/default/files/docs/ROTULO_ROHS_\%5BEN\%5D _\%5BEUSMECENTER\%5D.pdf> Acesso em: ago. 2015.

EUA, "H.R.2420 - Environmental Design of Electrical Equipment Act (EDEE) Act", 2009. Disponível em: <https://www.congress.gov/bill/111thcongress/house-bill/2420> Acesso em: ago. 2015.

EEB "Ecodesigning our electric and electronic equipment - Mining eWaste - Circular Economy", 2014.2 Disponível emhttp://ec.europa.eu/environment/archives/greenweek2014/docs/present ations/parallel-side-sessions-2/2-4/stephane_arditi_2.4.pdf. Acesso em: 31 mai. 2015.

FEAM, "Diagnóstico da Geração de Resíduos Eletrônicos no Estado de Minas Gerais. 2009. 85p. Disponível em: http://www.mma.gov.br/port/conama/processos/4E1B1104/DiagGer_REE_ MG_FEAM_EMPA.pdf. Acesso em: ago. 2015.

FELDMANN, F. "Entendendo o meio ambiente" Coordenação geral da Secretaria de Estado do Meio Ambiente de São Paulo. São Paulo: SMA, 1997. 35p. disponível em < http://www.terrabrasilis.org.br/ecotecadigital/pdf/tratados-e-organizacoesinternacionais-em-materia-de-meio-ambiente.pdf > Acesso em: 06 jun. 2015

FURUNO E. C., "Green Procurement Standards for Parts and materials $4^{\text {th }} \quad$ Edition". $2014, \quad 14 p . \quad$ Disponivel em: www.furuno.co.j/en/corporate/procurement/activity/html Acesso em: 28 fev. 2015.

GERBASE A. E., Oliveira C. R., "Reciclagem do Lixo de Informática: uma Oportunidade para a Química". Instituto de Química, Universidade Federal do Rio Grande do Sul, RS, Brasil, 2011, 7p. Disponível em: http://www.scielo.br/scielo.php?pid=S0100-40422012000700035\& script= sci_arttext. Acesso em: ago. 2015.

GORDON, P., et al. "Economic Impact of the European Union RoHS Directive on the Electronics Insustry." - Consumer Electronics Association - /Technology Forecasters Inc. CEA/TFI, 2008. Disponível em:<http://www.smfederation.org.sg/Portals/0/Events/Ppt\%20Slides/Repo rt\%20FINAL\%20TFI-CES\%202008-01-23\%20JS.pdf> Acesso em: 17 jan. 2015.

GREENPEACE, "Greenpeace briefing. Toxic tech. The dangerous chemicals in electronic products." 21p. Disponivel em: < 
http://www.greenpeace.org/international/PageFiles/24478/toxic-techchemicals-in-elec.pdf> Acesso em: mar. 2015.

GRIPP, Patricia, "AGU finaliza parecer sobre licitações sustentáveis na administração pública." Artigo. Advocacia Geral da União. 2010. Disponível em:

< www.agu.gov.br/content/detail/id_conteudo/145004 > Acesso em: ago. 2015.

IBGE, "Pesquisa nacional por amostra de domicílios. Síntese de indicadores 2013", 2014, 88p.

IC2IC, "RFQ: MAD2 V28". Disponível em: $<$ http://www.ic2ic.com/search.jsp?sSearchWord=MAD2 V28\&q=MAD2 V28>. Acesso em: jun, 2014.

IDEC, Market Analysis, "Ciclo de vida de eletrônicos", 2013, 72p. Disponível em:<http://www.idec.org.br/uploads/testes_pesquisas/pdfs/market_analysi s.pdf. > Acesso em: out. 2015.

IEC, IEC 62321, ed. 1. "Electrotechnical products - determination of levels of six regulated substances (lead, Mercury, hexavalent chronium, poly brominated biphenyls, poly brominated diphenyl ethers), 2008, 59p.

IEC, IEC 62474, "Material Declaration for Products of and for the Electrotechnical Industry", 2015. Disponível em: < http://std.iec.ch/iec62474/iec62474.nsf/MainFrameset> Acesso em: AGO 2015;

INDIUM CORPORATION, "Leading pb-free solder pastes", Disponível em: <www.indium.com/solder-paste-and-powders/leading-pb-free-solderpaster> Acesso em: jul, 2015.

IPT. "Diretiva RoHS (Restriction of Certain Hazardous Substances)": Testes de Certificação. 2011 $<$ http://portal.anvisa.gov.br/wps/wcm/connect/6e5e478047458d9b9713d73 fbc4c6735/Semin\%C3\%A1rio+2+$+1 \% \mathrm{C} 2 \% \mathrm{AA}+$ Apresenta\%C3\%A7\%C3\%A30++Cl\%C3\%A1udia+de+Souza+-+IPT.pdf?MOD=AJPERES>

IPT. "INFORMATIVO". Disponível em: <http://www.abinee.org.br/informac/ arquivos/iptRoHS.pdf> Acesso em: 07 ago. 2014.

JAPÃO, "Law for Promotion of Effective Utilization of Resources", $2000 . \quad$ Disponível em: $<$ www.meti.go.jp/english/information/data/creeffectle.pdf $>$ Acesso em: 28 fev. 2015 
JEITA, “Japan Green Procurement Survey Standardization Initi brominate ative. Guidelines for standardizaron of material declaration". 2003. Disponível em: < www.jeita.or.jp/eps/greendata/jgpssiguidelines20030722/guidelines-eg20030722.pdf > Acesso em: mar. 2015

JGPSSI, "Material composition survey and response manual", 2012, 57p. Disponível em: < http://www.shimadzu.com/about/csr/k25cur0000002bsm-att/130910_v4.3sr_manual_1.1_eg.pdf > Acesso em: fev. 2015.

JORNAL DO COMÉRCIO, "Curta vida de eletrônicos aumenta a produção de resíduos". Edição impressa de 23 de julho de 2013. Disponível em: <http://jcrs.uol.com.br/site/noticia.php?codn=130054> Acesso em: out. 2015.

KEMP, R., Smith, K. \& Becher, G. "The impact of EU regulation on innovation of European Industry. How we should study the relationship between environmental regulation and innovation".may, 2000, EU, European Commission JRC-IPTS and Enterprise DG, 79p. Disponível em: <http://ftp.jrc.es/EURdoc/eur19827en.pdf> Acesso em: 17 dez. 2014

KLRI, "Motor Vehicle Management Act", 1986. 33p. Disponível em: $<$ http://elaw.klri.re.kr/kor_service/converter.do?hseq=8825\&type=PDF>. Acesso em: jul. 2015.

LUNDGREN, K. "The global impact of e-waste: addressing the challenge". International Labour Office, Programme on Safety and Health at Work and the Environment (SafeWork), Sectoral Activities Department (SECTOR). - Genebra ILO, 2012. 72p. Disponível em: < http://www.ilo.org/wcmsp5/groups/public/@ed_dialogue/@sector/documen ts/publication/wcms_196105.pdf. > Acesso em: jan. 2015.

MASARU. Y., "Environmental regulation and innovation through the formation of networks: the development of lead-free solders in Japan, Europe and USA". Kyoto, July, 2006. Disponível em; $<w w w . w e b n e e t s / . c o m / f i l e s / p a p e r s / E R E / W C 3 / 799>$ Acesso em: 04 jan. 2015.

MCCANN, D., Wiltmann A., 'E-Waste Prevention, take-back System Design and Policy Approaches", Step, Solving the e-waste problem. 2015, 92p. Disponível em < http://www.step-initiative.org/?file=files/step2014/Publications/Green\%20and\%20White\%20Papers/Step\%20Green\%2 OPaper_Prevention\%26Take-backy\%20System.pdf > Acesso em: jun. 2015.

MENDES, Luiz Tadeu Freire, "Estudo experimental da migração eletroquímica em soldagem eletrônica $\mathrm{Sn} / \mathrm{Ag} / \mathrm{Cu}$ lead Free", Escola 
Politécnica da Universidade de São Paulo. Departamento de Sistemas Eletrônicos. São Paulo, 2009, 54p.

MMA, "Governança Ambiental, Gestão Estratégica" Disponível em: <http://www.mma.gov.br/governanca-ambiental/gest\%C3\%A3oestrat\%C3\%A9gica> Acesso em: jun. 2015.

MMA, "Governança Ambiental, Economia verde" Disponível em: $<$ http://www.mma.gov.br/governanca-ambiental/economia-verde> Acesso em: jun. 2015.

MMA, "Agenda Ambiental na administração Pública (A3P)”. 2009. 100p. Disponível <http://www.mma.gov.br/estruturas/a3p/_arquivos/cartilha_a3p_36.pdf >Acesso em: mar. 2015.

MMA, CONAMA N 12 de 8 de junho de 2011. Recomenda a adoção de práticas sustentáveis no âmbito da Administração Pública. Disponível em: http://www.mma.gov.br/port/conama/legiabre.cfm?codlegi=651. Acesso em: set. 2015.

MMA, CONAMA N 401 de 4 de novembro de 2008. Estabelece os limites máximos de chumbo, cádmio e mercúrio para pilhas e baterias comercializadas no território nacional e os critérios e padrões para o seu gerenciamento ambientalmente adequado, e dá outras. Disponível em: http://www.mma.gov.br/port/conama/legiabre.cfm?codlegi=589. Acesso em: set. 2015.

MMA, "Contribuição Brasileira à Conferência RIO+20". 37p. 2015. Disponível em:<http://hotsite.mma.gov.br/rio20/wpcontent/uploads/BRASIL_Rio_20_portugues.pdf> Acesso em: nov. 2015.

MMA, "Agenda 21". Disponível em: <http://www.mma.gov.br/responsabilidade-socioambiental/agenda-21> Acesso em. 2015;

MMA, "Convenção-quadro das Nações Unidas sobre a mudança do clima". Disponível em: <http://www.mma.gov.br/clima/convencao-dasnacoes-unidas > Acesso em: nov. 2015;

MMA, "Convenção das Nações Unidas de Combate à Desertificação e Mitigação dos Efeitos da Seca" Disponível em: http://www.mma.gov.br/gestao-territorial/combate-adesertificacao/convencao-da-onu Acesso em: nov. 2015;

MONDEGO, V. S. Estudo dos resíduos eletroeletrônicos de uma prestadora de serviços do setor naval, com vistas ao gerenciamento ambiental. Rio de Janeiro, 2012. 109p. Dissertação (Mestrado em Engenharia Ambiental) - Universidade do Estado do Rio de Janeiro, Faculdade de Engenharia. 
MONTROSE, F. "Think Before you Shuffle". Wellcorps International, 2011. Seção "News To Use". Disponível em: <www.wellcorps.com/ThinkBefore-You-Shuffle.html> Acesso em: 22 abr. 2014.

MPOG, Instrução Normativa $n^{\circ} 01$ de 19 de janeiro de 2010 da Secretaria de Logística e Tecnologia da Informação do Ministério do Planejamento, Orçamento e Gestão do Ministério do Planejamento. Dispõe sobre os critérios de sustentabilidade ambiental na aquisição de bens, contratação de serviços ou obras pela Administração Pública Federal Direta, Autárquica e Fundacional e dá outras providências. Disponível em: <http:/www.cpsustentaveis.planejamento.gov.br/upcontent/uploads/2010/03/Instrução-Normativa-01-10.pdf>. Acesso em: 23 abr. 2014.

\begin{tabular}{lcccr} 
MPOG, “Informações & Gerenciais de & $\begin{array}{c}\text { Contratações } \\
\text { Disponível }\end{array}$ & $\begin{array}{r}\text { Públicas } \\
\text { Sustentáveis”, }\end{array}$ \\
\hline
\end{tabular} <http://www.comprasgovernamentais.gov.br/03-informativos-comprasnetcompras-sustentaveis-jan-a-mar.pdf> Acesso em: 24 mar. 2015;

MINISTÉRIO DA SAÚDE, Secretaria de Atenção à Saúde. Departamento de Ações Programáticas Estratégicas. "Atenção à saúde dos trabalhadores expostos ao chumbo metálico. "Brasília : Editora do Ministério da Saúde, 2006. 44 p. Disponível em: <http://bvsms.saude.gov.br/bvs/publicacoes/protocolo_atencao_saude_tra b_exp_chumbo_> Acesso em: jul. 2015.

NASA, "Basic information regarding tin whiskers/FAQ". Disponível em: <http://nepp.nasa.gov/Whisker/background/index.htm> Acesso em: ago. 2015.

NASA, "Human hair vs metal whisker". Disponível em: <https://nepp.nasa.gov/whisker/photos/hair-vs-whisker.jpg> Acesso em: ago 2015.

OFFICE OF THE SECRETARY OF DEFENCE, "Commercial item acquisition considerations and lessons learned" JUN 2000. Disponível em < http://www.acq.osd.mil/dpap/Docs/cotsreport.pdf.> Acesso em: jul. 2015.

OMS, "Substâncias químicas perigosas à saúde e ao ambiente". Programa Internacional de Segurança Química; tradução Janaína Conrado Lyra da Fonseca, Mary Rosa Rodrigues de Marchi, Jassyara Conrado Lyra da Fonseca. -- São Paulo: Cultura Acadêmica, 2000, 119 p. Disponível em <http://www.unesp.br/pgr/manuais/subs_quimicas.pdf>. Acesso em: 31 mai. 2015.

OMS, "Global Burden Disease 2004 Report". 2004. Disponível.em: $<w w w$.who.int/healthinfo/global_burden_disease/2004_report_update/en/i ndex.html>. Acesso em: Jan 2015. 
PETTERSON, D., "The costs of doing businness in the new RoHS World" 2007, Open Systems Publishing, Military Embedded Systems, 2p. Disponível em: <www.mil-embedded.com/pdfs/Aitech.Sep07.pdf> Acesso em: 23 dez. 2014.

RODRIGUES, A. C., 2007. "Impactos socioambientais dos resíduos de equipamentos elétricos e eletrônicos: estudo da cadeia pós-consumo no Brasil". 2007. 301p. Dissertação (Mestrado). Universidade Metodista de Piracicaba, Faculdade de Engenharia, Arquitetura e Urbanismo, Programa de Pós-Graduação em Engenharia de Produção. Santa Bárbara d'Oeste, SP. Disponível em: $<$ https://www.unimep.br/phpg/bibdig/aluno/visualiza.php?cod=299> Acesso em: abr. 2015.

RODRIGUES, A. C., 2012. "Fluxo domiciliar de geração e destinação de resíduos de equipamentos elétricos e eletrônicos no Município de São Paulo- SP: caracterização e subsídios para políticas públicas". 2012. 247p. Tese (Doutorado). Universidade de São Paulo, Faculdade de Saúde Pública. Disponível em: <http://www.teses.usp.br/teses/disponiveis/6/6134/tde-12032012113745/pt-br.php> Acesso em: jan. 2015.

RSJ TECHNICAL CONSULTING, "Sumary of Korea RoHS". Disponível em <www.rsjtechnical.com/whatisKoreaRoHS.htm> Acesso em 13 fev. 2015;

SCHLUEP, M.; et al. "Recycling from E-Waste to Resources". United Nations Environment Programe, 2009, p. 120. Disponível em <www.ewasteguide.info/UNEP_2009_ew2r>. Acesso em: 22 fev. 2015;

SENA, F. R. Evolução da Tecnologia Móvel Celular e o Impacto nos Resíduos Eletroeletrônicos. Rio de janeiro, 2013. 185p. Dissertação (Mestrado em Engenharia Urbana e Ambiental). Pontifícia Universidade Católica do Rio de Janeiro, Departamento de Engenharia Civil.

SILVA, A L. O; et al. "Dietary intake and health effects of selected toxic elements". Braz. J. Plant Physiol. [online]. 2005, vol.17, n.1, pp. 79-93. ISSN 1677-0420. Disponível em: <http://dx.doi.org/10.1590/S167704202005000100007> Acesso em: 31 jul. 2014.

SOUZA. F. M., Alencar. F. M. R., "O impacto dos COTS no processo de engenharia de requisites". Disponível em: < http://wer.inf.pucrio.br/WERpapers/artigos/artigos_WER99/souza.pdf > Acesso em: jun. 2015

STEP-INITIATIVE, "Overview of e-waste related information". Disponível em: < www.step-initiative.org/overview-world.html > Acesso em: 02 jun. 2015. 
TEXAS INSTRUMENTS, "Eco-Info \& Lead-free (Pb-free): China RoHS and Chasing Arrow Information." Disponível em: $<w w w . t i . c o m / c o r p / d o c s / l e g a l / p r i v a c y . s h t m l>$. Acesso em: 21 fev. 2015;

Vieira, M.A.C. "Avaliação do emprego de Componentes COTS (Commercial-Off-the-Shelf) em Sistemas Digitais Operativos". 2007. 114p. Disponível em: $<$ http://www.bdtd.ndc.uff.br/tde_busca/arquivo.php?codArquivo=2475>. Acesso em: set. 2015.

WÄGER, P., Schluep M. and Müller, E. (2010) 'RoHS Substances in Mixed Plastics from Waste Electrical and Electronic Equipment'. Swiss Federal Laboratories for Materials Science and Technology (Empa). September 17, 2010.2 Disponível em <http://ewasteguide.info/files/Waeger_2010_Empa-WEEEForum.pdf>. Acesso em: 31 mai. 2015.

UNU, "The Global E-Waste Monitor, Quantities, Flows and Resources", 2014, 41p. Disponível em: http://i.unu.edu/media/unu.edu/news/52624/UNU-1stGlobal-E-WasteMonitor-2014-small.pdf .Acesso em: ago. 2015.

USA, "H.R.2420 - Environmental Design of Electrical Equipment Act (EDEE) Act", 2009. Disponível em: <https://www.congress.gov/bill/111thcongress/house-bill/2420> Acesso em: ago. 2015.

USA (Department of Defense), "Commercial item acquisition Considerations and lessons learned". 2000. 25p. Disponível em; < http://www.acq.osd.mil/dpap/Docs/cotsreport.pdf .> Acesso em: fev. 2015

WIKIPEDIA, "Whisker (metallurgy)". Disponível em: <https://en.wikipedia.org/wiki/Whisker(metallurgy)> Acesso em: jul. 2015. 


\section{Anexos}

\section{Anexo 01}

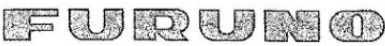

(7) FURUNO ELECTRIC CO., LTD.

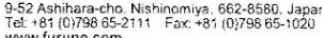

Publication No. DOCQA9002

Declaration of Conformity
We FURUNO ELECTRIC CO., LTD.
(Manufacturer)
9-52 Ashihara-Cho, Nishinomiya City, 662-8580, Hyogo, Japan
(Address)
GP-1670, GP-1870, MFD8, MFD12, MFDBB
TZT9, TZT14, TZTBB
(Model name. type number)
document(s) which this declaration relates is in conformity with the following standard(s) or other normative
EN50581: 2012 (title andior number and date of issue of the standard(s) or other normative document(s))
(s)

This declaration is issued according to Directive 2011/65/EU of the European Parliament and of the Council of 8 June 2011 on the restriction of the use of certain hazardous substances in electrical and electronic equipment.

On behalf of Furuno Electric Co., Ltd.

Nishinomiya City, Japan July 16,2014

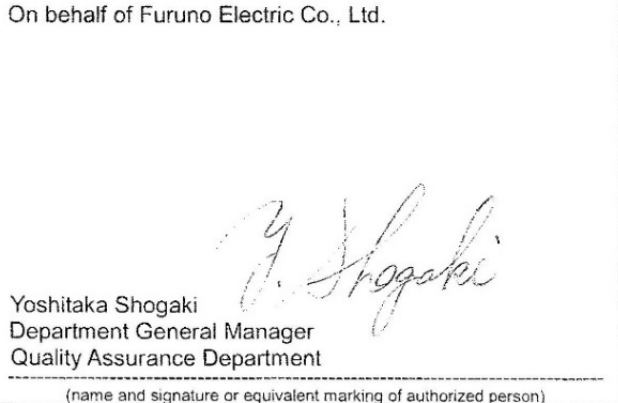


Anexo 02

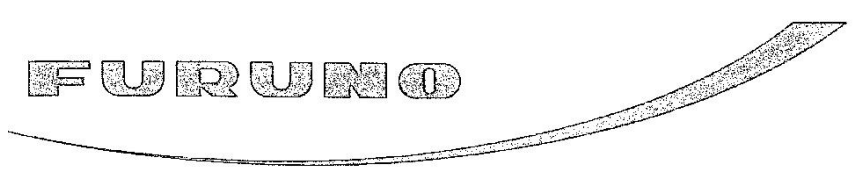

PI FURUNO ELECTRIC CO., LTD.

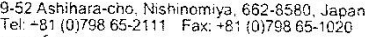
whrs.furuno.com

Publication No. DOCQA9007

Declaration of Conformity
WU
FURUNO ELECTRIC CO., LTD.
(Manufacturer)
9-52 Ashihara-Cho, Nishinomiya City, 662-8580, Hyogo, Japan
(Address)
FELlare under our sole responsibility that the product
GP-170, GP-3500, NX-700A and RD-50
(Model name. :ype number)

to which this declaration relates is in conformity with the following standard(s) or other normative document(s)

EN50581: 2012

(title and/or number and date of issue of the standard(s) or other normative document(s)

This declaration is issued according to Directive 2011/65/EU of the European Parliament and of the Council of 8 June 2011 on the restriction of the use of certain hazardous substances in electrical and electronic equipment.

On behalf of Furuno Electric Co.. Lid.

Nishinomiya City, Japan

January 30,2015

(Place and date of issue)
Yoshitaka Shogaki

Department General Manager

Quality Assurance Department 


\section{Anexo 03}

<Date of declaration>

Material Declaration

E \begin{tabular}{|l|r|}
\hline Date & 2010/12/25 \\
\hline
\end{tabular}

$<$ MD ID number>

\begin{tabular}{l|l|} 
MO 10 no. & MD_FEC GPS_GP-150_20104225 \\
\hline
\end{tabular}

<Other information>

\begin{tabular}{|l|l|}
\hline Remark 1 & \\
\hline Remark 2 & \\
\hline Remark 3 & \\
\hline
\end{tabular}

<Supplier (respondent) information>

\begin{tabular}{|c|l|}
\hline Company name & FURUNO ELECTRIC CO.LTD \\
\hline Division name & Production Engrieering Department Marine Electronic Products Division \\
\hline Addrass & $9-52$ Ashihara-citio.Nishinomiya,662-8580,Japan \\
\hline Contact person & Misao Hamane \\
\hline Telephone number & $0798-63-1175$ \\
\hline Faxnumber & $0798-63-1117$ \\
\hline E-mail address & \\
\hline SDoC ID no. & SD. FEC_20101225 \\
\hline
\end{tabular}

<Product information>

\begin{tabular}{|c|c|c|c|c|}
\hline Product name & Product number & Detiverter & & Product intormation \\
\hline DISPLAY UNIT for GPS & GP-150 & 2 & piece & $2.4 \mathrm{~kg}$ \\
\hline
\end{tabular}

$<$ Materials information>

This materials information shows the amount of hazardous materials contained in \begin{tabular}{|c|c|}
\cline { 3 - 3 } & Unit \\
\hline
\end{tabular}

\begin{tabular}{|c|c|c|c|c|c|c|c|}
\hline \multirow{2}{*}{ Table } & \multirow{2}{*}{\multicolumn{2}{|c|}{ Material name }} & \multirow{2}{*}{$\begin{array}{c}\text { Threshold } \\
\text { level }\end{array}$} & \multirow{2}{*}{$\begin{array}{c}\text { Presemt above } \\
\text { thresholif level }\end{array}$} & \multicolumn{2}{|c|}{ If yes, matential mass } & \multirow{2}{*}{ If yes, information on where it is used } \\
\hline & & & & & Mass & IUnit(g) & \\
\hline \multirow{12}{*}{ 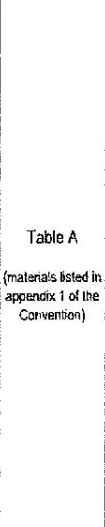 } & & Asbestos & no threshold level & No & & & \\
\hline & Polychl & Iorinated biphenys (PCBs) & กo threshald leved & No & & & \\
\hline & \multirow{9}{*}{$\begin{array}{c}\text { Ozane depleting } \\
\text { substences }\end{array}$} & 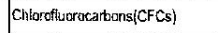 & \multirow{9}{*}{ no threstold iever } & No & & & \\
\hline & & Hations & & No & & & \\
\hline & & Other fully hakogenated CFCS & & No & & & \\
\hline & & Carbon terracthispride & & No & & & \\
\hline & & $\begin{array}{l}\text { 1,1, 1-Tnedibroethane (Methyl } \\
\text { chlorofortin) }\end{array}$ & & No & & & \\
\hline & & Hydractlorafluorccartions & & No & & & \\
\hline & & Hydrob:omolluaracartons & & No & & & \\
\hline & & Methyl bromide & & No & & & \\
\hline & & Bmmochloromethane & & No & & & \\
\hline & \multicolumn{2}{|c|}{$\begin{array}{l}\text { Anti-ifouling systems conlaining organotin } \\
\text { compounds as a hiocide }\end{array}$} & $\begin{array}{l}2,506 \mathrm{mg} \text { lotal } \\
\text { ininkg }\end{array}$ & No & & & \\
\hline \multirow[t]{2}{*}{ Table } & \multirow{2}{*}{\multicolumn{2}{|c|}{ Material name }} & \multirow{2}{*}{$\begin{array}{l}\text { Threshold } \\
\text { level }\end{array}$} & $\begin{array}{l}\text { Prosent above } \\
\text { Threshatd level }\end{array}$ & \multicolumn{2}{|c|}{ If yes, material mass } & \multirow{2}{*}{ If yes, infarmation on where it is used } \\
\hline & & & & Yes/No & Mass & Unir(g) & \\
\hline \multirow{9}{*}{$\begin{array}{l}\text { Table B } \\
\text { (matarials listed in } \\
\text { sppendix } 2 \text { of the } \\
\text { Convervory) }\end{array}$} & \multicolumn{2}{|c|}{ Cadmium and cadmium compounds } & $100 \mathrm{mg} k \mathrm{~kg}$ & No & & & \\
\hline & \multicolumn{2}{|c|}{$\begin{array}{l}\text { Hexasvalent chromium and hexavalent chromium } \\
\text { compotints }\end{array}$} & $1,000 \mathrm{mg} / \mathrm{kg}$ & No & & & \\
\hline & \multicolumn{2}{|c|}{ Lead and lead compounds } & $1,000 \mathrm{mg} / \mathrm{kg}$ & Yes & 1. & g & lead solder / Elecironic pans on PWB \\
\hline & \multicolumn{2}{|c|}{ Mercuny and mercoury compounds } & $1,000 \mathrm{mg} / \mathrm{kg}$ & Yes & 0.5 & $\mathrm{~g}$ & $\operatorname{LCD}$ \\
\hline & \multicolumn{2}{|c|}{ Polybrominated biphenyy (PBBS) } & $1.080 \mathrm{mg} / \mathrm{kg}$ & No & & & \\
\hline & \multicolumn{2}{|c|}{ Polyturominated diphenyl eathers (PBDES) } & $1,000 \mathrm{mg} / \mathrm{kg}$ & No & & & \\
\hline & \multicolumn{2}{|c|}{ Poychallorinater nanithalemes (more than 3 chlorine aloms) } & no threstroid level & No & & & \\
\hline & \multicolumn{2}{|c|}{ Radioactive substances } & fo threshods level & No & & & \\
\hline & \multicolumn{2}{|c|}{$\begin{array}{l}\text { Certains shontchain chlcrinated parafins (Alkanes, } \\
\text { C10.C13, chlaro) }\end{array}$} & $1 \%$ & No & & & \\
\hline
\end{tabular}

